Aus der Poliklinik für Präventive Zahnmedizin, Parodontologie und Kariologie

(Prof. Dr. med. dent. A. Wiegand)

im Zentrum für Zahn-, Mund- und Kieferheilkunde

der Medizinischen Fakultät der Universität Göttingen

\title{
Vergleichende Studie zur Entfernung \\ von Kalziumhydroxid aus dem \\ Wurzelkanal mit Hilfe \\ unterschiedlicher Techniken
}

\author{
INAUGURAL-DISSERTATION \\ zur Erlangung des Doktorgrades \\ für Zahnheilkunde \\ der Medizinischen Fakultät der \\ Georg-August-Universität zu Göttingen
}

vorgelegt von

Anne Reus (geb. Neubauer)

aus

Erfurt

Göttingen 2018 
Dekan:

Prof. Dr. rer. nat. H. K. Kroemer

\section{Betreuungsausschuss}

Betreuer/in

Ko-Betreuer/in:

\section{Prüfungskommission}

Referent/in

Ko-Referent/in:

Drittreferent/in:
Prof. Dr. med. dent. M. Hülsmann

Priv.-Doz. Dr. med. dent. M. Rödiger
Prof. Dr. med. dent. M. Hülsmann

Priv.-Doz. Dr. med. dent. M. Rödiger

Prof. Dr. med. M. Oppermann

Datum der mündlichen Prüfung: 13.11.2018 
Hiermit erkläre ich, die Dissertation mit dem Titel "Vergleichende Studie zur Entfernung von Kalziumhydroxid aus dem Wurzelkanal mit Hilfe unterschiedlicher Techniken" eigenständig angefertigt und keine anderen als die von mir angegebenen Quellen und Hilfsmittel verwendet zu haben.

Göttingen, den 03.11.2018

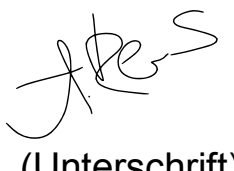

(Unterschrift) 


\section{Inhaltsverzeichnis}

Abbildungsverzeichnis ..........................................................................

Tabellenverzeichnis .............................................................................. IV

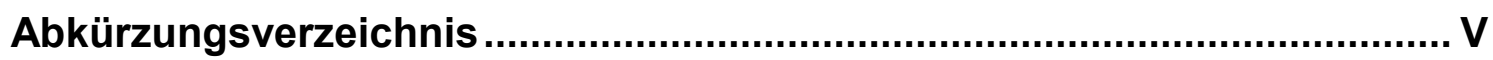

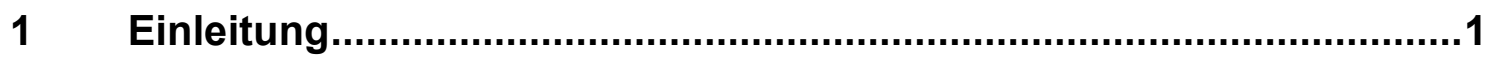

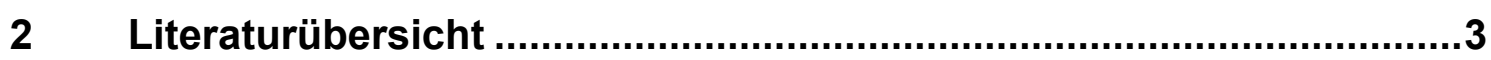

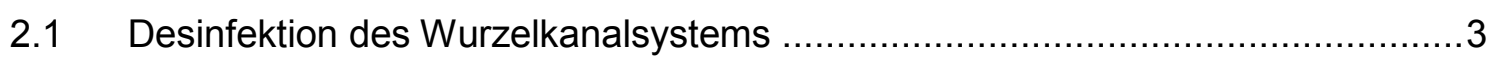

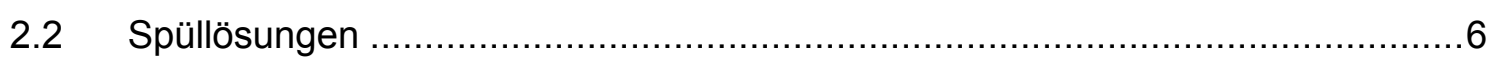

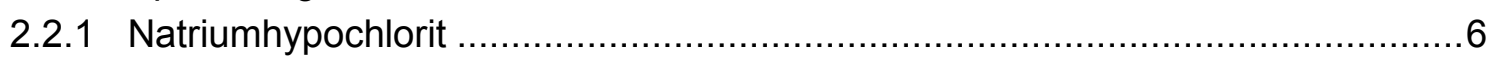

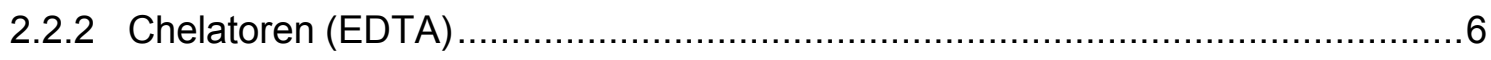

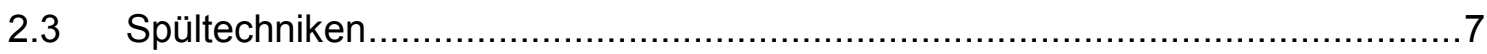

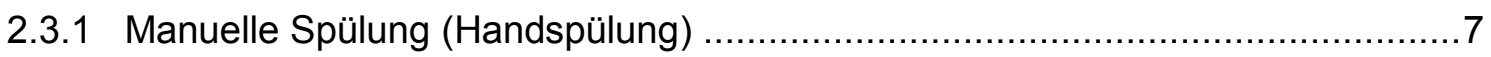

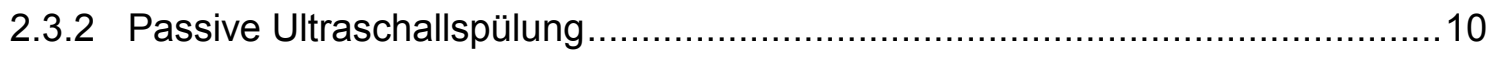

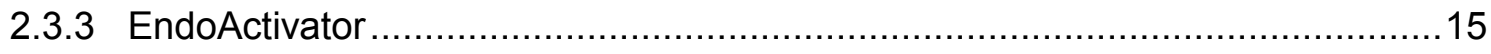

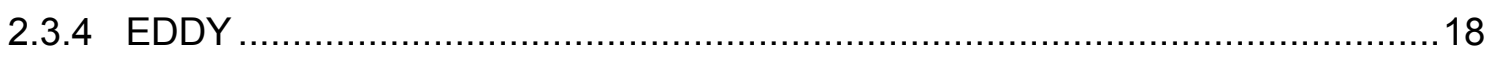

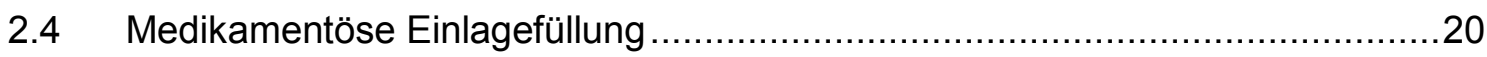

2.4.1 Funktion einer medikamentösen Einlagefüllung............................................20

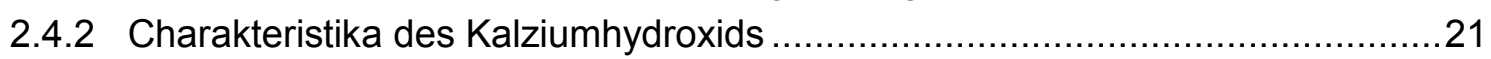

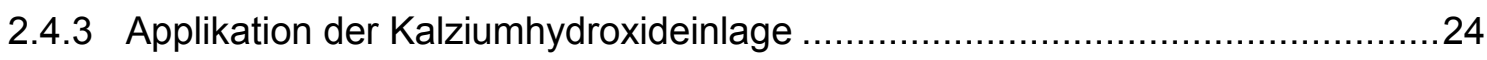

2.4.4 Entfernung der Kalziumhydroxideinlage ...................................................2

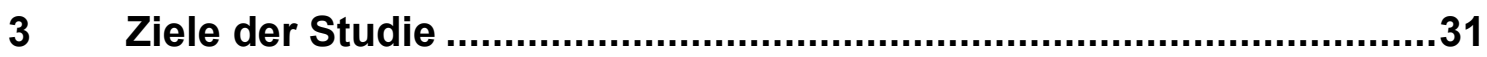

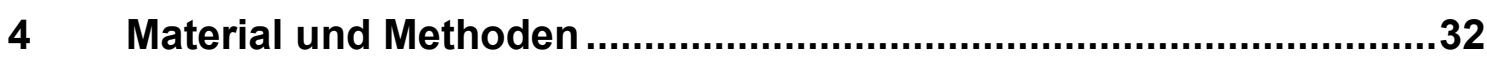

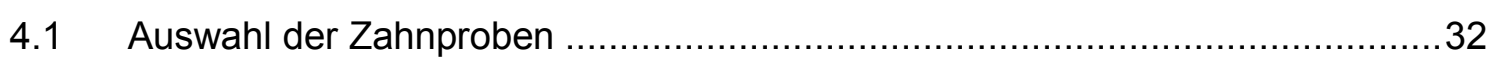

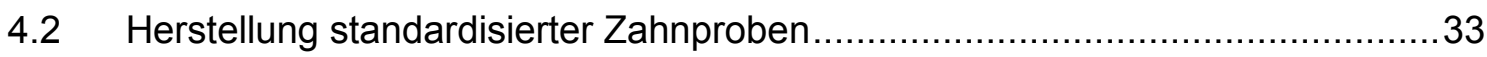

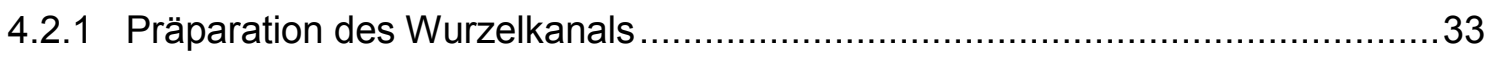

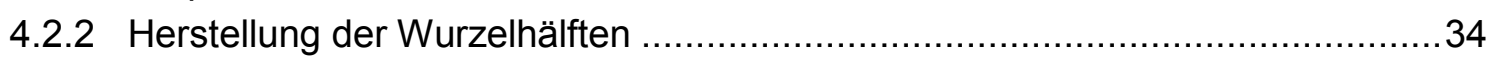

4.2.3 Präparation der apikalen und koronalen Gruben ...........................................35

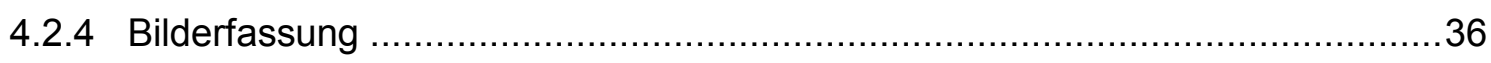

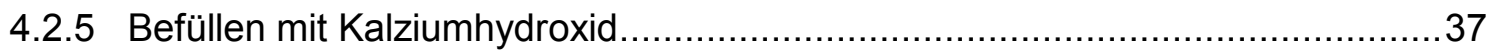

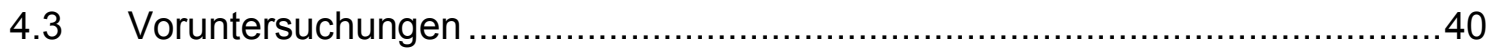

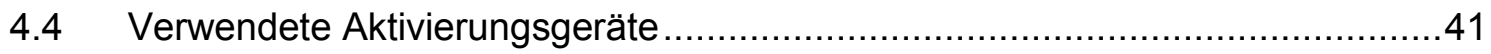

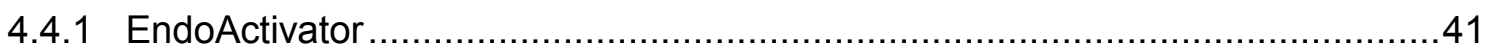

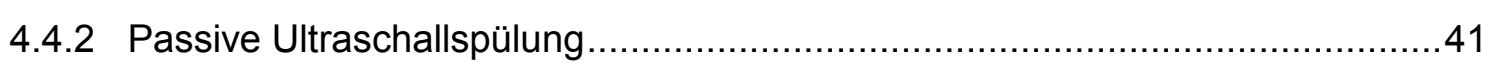

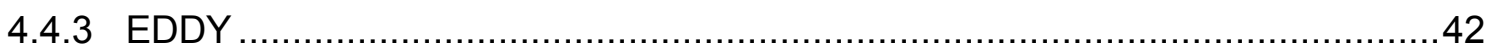

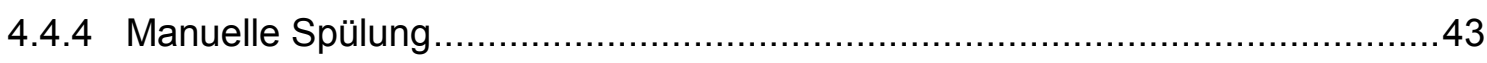

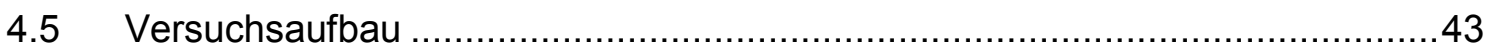




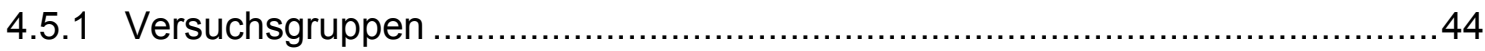

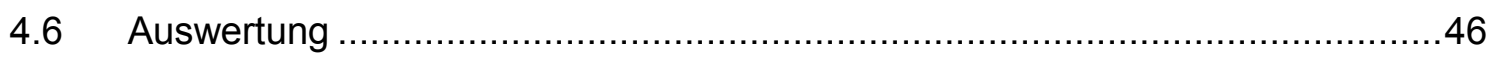

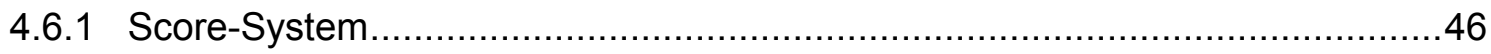

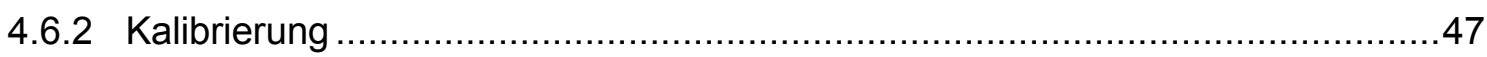

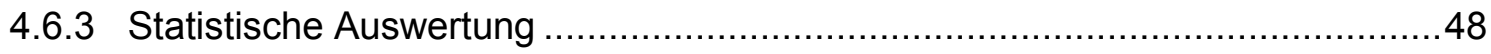

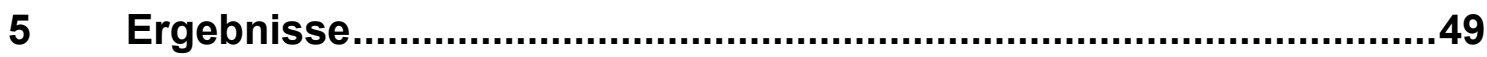

5.1 Reproduzierbarkeit der Ergebnisse .....................................................49

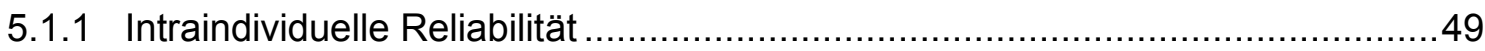

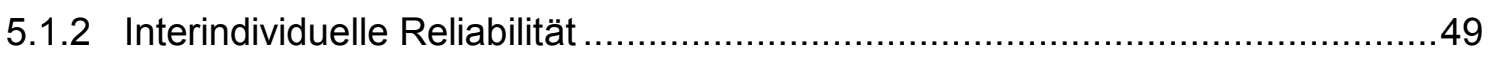

$5.2 \quad$ Ergebnisse des Hauptversuchs ................................................................ 50

5.2.1 Ergebnisse für das Wurzelkanallumen ..................................................... 50

5.2.2 Ergebnisse für die Reinigung der koronalen Kavität ......................................53

5.2.3 Ergebnisse für die Reinigung der apikalen Kavität.................................56

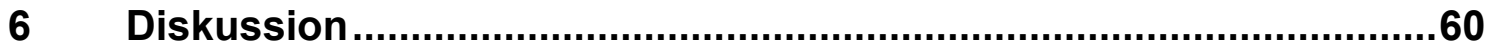

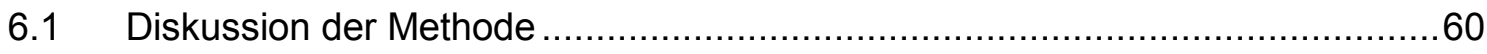

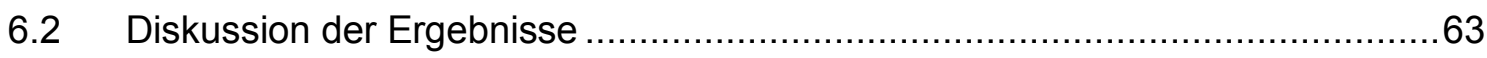

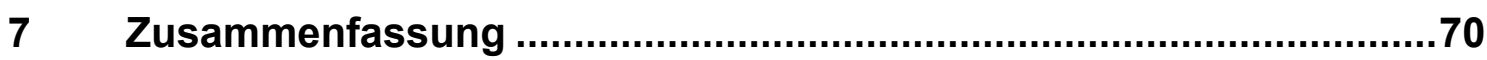

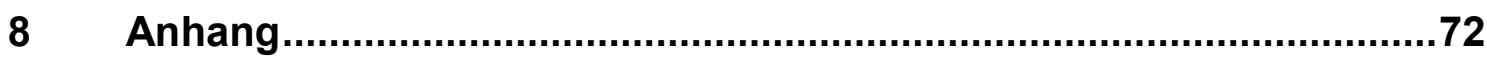

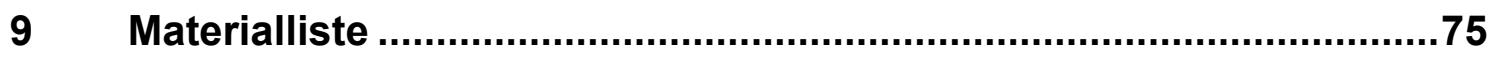

10 Literaturverzeichnis ........................................................... 


\section{Abbildungsverzeichnis}

Abb. 2-1: $\quad$ Ultraschallspitze in Bewegung mit dem charakteristischen Strömungsbild. Der Abdruck erfolgt mit freundlicher Genehmigung der Firma Acteon.

Abb. 2-2: Bewegungsmuster des EDDY. Der Abdruck erfolgt mit freundlicher Genehmigung der Firma VDW.

Abb. 4-1: Zahn im Acrylröhrchen mit Silikonmasse

Abb. 4-2: Zahn beim Fräsen der vertikalen Rille mit einer diamantierten Trennscheibe

Abb. 4-3: Schematische Darstellung der Kavität nach Lage und Ausdehnung in den verschiedenen Wurzelhälften im vertikalen und horizontalen Schnitt, nach Lee et al. (2004). ..................................................... 36

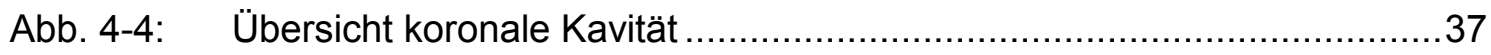

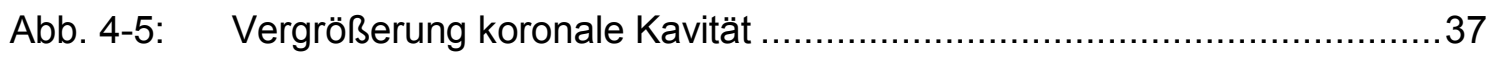

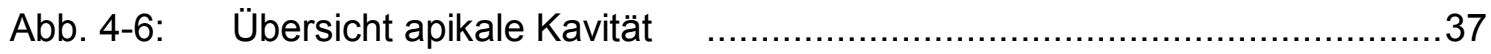

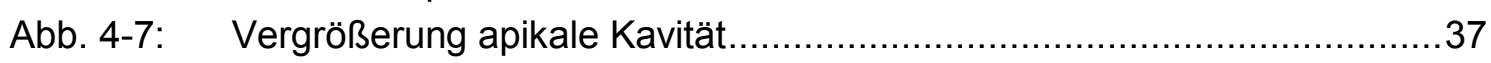

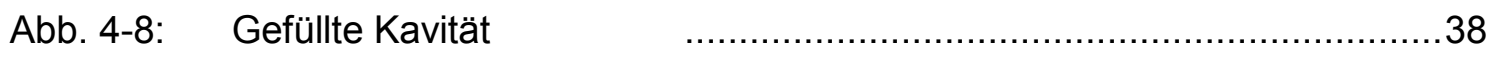

Abb. 4-9: Zusammengesetzter Zahn beim Verschluss mit Cervikalwachs ...............38

Abb. 4-10: Einzelzahnaufnahme zur Kontrolle einer homogenen Füllung des Wurzelkanals mit Kalziumhydroxid.....................................................39

Abb. 4-11: Spülspitze ActivatorTip Größe medium .................................................41

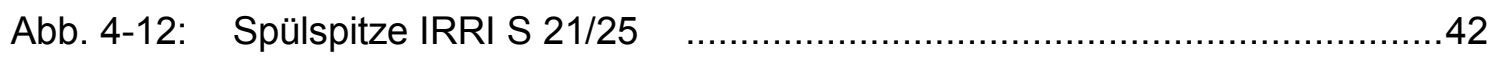

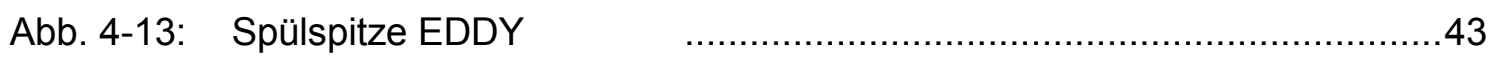

Abb. 4-14: Kavität mit Score $0 \quad$ …......................................................... 47

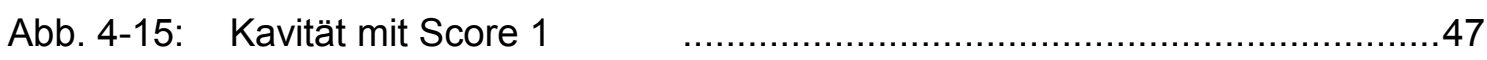

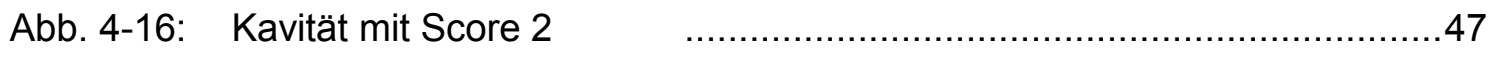

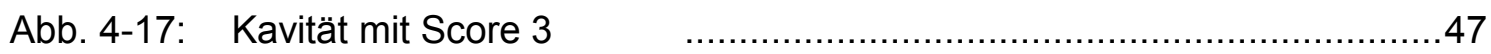

Abb. 5-1: Relative Häufigkeit der Score-Werte für das Wurzelkanallumen .............52

Abb. 5-2: Boxplot der verschiedenen Spültechniken für das Wurzelkanallumen.....53

Abb. 5-3: Relative Häufigkeit der Score-Werte für die koronale Kavität ...................55

Abb. 5-4: Boxplot der verschiedenen Spültechniken für die koronale Kavität ..........56

Abb. 5-5: Relative Häufigkeit der Score-Werte für die apikale Kavität ....................58

Abb. 5-6: Boxplot der verschiedenen Spültechniken für die apikale Kavität.............59 


\section{Tabellenverzeichnis}

Tab. 2-1: Übersichtstabelle Entfernung von $\mathrm{Ca}(\mathrm{OH})_{2}$ - Auszug aktueller Studien ...28

Tab. 5-1: Kappa-Koeffizienten für die intraindividuelle Reproduzierbarkeit beider Untersucher 49

Tab. 5-2: Kappa-Koeffizient für die interindividuelle Übereinstimmung beider Untersucher .50

Tab. 5-3: Spültechniken im Paarvergleich für das Wurzelkanallumen .51

Tab. 5-4: Absolute Häufigkeit der Score-Werte für das Wurzelkanallumen .. .51

Tab. 5-5: Spültechniken im Paarvergleich für die koronale Kavität...........................54

Tab. 5-6: Absolute Häufigkeit der Score-Werte für die koronale Kavität .................54

Tab. 5-7: Spültechniken im Paarvergleich für die apikale Kavität ............................57

Tab. 5-8: Absolute Häufigkeit der Score-Werte für die apikale Kavität ....................57

Tab. 8-1: $\quad$ Übersicht der Bewertung …............................................................ 72

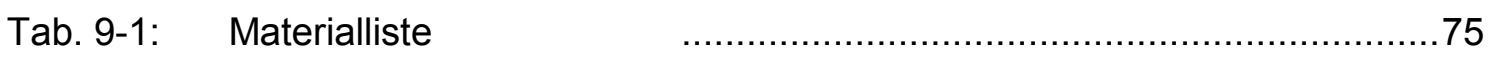




\section{Abkürzungsverzeichnis}

$\begin{array}{ll}\mathrm{Ca}(\mathrm{OH})_{2} & \text { Kalziumhydroxid } \\ \mathrm{Ca}^{2+} & \text { Kalzium-lon } \\ \mathrm{CFD} & \text { computational fluid dynamics } \\ \mathrm{CHX} & \text { Chlorhexidin } \\ \mathrm{cpm} & \text { cycles per minute } \\ \mathrm{CT} & \text { Computertomographie } \\ \mathrm{EDTA} & \text { Ethylendiamintetraacetat } \\ \mathrm{MAF} & \text { master apical file } \\ \mathrm{NaOCI} & \text { Natriumhypochlorit } \\ \mathrm{OH} & \text { Hydroxylion } \\ \mathrm{PIPS} & \text { photon-initiated photoacoustic streaming } \\ \mathrm{PUI} & \text { passive ultrasonic irrigation } \\ \text { SAF } & \text { self-adjusting file } \\ \text { SEM } & \text { scanning electron microscope }\end{array}$




\section{$1 \quad$ Einleitung}

Die Endodontie gehört neben der Parodontologie und der Füllungstherapie zu den Schwerpunkten der konservierenden Zahnheilkunde. Pro Jahr werden über 7 Millionen Wurzelkanalbehandlungen von Zahnärzten durchgeführt (KZBV Statistik 2016). Eine endodontische Behandlung strebt in erster Linie den Erhalt des natürlichen Zahnes und infolgedessen die Wahrung von Aussehen und Funktion des körpereigenen Kausystems an. Nach einer erfolgreichen Behandlung ist der Patient zudem schmerzfrei. Studien bestätigen der endodontischen Therapie eines Zahnes mit irreversibler Pulpitis eine Erfolgsquote von 85-95\% (DGZMK 2001). Die Erfolgsaussichten steigen mit der vollständigen Entfernung von Bakterien und deren Stoffwechselprodukten aus dem Wurzelkanalsystem. Aufgrund der komplexen Wurzelkanalanatomie kann durch die mechanische Bearbeitung des Wurzelkanals trotz neuster Techniken ausschließlich eine Keimreduktion erzielt werden. Deshalb wird die Anwendung von antibakteriellen Agenzien, wie dem Spülmedium Natriumhypochlorit, als Ergänzung empfohlen. Jedoch garantiert auch eine einwandfreie chemomechanische Präparation des Kanalsystems keinen sterilen Wurzelkanal (Blome et al. 2008).

Unterstützend wird deshalb Kalziumhydroxid als medikamentöse Einlagefüllung eingesetzt. Dem biokompatiblen Medikament wird neben seiner antimikrobiellen Wirkung unter anderem die Anregung der Zahnhartgewebsneubildung (Sawicki et al. 2008) und die Inhibition von Wurzelresorptionen nachgesagt. Im Rahmen der herkömmlichen Wurzelkanalbehandlung wird Kalziumhydroxid zwischen einzelnen Behandlungsterminen als medikamentöse Einlage angewandt. Dies kann indiziert sein, wenn aus Zeitgründen eine Behandlung nicht in einer Sitzung beendet werden kann, Bakterien gegenüber einer Routinebehandlung resistent sind oder der Patient weiterhin über Schmerzen klagt (Gomes et al. 2003).

Trotz der positiven Eigenschaften ist eine vollständige Entfernung des Kalziumhydroxids aus dem Wurzelkanal vor der abschließenden Obturation zwingend erforderlich, erweist sich jedoch bis heute als äußert schwierig (Rödig et al. 2011). Ein Verbleib des Kalziumhydroxids verhindert die Penetration des 
Sealers in die Dentintubuli und den Ausgleich zwischen Kanalunebenheiten und Kernmaterial mit Hilfe des Sealers (Nandini et al. 2006). Tritt Kalziumhydroxid mit Sealer auf Zinkoxid-Eugenol-Basis in Interaktion, resultiert dies in einer beschleunigten Abbindegeschwindigkeit und brüchigen Konsistenz des Sealers (Margelos et al. 1997). Auf lange Sicht gesehen wird so die Entstehung von Microleakages begünstigt (Nandini et al. 2006).

Zahlreiche Studien untersuchten diverse Techniken, einschließlich verschiedener Kombinationen von Spültechnik und Spülmedium, zur Entfernung von Kalziumhydroxid aus dem Wurzelkanal. Die aktuelle Studienlage zeigt jedoch widersprüchliche Ergebnisse hinsichtlich der effektivsten Technik, sie unterstreicht dennoch das Unvermögen der üblichen Techniken, Kalziumhydroxid vollständig zu entfernen (Lambrianidis et al. 1999; Kenee et al. 2006; Rödig et al. 2011; Khademi et al. 2015). Dieser Sachverhalt führt zur stetigen Entwicklung neuester Technologien wie dem EDDY. Der kürzlich auf den Markt gebrachte EDDY erzeugt eine schallbasierte Aktivierung des Spülmediums und soll die Reinigungsleistung während einer Wurzelkanalbehandlung steigern.

Die vorliegende Studie untersucht den Effekt des EDDY bezüglich der Entfernung von Kalziumhydroxid aus dem Wurzelkanal im Vergleich zu traditionellen Techniken wie der manuellen Handspülung und der passiven Ultraschallspülung sowie neueren Techniken wie dem EndoActivator. 


\section{Literaturübersicht}

\subsection{Desinfektion des Wurzelkanalsystems}

Die Desinfektion des Wurzelkanalsystems verfolgt vor allem folgende Ziele:

- Reduzierung der Keimzahl im Wurzelkanal

- Dekontamination des Dentins

- Entfernung des groben Debris

- Entfernung der Schmierschicht und Freilegung der Dentintubuli

- Entfernung der medikamentösen Einlagefüllung.

Oberstes Ziel einer Wurzelkanalbehandlung ist die möglichst vollständige Elimination von Bakterien, Toxinen und Keimen aus dem Wurzelkanal (Sundqvist et al. 1998), denn orale Mikroorganismen stellen den Hauptgrund für das Auftreten von pulpalen und periapikalen Erkrankungen dar (Baumgartner 1991; Siqueira und Rôças 2008; Antunes et al. 2015). Verschiedene Arten von Mikroorganismen, beispielsweise Bakterien, Pilze oder Viren, können die Pulpa und das umliegende Gewebe infizieren. Bislang wurden über 460 einzelne Bakterientaxa innerhalb verschiedenster endodontischer Infektionen ermittelt (Siqueira und Rôças 2009). Häufig isolierte Mikroorganismen sind gramnegative anaerobe Stäbchen, grampositive anaerobe Kokken, grampositive anaerobe und fakultative Stäbchen (z. B. Prevotella, Porphyromonas, Tannerella forsythia, Dialister, Fusobacterium, Spirochetes), Laktobazillen und grampositive fakultative Streptokokken (Waltimo et al. 2003). Fakultativ anaerobe Bakterien wie Streptococcus gordonii, Fusobacterium nucleatum und Actinomyces oris wurden in endodontisch erst-infizierten Zähnen nachgewiesen (Siqueira und Rôças 2008). Die Bakterienvielfalt innerhalb des Endodonts ist demnach groß (Stuart et al. 2006; Jacinto et al. 2007), zeigt jedoch zeitgleich Variationen abhängig vom Krankheitsbild (Sakamoto et al. 2006; Siqueira und Rôças 2009). Zwischen symptomatischen und asymptomatischen Infektionen des Endodonts unterscheiden sich beispielsweise die Bakterienzusammensetzung und -struktur (Sakamoto et al. 2006). Dies gilt ebenfalls für erst-infizierte und revisionsbedürftige Zähne. 
Der Verbleib von Mikroorganismen im Wurzelkanal ist der Hauptgrund für einen Misserfolg einer endodontischen Behandlung (Lin et al. 1992; Sakamoto et al. 2007; Denotti et al. 2009). Die Notwendigkeit einer Revisionsbehandlung ist häufig auf persistierende oder neu hinzugekommene Bakterien zurückzuführen. In Proben von Zähnen mit persistierender apikaler Parodontitis wurden in großen Mengen Streptokokken, Aktinobakterien und Pseudoramibacter alactolyticus gefunden (Antunes et al. 2015). Viel häufiger aber werden mit persistierenden apikalen Läsionen und der Ursache für Revisionsbehandlung die Mikroorganismen Enterococcus faecalis (Sundqvist et al. 1998; Portenier et al. 2005; Mohammadi 2015) und Candida albicans (Waltimo et al. 2003; Siqueira und Sen 2004; Mohammadi und Shalavi 2014) assoziiert. In 24-77\% der Fälle wurde bei periradikulären Läsionen Enterococcus faecalis nachgewiesen (Stuart et al. 2006). Enterococcus faecalis besitzt die Fähigkeit, an der Dentinwand zu haften, in die Dentintubuli einzudringen und sich in Form eines Biofilms zu formieren (Distel et al. 2002; Zehnder 2006). Es ist anzunehmen, dass Bakterien innerhalb der Dentintubuli in der Lage sind, die chemomechanische Aufbereitung und die medikamentöse Einlagefüllung zu überleben und als Quelle für die erneute Infizierung des Wurzelkanalsystems zu dienen (Kreft et al. 1992). Ein Verbleib von Bakterien im Wurzelkanal nach endodontischer Behandlung resultierte zu $79 \%$ in einer ausbleibenden Ausheilung der periapikalen Läsion (Fabricius et al. 2006). Die alleinige Instrumentierung des Wurzelkanals führt durch die Entfernung von Mikroorganismen und infiziertem Dentin zu einer Reduktion der Bakterienzahl, sie erzielt jedoch keine Bakterienfreiheit (Peters et al. 2001). In Ergänzung zur mechanischen Aufbereitung werden antibakterielle Spüllösungen und Medikamente unterstützend angewandt. Eine korrekt durchgeführte chemomechanische Präparation des Wurzelkanals ist in der Lage, die Bakterienzahl um wenigstens $95 \%$ zu reduzieren (Blome et al. 2008).

Es ist festzuhalten, dass ein optimales Ergebnis einer endodontischen Behandlung nur durch die Beseitigung bzw. signifikante Reduzierung von Bakterien im Wurzelkanal zu erreichen ist (Fabricius et al. 2006; Siqueira und Rôças 2008). Eine erfolgreiche Wurzelkanaltherapie beruht auf der Kombination der sachgerechten Instrumentierung, Desinfektion und Obturation des Wurzelkanals (Krause et al. 2007). 
An den bearbeiteten Dentinflächen entsteht infolge der Wurzelkanalaufbereitung eine präparationsbedingte Schmierschicht (smear layer). Diese circa 1-5 $\mu \mathrm{m}$ dicke Schmierschicht (Brännström und Johnson 1974; Mader et al. 1984) besteht aus Prädentin, Dentinspänen, pulpalen Gewebsresten, Odontoblasten, Rückständen des Spülmediums und bei infizierten Wurzelkanälen zusätzlich aus Toxinen, Bakterien und Bakterienabbauprodukten (McComb und Smith 1975; Sen et al. 1995). Die Schmierschicht breitet sich oberflächlich aus und kann bis zu $40 \mu \mathrm{m}$ tief in die Dentintubuli gepresst werden (Mader et al. 1984). Bakterien können das Dentin radikulär gar 300-800 $\mu \mathrm{m}$ tief penetrieren (Gordon et al. 2007). Eine unvollständige Entfernung des smear layers kann in einer erneuten Vermehrung der Mikroorganismen und der Reinfektion des Wurzelkanalsystems resultieren (Drake et al. 1994). Zusätzlich kann die Effizienz medikamentöser Einlagen verzögert, inhibiert oder ausgesetzt werden (Ørstavik und Haapasalo 1990; Drake et al. 1994). Außerdem kann der Erhalt des smear layers die Penetration des Sealers in die Dentintubuli verhindern (White et al. 1984; Kokkas et al. 2004; Xu et al. 2005). Sealer dient als Wurzelkanalfüllpaste, welche Inkongruenzen zwischen dem Kernmaterial und der Wurzelkanalwand, wie beispielsweise Ramifikationen und Unebenheiten in der Kanalwand, volumenstabil ausfüllt. Die Bildung von sealer tags in den Dentintubuli steht für eine gute Adaptation (De-Deus et al. 2011). Bei mangelhaftem Sealerverschluss der Wurzelkanalwand mit dem Kernmaterial können apikale und koronale Microleakages auftreten (Park et al. 2004; Türkün et al. 2005). Diese können im späteren Verlauf zu einem endodontischen Misserfolg führen. Die Obturation des Wurzelkanals nach der Entfernung des smear layers führt zu weniger apikalen Leakages (Xu et al. 2005; Likhitkar et al. 2016). In einer kürzlich veröffentlichten Studie wurde zudem gezeigt, dass mit der Entfernung des smear layers vor der thermoplastischen Obturation deutlich weniger apikale Leakages verbleiben als bei der lateralen Kondensation der Guttapercha (Likhitkar et al. 2016). Andere Studien belegten, dass die Präsenz oder die Abwesenheit des smear layers keinen Einfluss auf die Entstehung eines apikalen Microleakages hat (Du und Zhu 2005; Mokhtari et al. 2015). Andererseits sprechen einige Autoren dem smear layer einen positiven Effekt zu. Die Schmierschicht verzögere zwar die Desinfektionswirkung, verhindere diese aber nicht und sei zugleich eine Barriere 
für den Eintritt von Mikroorganismen in die Dentintubuli (Asnaashari und Safavi 2013).

Heutzutage wird über die Entfernung des smear layers kontrovers diskutiert. Der Entfernung der medikamentösen Einlagefüllung dagegen wird für die Desinfektion des Wurzelkanals eine wichtige Rolle zugesprochen (siehe 2.4.4).

\subsection{Spüllösungen}

\subsubsection{Natriumhypochlorit}

Zu den ältesten und verbreitetsten Spüllösungen gehört Natriumhypochlorit $(\mathrm{NaOCl})$. Schon während des ersten Weltkriegs von Alexis Carrel und Henry Drysdale Dakin für die Spülung von infizierten Wunden verwendet (Dakin 1915), wurde es ursprünglich als Bleichmittel eingesetzt. Bereits 1920 zählte $\mathrm{NaOCl} z u$ den Hauptspüllösungen in der endodontischen Behandlung (Zehnder et al. 2003).

$\mathrm{NaOCl}$ zeigt eine breite antimikrobielle Wirkung gegen viele für die Endodontie bedeutsamen Mikroorganismen wie Actinomyces, Candida und Enterococcus. In Konzentrationen von $1-5 \%$ ist $\mathrm{NaOCl}$ in der Lage, die Membran von Mikroorganismen wie Enterococcus faecalis, Streptococcus anginosus, Streptococcus gordonii und Lactobacillus paracasei anzugreifen und den Biofilm zu entfernen (Chávez de Paz et al. 2010). Außerdem wirkt es auflösend auf vitales und nekrotisches Pulpagewebe und die organischen Komponenten des smear layers und dient zugleich als Gleitmittel während der mechanischen Präparation des Wurzelkanals (Andersen et al. 1992; Baumgartner und Cuenin 1992; Naenni et al. 2004; Mohammadi 2008). Des Weiteren zeigt $\mathrm{NaOCl}$ bei der Entfernung von Debris aus dem Wurzelkanal eine hohe Effektivität, allerdings ist dieser Reinigungseffekt abhängig von der Eindringtiefe der Spülnadel (Boutsioukis et al. 2010d). Nach aktuellem Wissensstand ist $\mathrm{NaOCl}$ die Desinfektionslösung der ersten Wahl.

\subsubsection{Chelatoren (EDTA)}

Ethylendiamintetraacetat (EDTA) gehört in die Stoffgruppen der Chelatoren. Im Handel erhältlich sind flüssige und gelförmige Chelator-Präparate. Die flüssigen Präparate beinhalten in der Regel etwa 15-17\% EDTA und Natriumhydroxid. Die 
gelförmigen Pasten enthalten etwa 15\% EDTA und knapp 10\% Harnstoffperoxid. Die empfohlene Konzentration liegt zwischen $15-20 \%$, am gängigsten sind 1517\%ige Lösungen. In erster Linie wird EDTA zur Entfernung des smear layers verwendet.

\subsection{Spültechniken}

\subsubsection{Manuelle Spülung (Handspülung)}

Die Handspülung zählt zu den meist verwendeten Spültechniken. Gründe hierfür sind die vergleichsweise einfache Handhabung, die gute Kontrolle über die abgegebene Spüllösungsmenge und die Eindringtiefe der Spülkanüle (van der Sluis et al. 2006) sowie die geringen Kosten.

Für die manuelle Spülung werden herkömmliche Spritzen mit einem Fassungsvolumen von in der Regel $1-5 \mathrm{ml}$ und Spülkanülen mit unterschiedlichem Durchmesser (0,23-0,4 mm) verwendet. Variationen bestehen in der Lage der Spülkanülenöffnung. Es werden die seitliche Öffnung (side-vented needle) und die Öffnung an der Spitze (open-ended needle) der Spülkanüle unterschieden. Abhängig von der Lage der Öffnung der Applikationsnadel resultieren zwei verschiedene Nadelpositionen. Die Applikationsnadel mit seitlicher Öffnung sollte in den Wurzelkanal bis $1 \mathrm{~mm}$ vor Arbeitslänge inseriert werden. Diese Ansicht teilen zahlreiche Autoren (Abou-Rass und Piccinino 1982; Zehnder 2006; Boutsioukis et al. 2009). Für Applikationsnadeln mit Öffnung an der Spitze empfehlen Boutsioukis et al. (2010a) die Positionierung 2-3 mm koronal der endodontischen Arbeitslänge. Dies soll ein Überpressen der Spülflüssigkeit über den Apex hinaus verhindern. Manogue et al. (2005) empfehlen zur Vermeidung der apikalen Extrusion die generelle Anwendung von Nadeln mit seitlicher Öffnung. Nach Chang et al. (2015) soll bei einer openended-Spülnadel eine Spülrate über $100 \mu \mathrm{L} / \mathrm{s}$ das Risiko einer apikalen Extrusion erhöhen, wohingegen eine Aufbereitung des Wurzelkanals auf ISO-Größe 40 die Menge der apikalen Extrusion reduziert.

Für eine sichere und effektive Spülung kann eine dynamische Spültechnik benutzt werden (Devi und Abbott 2012). Die Bewegung findet in Form kleiner vertikaler Hubbewegungen statt, eine Friktion der Nadel ist dabei unbedingt zu vermeiden (Moser und Heuer 1982). Bereits 1995 berichteten Kahn et al. über 
erhebliche Folgen, welche durch ein Verklemmen der Spülnadel ausgelöst wurden. Nach Gulabivala und Stock (2005) sollte kein Verklemmen der Nadel stattfinden, um den koronalen Abtransport von Spülflüssigkeit mit Debris zu gewährleisten.

Dünne Applikationsnadeln können tiefer in den Wurzelkanal inseriert werden, ohne dabei zu verklemmen. Sie können jedoch schneller mit $\mathrm{NaOCl}$-Kristallen verstopfen bzw. frakturieren (Moser und Heuer 1982). Für Spülnadeln mit großen Durchmessern sind diese Faktoren zu vernachlässigen, wobei diese Nadeln meist nicht bis in den apikalen Wurzelkanal gelangen und damit keine effiziente Spülung erreicht werden kann (Chow 1983). Bei den dünnen Applikationsnadeln wird dagegen auch im apikalen Wurzelkanal ein ausreichender Austausch an Spülflüssigkeit erreicht (Chow 1983; van der Sluis et al. 2006; Hsieh et al. 2007). Ein Vergleich zwischen drei Durchmessergrößen (25-, 27- und 30-gauge) der Spülnadeln zeigt, dass mit kleiner werdendem Nadeldurchmesser der Druck auf bis zu 400-500 kPa ansteigt, die Abgabedauer von 11,66 Sekunden auf 17,23 Sekunden zunimmt und die Fließrate sinkt (Boutsioukis et al. 2007).

Neben der Spülkanüle und dem Spülmedium (siehe 2.2) spielt auch die Präparation des Wurzelkanals eine entscheidende Rolle. Ein ausreichender Austausch des Spülmediums hängt unter anderem von der Konizität des präparierten Wurzelkanals ab (Boutsioukis et al. 2010e). Es ist mindestens ein apikaler Präparationsdurchmesser der ISO-Größe 40 notwendig, um eine ausreichende Spülung des Wurzelkanals zu erzielen (Ram 1977). Aktuellere Studien bestätigen diese Erkenntnis (Wu und Wesselink 1995; Hsieh et al. 2007; Boutsioukis et al. 2010c). Jedoch können mit zunehmender Erweiterung des Wurzelkanals Turbulenzen während des Spülvorgangs auftreten, die den koronalen Abtransport von Mikroorganismen und Dentindebris behindern (Hsieh et al. 2007). Nach Boutsioukis et al. (2010c) scheint ein apikaler Wurzelkanalquerschnitt größer als ISO-Größe 25 die Wirkung der manuellen Spülung bezüglich des Flüssigkeitsaustausches, der Scherspannung auf die Kanalwand und des Drucks am Foramen apicale zu verbessern. Die Flüssigkeitsverteilung von Wurzelkanalspülungen kann durch große Nadeldurchmesser, größer werdende Distanz zwischen der Nadelspitze und dem apikalen Stopp sowie einem schmalen Wurzelkanal negativ beeinflusst werden (Hsieh et al. 2007). 
Boutsioukis et al. (2014) nutzten eine Kombination aus Experiment und numerischer Strömungssimulation um herauszufinden, dass in $48 \%$ der Fälle während der Handspülung ein Vapor-Lock-Effekt vorliegt. Durch kleine Gasbläschen, welche durch die eingebrachte Spüllösung in den apikalen Wurzelkanalbereich geschoben werden, fehlt in diesem Bereich eine Mikrozirkulation. Unter dem fehlenden Austausch der Spüllösung leidet die Reinigungswirkung der manuellen Spülung im apikalen Bereich (Tay et al. 2010; Gade et al. 2013). In einem geschlossenen System tritt der Vapor-Lock-Effekt bei der Verwendung einer side-vented-Nadel auf einer Länge von 0,5-1 mm im apikalen Wurzelkanal auf (Tay et al. 2010). Der Vapor-Lock-Effekt wird kleiner mit steigender apikaler Präparationsgröße des Wurzelkanals, mit einer näheren Nadelposition zur Arbeitslänge, bei der Nutzung einer open-ended-Nadel und mit einer höheren Fließrate des Spülmediums. Eine Fließrate von 0,260 ml/s ohne Positionsveränderung der Spülnadel ist in der Lage, den Vapor-Lock-Effekt aufzuheben (Boutsioukis et al. 2014).

Eine Vielzahl von Studien beschäftigt sich mit der Strömungsdynamik während der Handspülung. Boutsioukis et al. (2010e) untersuchten mit Hilfe eines computerunterstützten Fluss-Dynamik-Modells (CFD $=$ computational fluid dynamics) die Auswirkung von Tapern auf den Spülfluss der manuellen Spülung. Mit größerem Taper kommt es zu einer breiteren Verteilung der Wandscherspannung im Kanal mit einer sinkenden Maximalspannung, außerdem wird der Austausch der Spülflüssigkeit verbessert und das Risiko der apikalen Extrusion verringert (Boutsioukis et al. 2010e). Eine side-ventedSpülnadel zeigt eine größere Wandscherspannung als eine an der Spitze geöffnete Spülnadel, allerdings wirkt diese Kraft auf einen kleineren Bereich der Kanalwand (Chen et al. 2014). 2010 veröffentlichen Boutsioukis et al. eine CFDStudie, um den Spülfluss verschiedener Spülnadeln miteinander zu vergleichen. An der Spitze geöffnete Nadeln erzeugen einen Spülstrahl in Richtung Apex mit maximalem Austausch der Spülflüssigkeit und hohem apikalen Druck. Die seitlich geöffneten Spülkanülen produzieren Turbulenzen und sind weniger effektiv im Austausch der Spülflüssigkeit (Boutsioukis et al. 2010a). Der Austausch der Spüllösung ist auf 1-1,5 mm apikal der Spülspitze limitiert (Boutsioukis et al. 2009). Bereits kleine laterale Verschiebungen der seitlich geöffneten Nadel im 
Wurzelkanal haben limitierende Auswirkungen auf das Strömungsfeld (Boutsioukis et al. 2010b).

Bei der Handspülung lassen sich anwenderspezifische Variationen nicht ausschließen. Die Erfahrung des Zahnarztes hat keinen Einfluss auf das Spülvolumen, die Abgabedauer und die Durchflussrate, jedoch wurden geschlechtsspezifische Unterschiede festgestellt (Boutsioukis et al. 2007).

\subsubsection{Passive Ultraschallspülung}

Die Verwendung von Ultraschall in der Zahnmedizin geht bis auf das Jahr 1952 zurück. 1957 führte Richman erstmals Ultraschall in die Endodontie ein (Gomma et al. 1992). Mit der Einführung der piezoelektrischen Geräte haben sich die Anwendungsgebiete des Ultraschalls auf alle Phasen der Endodontiebehandlung ausgebreitet. Dabei werden spezielle Instrumente für die Präparation der Zugangskavität, die Darstellung der Kanaleingänge, die Entfernung von Obstruktionen (z. B. Dentikeln) und die Erschließung obliterierter Wurzelkanäle angeboten. Die Reinigung des Wurzelkanalsystems kann mit ultraschallgestützten Spülungen erfolgen. Ein Einsatz ultraschallbetriebener Geräte während der Wurzelkanalfüllung ist bei der Applikation des Sealers und der Kondensation der Guttapercha möglich. Die Nutzung des Ultraschalls kann bei der Entfernung von Metallstiften, abgebrochenen Instrumentenspitzen oder der Überwindung einer Verblockung bzw. Stufe im Wurzelkanal notwendig sein.

Schall mit Frequenzen oberhalb der menschlichen Hörschwelle ab circa 16 kHz wird als Ultraschall bezeichnet. Zur Erzeugung von Ultraschall in Flüssigkeiten wurden zunächst magnetostriktive Wandler verwendet, heutzutage kommen vermehrt piezoelektrische Keramik- oder Quarzschwinger zum Einsatz. Durch das Anlegen einer elektrischen Spannung wird eine gezielte Verformung des piezoelektrischen Materials erzeugt. Dies äußert sich in einer Bewegung über die gesamte Instrumentenlänge. Entlang des Instruments bilden sich Schwingungsknoten und -bäuche aus, welche sich in einem charakteristischen Strömungsbild bemerkbar machen (van der Sluis et al. 2007a). Die Schwingung zeichnet sich als Kette von aufeinanderfolgenden Achten ab (siehe Abbildung 2-1). Durch die Schwingung kommt es zur Ausbildung akustischer Mikroströmungen (acoustic streaming) und Kavitationen im Spülmedium (Ahmad et al. 1987). Der Effekt der 
Kavitationen scheint jedoch nebensächlich zu sein (Ahmad et al. 1987; Stock 1991).

Grundsätzlich sind zwei Formen der Ultraschallanwendung zu unterscheiden: die aktive Ultraschallanwendung, bei welcher das Instrument im direkten Kontakt zur Zahnhartsubstanz oder dem Fremdkörper (Metallstift, frakturiertes Instrument) steht, und die passive Ausführung. Der Begriff der passiven Ultraschallspülung wurde erstmals 1980 von Weller et al. verwendet. Ein freies Schwingen der Feile, wobei Wandkontakte zu vermeiden sind, ist charakteristisch für die passive Ultraschallspülung (PUI = passive ultrasonic irrigation) (Haapasalo et al. 2010).

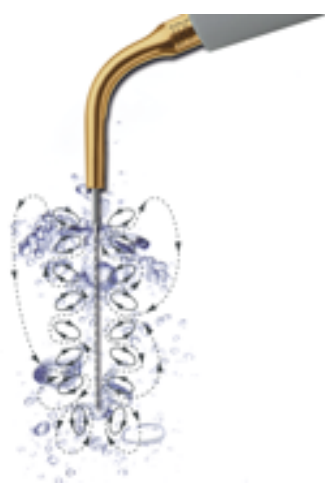

Abb. 2-1: Ultraschallspitze in Bewegung mit dem charakteristischen Strömungsbild. Der Abdruck erfolgt mit freundlicher Genehmigung der Firma Acteon.

Die passive Ultraschallspülung erfolgt bis auf 2-3 mm koronal der Arbeitslänge mit dünnen Reamern der ISO-Größe 15. Dies ermöglicht ein freies Schwingen des Instruments im Wurzelkanal, wodurch Stufenbildungen innerhalb des Wurzelkanalverlaufs und eine Dämpfung der Schwingung verhindert werden sollen (Drebenstedt 2009). Außerdem werden Perforationen und Formveränderungen des Wurzelkanals vermieden. Des Weiteren wird der Effekt des acoustic streaming reduziert, wenn die Feile im Wurzelkanal nicht frei schwingt (Ahmad et al. 1992). Nach Boutsioukis et al. (2013) findet jedoch während $20 \%$ der Dauer der Schallaktivierung ein Feilen-Wandkontakt statt. Auf den Feilenkontakt zur Wurzelkanalwand kann Einfluss genommen werden, indem beispielsweise die Feile weiter koronal der bestimmten Arbeitslänge oder in weiter präparierten Wurzelkanälen zum Einsatz kommt. Um die maximalen Schwingungsamplituden von $135 \mu \mathrm{m}$ zu erreichen, empfiehlt sich eine Erweiterung des Wurzelkanals bis auf die ISO-Größe 40 für Ultraschallspitzen 
der ISO-Größe 15 (Ahmad et al. 2009). Wird die Spülspitze unter Friktion im Wurzelkanal aktiviert bzw. verwendet, können Instrumentenfrakturen resultieren (Drebenstedt 2009). Bei der Arbeit mit Ultraschallspitzen in gekrümmten Wurzelkanälen wird das Vorbiegen des Instruments als vorteilhaft beurteilt (Lumley und Walmsley 1992).

Die passive Ultraschallspülung ist der traditionellen Handspülung in der Reduzierung von Enterococcus faecalis weit überlegen (Cachovan et al. 2013; Cherian et al. 2016; Mohmmed et al. 2016). Ein Vergleich mit der schallgestützten Aktivierung der Spüllösung kommt zum selben Ergebnis (Mohmmed et al. 2016). Eine Gegenüberstellung mit neusten Techniken wie der fotodynamischen Therapie zeigt, dass die passive ultraschallgestützte Spülung mit $\mathrm{NaOCl}$ und EDTA bessere Resultate in der Reduzierung der Bakterienbelastung und der Zerstörung der Biofilmstruktur vorweisen kann (Muhammad et al. 2014). Laut Ghinzelli et al. (2014) steigert vielmehr die ultraschallgestützte Aktivierung während der fotodynamischen Therapie die Effizienz der Reduktion von Enterococcus faecalis. Der Vorteil der PUI hinsichtlich der Bakterienreduktion lässt sich auf zwei Faktoren zurückführen. Erstens zerstört die Ultraschallkraft die Bakterienagglomeration und zweitens führt die Kavitation zu einer vorübergehenden Schwächung der Zellmembran, wodurch diese für $\mathrm{NaOCl}$ durchlässig wird (Carver et al. 2007). Vereinzelte Studien bestätigen der PUI keine Überlegenheit in der Reduktion von Enterococcus faecalis im Vergleich mit der manuellen Spülung (Guerreiro-Tanomaru et al. 2015).

Grundsätzlich nimmt das angewendete Spülmedium Einfluss auf die Bakterienreduktion der PUI. Nach de Almeida et al. (2014) kann Kalziumhypochlorit $\left(\mathrm{Ca}(\mathrm{OCl})_{2}\right)$ im Zusammenspiel mit der passiven Ultraschallspülung den antimikrobiellen Effekt steigern. Eine Anwendung der PUI mit natürlichen Spüllösungen wie Aloe Vera oder Propolis zeigt dagegen keine effiziente antibakterielle Wirkung (Bhardwaj et al. 2013).

Der passiven Ultraschallspülung wird in Bezug auf die Entfernung des smear layers und des Debridements im Vergleich zur herkömmlichen Handspülung eine verbesserte Effektivität zugeschrieben (Rödig et al. 2010a; Rödig et al. 2010d; Agrawal und Kapoor 2012; Andrabi et al. 2014). Agrawal und Kapoor (2012) zeigten in einer In-vitro-Studie die Überlegenheit der PUI im Vergleich mit der 
manuellen Handspülung und dem Spülmedium $\mathrm{NaOCl}$. Trotz einer Konzentrationserhöhung auf 2,5\% $\mathrm{NaOCl}$ bei der Handspülung wurden die Werte der PUI mit 1\% NaOCI nicht erreicht.

Jiang et al. (2011) zeigten, dass aus der Zunahme der Ultraschallintensität eine verbesserte Reinigungswirkung resultiert. Mit steigender Intensität vergrößert sich die Amplitude der oszillierenden Feile. Dies führt zu einer höheren Fließgeschwindigkeit der Spüllösung um die Feile und resultiert schließlich in einer gesteigerten Reinigungseffizienz der PUI. Zusätzlich scheint auch in der Entfernung von Debris das Spülmedium Auswirkungen auf die Effektivität der PUI zu haben. Die Nutzung der passiven Ultraschallspülung mit Wasser führte zu weniger Entfernung von Debris als deren Verwendung mit $\mathrm{NaOCl}$ (van der Sluis et al. 2007a).

Zahlreiche Autoren bestätigen der PUI ebenfalls einen positiven Effekt auf die Entfernung von Kalziumhydroxid $\left(\mathrm{Ca}(\mathrm{OH})_{2}\right)$ aus dem Wurzelkanal. Capar et al. (2014) füllten $\mathrm{Ca}(\mathrm{OH})_{2}$ in zuvor künstlich geschaffene Gruben in der Kanalwand und spülten die Proben anschließend mit $\mathrm{NaOCl}$ und verschiedenen Spültechniken. Die PUI erzielte signifikant bessere Werte als die manuelle Handspülung, der EndoVac und die SAF (self-adjusting file). Zu gleichen Ergebnissen bezüglich des Vergleichs zwischen PUI und traditioneller Handspülung bzw. SAF kommen Ahmetoğlu et al. (2013). Eine vollständige Entfernung des Kalziumhydroxids aus dem Wurzelkanal scheint mit der PUI jedoch nicht immer zu gelingen (Rödig et al. 2011; Ahmetoğlu et al. 2013; Zorzin et al. 2016). Lediglich in 11,7\% der Fälle erfolgte eine komplette Entfernung des Kalziumhydroxids aus dem Wurzelkanal (Rödig et al. 2011). Neben der Aktivierung der Spüllösung stellt das Spülvolumen eine Einflussgröße auf die Entfernung von $\mathrm{Ca}(\mathrm{OH})_{2}$ dar. Mit zunehmendem Spülvolumen bei der PUI sinkt das Ausmaß der Kalziumhydroxidrückstände (Zorzin et al. 2016).

Aufgrund der komplexen Wurzelkanalanatomie ist die Penetrationstiefe der Spüllösung limitiert. Dies zeigt sich vor allem beim Erreichen des apikalen Wurzelkanalbereichs und lateraler Seitenkanäle. In einer In-vivo-Studie von Munoz und Camacho-Cuadra (2012) wurde an Molaren die Distanz zwischen der Arbeitslänge und der maximalen Reichweite der Spüllösung ermittelt. Mit einer Durchschnittsdistanz von $0,21 \mathrm{~mm}$ schnitt die PUI deutlich besser ab als die 
konventionelle Handspülung mit 1,51 mm. Dem steht die Studie von de Gregorio et al. (2010) gegenüber, in welcher der PUI keine verbesserte Penetration der Spüllösung in Abhängigkeit von der Arbeitslänge, aber hinsichtlich der Penetration in künstlich simulierte Seitenkanäle zugesprochen wird. Nach der Anwendung der passiven Ultraschallspülung als Abschlussspülung zeigte sich in den Dentintubuli eine höhere Sealerpenetration als bei der konventionellen Handspülung (Akcay et al. 2016). Um eine möglichst dichte Wurzelkanalfüllung $\mathrm{zu}$ erreichen, muss bei einer vorangegangenen Revisionsbehandlung neben dem Wurzelfüllmaterial auch der Sealer entfernt werden. Die PUI scheint der CanalBrush, dem EndoActivator und der manuellen Handspülung in der Entfernung von AH Plus Sealer von der Wurzelkanalwand überlegen zu sein. Limitationen zeigen sich in der Entfernung von Sealer aus lateralen Rillen, welche beispielsweise laterale Seitenkanäle symbolisieren (Grischke et al. 2014).

Bei der PUI wird mit nicht-schneidenden Instrumenten passiv im Wurzelkanal gearbeitet. Die Feile arbeitet frei im Wurzelkanal, wodurch kein Abtrag von Zahnhartsubstanz erfolgt. Capar und Aydinbelge (2013) zeigten, dass der Einsatz der PUI sich nicht in einem veränderten Mineralgehalt der Dentinoberfläche äußerte. Kalzium-, Phosphat-, Magnesium- und Schwefelgehalt blieben unverändert.

Die Applikation der Spüllösung innerhalb der PUI kann kontinuierlich (über das Ultraschallgerät) oder periodisch (per Spritze) erfolgen (Al-Jadaa et al. 2009). Bei der periodischen Zufuhr von Spüllösung wird diese mehrfach, z.B. nach jedem Aktivierungszyklus, per Spritze in den Wurzelkanal eingebracht. Bei diesem Vorgehen kann die Eindringtiefe der Spülnadel in den Wurzelkanal und damit verbunden die Penetration der Spülflüssigkeit in den apikalen Bereich besser kontrolliert werden. Durch die kontinuierliche Zufuhr von Spüllösung wird pausenlos neue Spüllösung in den Kanal eingeführt, welches zu einer Verkürzung der benötigten Zeit für ultraschallgestützte Spülungen führt (Gu et al. 2009). Grundsätzlich sollte die Aktivierung der Ultraschallfeile nur in mit Spüllösung gefüllten Wurzelkanälen erfolgen.

Die Angaben für die Anwendungszeit liegen abhängig von der jeweiligen Technik zwischen 10 Sekunden und 3 Minuten. Kürzere Aktivierungszeiten vereinfachen die Handhabung der Feilenhaltung im Zentrum des Wurzelkanals, schützen vor 
Wandkontakt und damit verbundenen Wandschädigungen (Munley und Goodell 2007). Gutarts et al. (2005) zeigten, dass eine Aktivierung des Ultraschalls für 1 Minute in einem signifikant saubereren Wurzelkanal und Isthmusbereich resultierte.

Abschließend kann zusammengefasst werden, dass aufgrund der zahlreichen Vorteile der PUI gegenüber der konventionellen Handspülung die Ultraschallaktivierung von Spüllösungen während einer endodontischen Behandlung und vor allem als Abschlussspülung nach aktuellem wissenschaftlichen Stand als Goldstandard bezeichnet werden kann.

\subsubsection{EndoActivator}

Der EndoActivator (DENTSPLY Maillefer, Santa Barbara, USA) gehört zu der Gruppe der schallaktivierten Aktivierungshilfen. Mit einer Frequenz von 2000, 6000 oder $10000 \mathrm{cpm}$ (cycles per minute) erfolgt eine hydrodynamische Aktivierung der Spülflüssigkeit. Die erzeugten Schallwellen werden über das batteriebetriebene Handstück auf die flexible Polymerspitze (Activator Tips) weitergeleitet. Die Spitzen sind in drei verschiedenen Größen Small (15/.02), Medium (25/.04) und Large (35/.04) mit Farbcodierung erhältlich. Wie bei maschinellen Aufbereitungsinstrumenten gibt die erste Zahl den Instrumentenquerschnitt $1 \mathrm{~mm}$ vor der Spitze und die zweite Zahl die Instrumentenkonizität $(2 \%, 4 \%)$ an. Die Aufsätze sind unbeschichtet, nicht-schneidend und besitzen Tiefenmarkierungen bei 18, 19 und $20 \mathrm{~mm}$ bei einer Gesamtlänge von $22 \mathrm{~mm}$. Nach Herstellerangabe sollten die Aufsätze nach einmaligem Gebrauch verworfen werden.

Eine Aktivierung des Geräts soll laut Hersteller erst erfolgen, wenn die Polymerspitze sich an der endgültigen Position im mit Spülflüssigkeit gefüllten Wurzelkanal befindet. Die Spülung soll in wiederholten Zyklen von 30-60 Sekunden stattfinden. Während eines Zyklus werden vertikale Hubbewegungen von 2-3 mm empfohlen, dabei ist darauf zu achten, dass die Spitze keinen Kontakt zur Kanalwand und einen Abstand von mindestens 2 mm zum Apex aufweist.

Capar und Aydinbelge (2013) bewiesen, dass die Anwendung des EndoActivators in der Dentinoberfläche im Wurzelkanal keine Veränderung des 
Mineralgehaltes (Calcium-, Phosphat-, Magnesium- und Schwefelgehalt) verursacht.

In einigen Studien zeigte sich der EndoActivator in der Bakterienreduktion der manuellen Spülung überlegen (Pasqualini et al. 2010; Shen et al. 2010). Nach einer 30-sekündigen Handspülung mit $\mathrm{NaOCl}$ zeigte die Probe eine höhere Keimzahl an Enterococcus faecalis als nach 30-sekündiger Aktivierung des $\mathrm{NaOCl}$ mit dem EndoActivator (Pasqualini et al. 2010). Dem stehen In-vitro- und In-vivo-Studien gegenüber, welche keinen signifikanten Unterschied in der Effektivität der Keimreduktion des EndoActivators gegenüber der Handspülung aufwiesen (Brito et al. 2009; Huffaker et al. 2010). Brito et al. (2009) kontaminierten extrahierte Zähne mit Enterococcus faecalis, spülten die Proben nach 7 Tagen mit der jeweiligen Spültechnik, $\mathrm{NaOCI}$ und EDTA, um zu dem Ergebnis zu gelangen, dass kein Unterschied zwischen den Spültechniken EndoActivator, Handspülung und EndoVac vorliegt. Aufgrund dessen sollte nach Huffaker et al. (2010) bei der Behandlung einer apikalen Parodontitis zur Keimeliminierung vielmehr ein mehrzeitiges Behandlungskonzept mit medikamentöser Einlage angestrebt werden. Die ultraschallgestützte und die laseraktivierte Spülung (PIPS $®$ = photon-initiated photoacoustic streaming) sind dem EndoActivator in diesem Bereich klar überlegen (Azim et al. 2016; RicoRomano et al. 2016).

Auf die Fähigkeit der Gewebeauflösung von $\mathrm{NaOCl}$ hat der EndoActivator keinen direkten Einfluss (Guneser et al. 2015).

Schwerpunkt vieler Untersuchungen ist die vollständige Entfernung von Kalziumhydroxid aus dem Wurzelkanal. Ma et al. (2015b) bewerteten die Entfernbarkeit von Kalziumhydroxid an Unterkiefermolaren mit gekrümmten Wurzelkanal mit Hilfe eines Mikro-CTs (Computertomographie). Im apikalen Wurzelkanaldrittel blieben bei der Verwendung des EndoActivators $28 \%$ des Kanals mit Kalziumhydroxid gefüllt. Die passive Ultraschallspülung erzielte dem EndoActivator gleichwertige Ergebnisse. Im Vergleich zur konventionellen Handspülung schnitt der EndoActivator signifikant besser ab. Die vollständige Entfernung von Kalziumhydroxid ist laut zahlreichen Studien mit den heutzutage üblichen Spültechniken nicht zu erzielen (Khaleel et al. 2013; Faria et al. 2014; Alturaiki et al. 2015; Ma et al. 2015b). Die Überlegenheit von schall- und 
ultraschallgestützten Spülungen gegenüber der manuellen Spülung bei der Entfernung von Kalziumhydroxid wurde auch für gerade Kanäle bestätigt (Khaleel et al. 2013; Faria et al. 2014).

Eine Vielzahl von Studien untersuchte des Weiteren die Entfernung von smear layer im gekrümmten Wurzelkanal mit dem Ergebnis, dass sich die Effizienz von Spülflüssigkeiten in der Entfernung der Schmierschicht durch deren Aktivierung deutlich steigern lässt (Caron et al. 2010; Rödig et al. 2010b; Blank-Gonçalves et al. 2011; Yeung et al. 2014). Rödig et al. (2010b) bewiesen in einer SEM-Studie (scanning electron microscope), dass sich die Entfernung des smear layers im koronalen Kanalbereich durch die Aktivierung der Spülflüssigkeiten $\mathrm{NaOCl}$ und EDTA signifikant verbessern lässt. Dabei erzielte der EndoActivator eine größere Reinigungswirkung als die Aktivierung mit Ultraschall und die CanalBrush. BlankGonçalves et al. (2011) wiesen diesen Effekt für das apikale Wurzeldrittel nach. Die schall- und ultraschallgestützte Spülung entfernte die Schmierschicht signifikant besser als die Handspülung. Dieser Effekt lässt sich auf gerade Wurzelkanäle übertragen (Çapar und Aydinbelge 2014; Kumar et al. 2015). Lediglich Uroz-Torres et al. (2010) erzielten keinen signifikanten Unterschied nach Verwendung unterschiedlicher Spülflüssigkeiten mit dem EndoActivator und der Handspülung mit Max-I-Probe bezüglich der Entfernung der Schmierschicht. Einzig die Verwendung von EDTA zeigte gegenüber $\mathrm{NaOCl}$ eine gesteigerte Reinigungskraft (Uroz-Torres et al. 2010). Eine vollständige Entfernung des smear layers ist jedoch äußerst schwierig und gelingt nicht sicher (Mancini et al. 2013; Çapar und Aydinbelge 2014).

Um die Entfernung von Debris aus schwer zugänglichen Bereichen des Kanalsystems zu simulieren, wurden in den Wurzelkanal standardisierte künstliche Rillen eingearbeitet. Anschließend wurde mit der jeweiligen Spültechnik gespült. Die laseraktivierte Spülung (PIPS ${ }^{\circledR}$ ) verbessert die Entfernung von Debris im Vergleich zur schall-, ultraschallgestützten und manuellen Spülung (Arslan et al. 2014a). Keinen Unterschied zwischen der schall-, ultraschallgestützten und manuellen Spülung in der Entfernung von Debris konnten ebenfalls Klyn et al. (2010) und Rödig et al. (2010b) feststellen. Dem stehen Studien gegenüber, welche zeigen, dass z. B. der EndoActivator der Handspülung überlegen ist (Çapar und Aydinbelge 2014; Topçuoglu et al. 2015). 
Die Auswahl der Spültechnik kann unter anderem ausschlaggebend für das Potenzial der apikalen Extrusion von Spülflüssigkeit wie $\mathrm{NaOCl}$ sein. Aktuelle Studien befassen sich mit dem Vergleich der apikalen Extrusion einzelner Spültechniken (Desai und Himel 2009; Rodríguez-Figueroa et al. 2014; Yost et al. 2015). Desai und Himel (2009) zeigten, dass beim Einführen der Activator Tips in den mit Spülflüssigkeit gefüllten Wurzelkanal bzw. beim Starten des EndoActivators eine apikale Extrusion verursacht wird. Die Menge der apikalen Extrusion wird jedoch als minimal bewertet. Eine Nutzung des EndoActivators $1 \mathrm{~mm}$ kürzer als die Arbeitslänge wird als sicher angesehen (Rodríguez-Figueroa et al. 2014).

Patienten zeigten nach einer endodontischen Behandlung mit dem EndoActivator weniger postoperative Schmerzen als bei einer Behandlung mit der konventionellen Handspülung (Ramamoorthi et al. 2015).

\subsubsection{EDDY}

Der EDDY (VDW, München, Deutschland) verursacht eine schallbasierte Aktivierung von Spülflüssigkeit. Die Spülspitze aus Polyamid ist flexibel, nichtschneidend und arbeitet demnach Dentin schonend. Der Dokumentationsaufwand entfällt, da die Spitzen steril verpackt und für den Einmalgebrauch vorgesehen sind. Der EDDY hat eine aktive Länge von $28 \mathrm{~mm}$ mit acht verschiedenen Tiefenmarkierungen und ist an der Spitze 0,2 $\mathrm{mm}$ dick.

Die Polyamid-Spitze wird in ein EDDY-kompatibles Schallhandstück, z. B. Airscaler Proxeo (W\&H Dentalwerk, Bürmoos, Österreich), eingeschraubt. Der Frequenzbereich liegt zwischen 5000 bis $6000 \mathrm{~Hz}$. Die Ultraschallschwingung wird vom Handstück über die Spitze weitergeleitet und an die Spülflüssigkeit abgegeben. Dabei wird der EDDY selbst in eine oszillierende Schwingung mit großer Amplitudenauslenkung gebracht. Wie bei der PUI werden Kavitationen und acoustic streaming beobachtet. Der Effekt der Kavitation beschreibt das Entstehen kleiner Gasbläschen an der Spitze des Instruments, verursacht durch die Schallbewegung. Diese Bläschen implodieren und sollen mit der freigesetzten Energie zu dem gewünschten Reinigungseffekt beitragen. Hinter dem acoustic streaming verbirgt sich das Fließmuster der Flüssigkeit um den schwingenden Körper. In der Spülflüssigkeit werden durch die hochfrequenten Bewegungen Wirbelströmungen (Eddy flow) erreicht, welche ebenfalls zu einem 
Reinigungseffekt beitragen. Bei der schallbasierten Aktivierung von Spülflüssigkeiten bilden sich Schallknoten und Schallbäuche, welche für eine Bewegung der Flüssigkeit um den oszillierenden Körper sorgen (siehe Abbildung 2-2). Der Schallknoten befindet sich an der Basis, der Schallbauch an der Spitze der Spülspitze (van der Sluis et al. 2007a). Geräte ohne Schallbäuche und -knoten erzielen demnach eine geringere Reinigungswirkung.

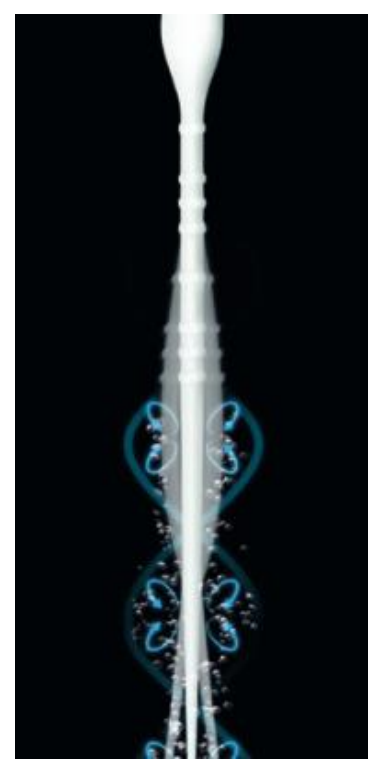

Abb. 2-2: Bewegungsmuster des EDDY. Der Abdruck erfolgt mit freundlicher Genehmigung der Firma VDW.

Laut Herstellerangaben sind eine Reinigung von Isthmen und Seitenkanälen bei anatomisch komplexen Wurzelkanalverlauf und eine effiziente Entfernung von Geweberesten und Debridement möglich. Außerdem kann der EDDY zur Applikation von Sealer und Kalziumhydroxid sowie zur Entfernung von Kalziumhydroxid verwendet werden. Für eine effektive Nutzung wird eine Aufbereitungsgröße von mindestens ISO 25 und Taper .06 empfohlen.

Die Beurteilung der theoretischen Aussagen muss mit Hilfe von In-vitro- und Invivo-Studien speziell für den EDDY noch erfolgen.

Bisher liegt nur eine geringe Anzahl an veröffentlichten Studien zum Einsatz mit dem EDDY vor. In einem In-vitro-Experiment verglichen Neuhaus et al. (2016) den antibakteriellen Effekt des EDDY mit herkömmlichen Methoden wie der PUI und der Handspülung. Humane Zähne wurden für 3 bzw. 21 Tage mit endodontisch relevanten Mikroorganismen geimpft und anschließend mit der jeweiligen Spültechnik und Natriumchlorid $(\mathrm{NaCl})$ bzw. $\mathrm{NaOCl}$ gespült. Der 
Vergleich der gespülten Proben nach 3-tägiger Liegedauer, wies eine signifikante Überlegenheit des EDDY gegenüber der PUI und der Handspülung für gerade und gekrümmte Wurzelkanäle nach. Kein signifikanter Unterschied in der antibakteriellen Wirkung wurde zwischen dem EDDY und der PUI nach längerer Liegedauer festgestellt. Beide Spültechniken entfernten die Mikroorganismen Streptococcus gordonii/Actinomyces oris und Streptococcus gordonii/ Fusobacterium nucleatum vollständig und zeigten zugleich eine geringe Effizienz gegen Enterococcus faecalis und Candida albicans.

In einer kürzlich veröffentlichten Studie von Urban et al. (2017) wurden verschiedene Aktivierungssysteme in ihrer Effektivität bezüglich der Entfernung von Debris und smear layer untersucht. Der EndoActivator, der EDDY und die PUI entfernten signifikant mehr Debris als die herkömmliche Handspülung. Der EDDY und die PUI zeigten zudem eine Überlegenheit in der Entfernung des smear layers gegenüber der manuellen Spülung.

\subsection{Medikamentöse Einlagefüllung}

\subsubsection{Funktion einer medikamentösen Einlagefüllung}

Das primäre Ziel jeder endodontischen Behandlung ist die Elimination von Mikroorganismen und deren Stoffwechselprodukten sowie die Entfernung von entstandenem Debris und zurückgebliebenem Pulpagewebe. Vor allem die Menge an Bakterien spielt in der Entwicklung und Ausbreitung von Erkrankungen der Pulpa und des periapikalen Parodonts eine entscheidende Rolle (Fabricius et al. 1982; Möller et al. 2004). Die mechanische Wurzelkanalpräparation unter gleichzeitiger Anwendung antibakterieller Agenzien leistet einen wesentlichen Beitrag zur Keimreduktion, garantiert allerdings keine absolute Keimfreiheit des Wurzelkanals (Byström und Sundqvist 1981). Eine in den Wurzelkanal eingebrachte und zwischen den einzelnen Behandlungsterminen verbleibende medikamentöse Einlage soll einer weiteren Keimreduzierung dienen (Walton 1984; Siqueira und Lopes 1999; Portenier et al. 2002).

Laut Athanassiadis et al. (2007) werden medikamentöse Einlagefüllungen in der Endodontie für folgende Zwecke genutzt:

- Zerstörung bzw. Eliminierung von verbleibenden Bakterien (z. B. nach erfolgter chemomechanischer Wurzelkanalpräparation) 
- Reduzierung periradikulärer Entzündungen und damit einhergehende Schmerzlinderung

- Beseitigung von apikalem Exsudat

- Vermeidung von entzündlichen Wurzelresorptionen und

- Verhinderung von Reinfektionen.

Über den Bedarf einer medikamentösen Einlagefüllung und die damit einhergehende Indikation einer ein- oder mehrzeitigen Behandlung wird in den letzten Jahren verstärkt diskutiert. Die Studienlage zeigt widersprüchliche Ergebnisse, welche auf unterschiedliche Studiendesigns zurückzuführen sind. In einem Review-Artikel wurde kein signifikanter Unterschied in der Heilungsrate und der mittelfristigen Schmerzempfindung zwischen ein- und mehrzeitigen Behandlungen von infizierten Wurzelkanälen sichtbar (Su et al. 2011). Eine medikamentöse Einlage gilt als indiziert, wenn Bakterien gegenüber einer Routinebehandlung resistent sind, weiterhin Schmerzen oder ein Exsudat vorliegen (Gomes et al. 2003) bzw. eine Behandlung aus Zeitgründen nicht in einer Sitzung abgeschlossen werden kann.

Als medikamentöse Einlagefüllungen können folgende Präparate in Betracht kommen: Kalziumhydroxid, Antibiotika (z. B. Kortikosteroide), Nicht-Phenolbiozide (z. B. Chlorhexidin), Phenolbiozide und jodhaltige Produkte. Im folgenden Abschnitt wird ausschließlich auf Kalziumhydroxid eingegangen.

\subsubsection{Charakteristika des Kalziumhydroxids}

Kalziumhydroxid hat derzeit in der Zahnmedizin ein breites Anwendungsspektrum. Ursprünglich von Herman 1920 zur Pulpaüberkappung eingesetzt, wird es dank seiner biologischen Fähigkeiten wie antimikrobielle Aktivität, Gewebeauflösung, Anregung von Hartgewebsneubildung und Inhibition von Wurzelresorption ferner im Rahmen der Behandlung von Zahntraumata zur Apexifikation der Wurzelspitze und als medikamentöse Einlagefüllung eingesetzt (Haskell et al. 1978; Akhlaghi und Khademi 2015; Damle et al. 2016; Lin et al. 2016).

Der pH-Wert liegt bei 12,5-12,8. Zudem besitzt es eine geringe Wasserlöslichkeit. In wässriger Lösung dissoziiert $\mathrm{Ca}(\mathrm{OH})_{2}$ zu Kalzium $\left(\mathrm{Ca}^{2+}\right)$ - und Hydroxyl $\left(\mathrm{OH}^{-}\right)$Ionen. Vor allem die $\mathrm{OH}^{-}$-Ionen sind für die hohe Alkalität und den damit 
einhergehenden antimikrobiellen Effekt des $\mathrm{Ca}(\mathrm{OH})_{2}$ verantwortlich (Heithersay 1975). Dies ist auf folgende Mechanismen zurückzuführen: Zerstörung der bakteriellen Zytoplasmamembran, Unterdrückung der Enzymaktivität, Störung des Zellmetabolismus und Inhibition der DNA-Replikation (Estrela et al. 1995; Siqueira und Lopes 1999). Außerdem wird das Lumen des Wurzelkanals durch das $\mathrm{Ca}(\mathrm{OH})_{2}$ als temporäres Medikament ausgefüllt und stellt für mögliche einwandernde Bakterien eine physikalische Barriere dar.

Der antimikrobielle Effekt des $\mathrm{Ca}(\mathrm{OH})_{2}$ wurde in zahlreichen Untersuchungen überprüft (Gencoglu und Külekçi 1992; Georgopoulou et al. 1993; Estrela et al. 1998; Tanomaru et al. 2007; Mohammadi et al. 2014; Rahimi et al. 2014). Gencoglu und Külekçi (1992) zeigten eine effektive Wirkung des $\mathrm{Ca}(\mathrm{OH})_{2}$ gegenüber Streptococcus mutans, Peptostreptococcus anaerobius, Porphyromonas gingivalis und Fusobacterium nucleatum. Leonardo et al. (2000) bewiesen für zwei $\mathrm{Ca}(\mathrm{OH})_{2}$-Pasten ebenfalls einen antibakteriellen Effekt gegen verschiedene Bakterienstämme (Micrococcus luteus, Staphylococcus aureus, Pseudomonas aeruginosa, Staphylococcus epidermidis, Escherichia coli, Enterococcus faecalis und Streptococcus mutans). Eine Auswirkung auf die Effektivität des $\mathrm{Ca}(\mathrm{OH})_{2}$ haben dessen Liegedauer und Konzentration. Laut Blanscet et al. (2008) besteht ein signifikanter Zusammenhang zwischen einer steigenden Konzentration $(40 \%, 50 \%$ und $60 \%)$ des $\mathrm{Ca}(\mathrm{OH})_{2}$ und einer größeren Inhibitionszone. Sie empfehlen für die Anwendung einer medikamentösen Einlagefüllung eine $50-60 \%$ ige $\mathrm{Ca}(\mathrm{OH})_{2}$-Paste. Eine effektive Elimination von Bakterien wird bei einer Liegedauer über 7 Tage im Wurzelkanal erreicht (Sjögren et al. 1991).

Einige Autoren beharren darauf, dass Bakterien wie Enterococcus faecalis (Pavelić et al. 1991; Ferreira et al. 2007) und Candida albicans (Waltimo et al. 1999) nur eine geringe Empfindlichkeit gegenüber $\mathrm{Ca}(\mathrm{OH})_{2}$ aufweisen. Nach Mattigatti et al. (2012) kann die Wirksamkeit von $\mathrm{Ca}(\mathrm{OH})_{2}$ gegenüber Enterococcus faecalis, Staphylococcus aureus und Candida albicans im Vergleich zu konventionellen und neueren Wurzelkanalmedikamenten (CHX (Chlorhexidin), MTAD (Mixture Tetrazyklin Acid Detergens) und Propolis) als schwach bezeichnet werden. Dem gegenüber steht die Studie von Chai et al. (2007), welche $\mathrm{Ca}(\mathrm{OH})_{2}$ eine $100 \%$ ige Effektivität in der Beseitigung von Enterococcus faecalis zuschreiben. Eine kombinierte Anwendung von $1 \% \mathrm{NaOCl}$ 
und $\mathrm{Ca}(\mathrm{OH})_{2}$ führt zu einer effektiven Reduzierung von Enterococcus faecalis und Candida albicans aus kontaminierten Wurzelkanälen (Valera et al. 2009). Um das Wirkspektrum von $\mathrm{Ca}(\mathrm{OH})_{2}$ zu erhöhen, ist zudem eine Mixtur mit $\mathrm{CHX}$ möglich (Gomes et al. 2006; Jhamb et al. 2010; Prabhakar et al. 2012). Die Alkalität des $\mathrm{Ca}(\mathrm{OH})_{2}$ bleibt dabei unverändert, allerdings zeigten sich negative Auswirkungen auf die mechanischen Eigenschaften des Dentins (Mohammadi et al. 2015). Saatchi et al. (2014) wiesen nach, dass kein signifikanter Unterschied in der Wirksamkeit gegenüber Enterococcus faecalis zwischen einer Mixtur aus $\mathrm{Ca}(\mathrm{OH})_{2} / \mathrm{CHX}$ und $\mathrm{Ca}(\mathrm{OH})_{2}$ alleine besteht. Wenige Autoren ordnen $\mathrm{Ca}(\mathrm{OH})_{2}$ beinahe keinen antimikrobiellen Effekt zu (Basrani et al. 2003; Gomes et al. 2009; Lee et al. 2013). Insgesamt bleibt daher festzuhalten, dass die aktuelle Studienlage zum Thema antimikrobieller Effekt des $\mathrm{Ca}(\mathrm{OH})_{2}$ widersprüchliche Ergebnisse aufzeigt.

Anhand eines In-vitro-Versuchs untersuchten Nerwich et al. (1993) die Veränderung des $\mathrm{pH}-$ Wertes nach der Applikation von $\mathrm{Ca}(\mathrm{OH})_{2}$ innerhalb eines Zeitraums von 4 Wochen. Dieser wurde mit Mikroelektroden in kleinen Kavitäten im apikalen und koronalen Bereich sowie im inneren (zum Wurzelkanal hin) und äußeren (zum Wurzelzement hin) Wurzeldentin bestimmt. Innerhalb von Stunden stieg der pH im inneren Wurzeldentin an (apikal 9,7 und koronal 10,8). Ein Anstieg des $\mathrm{pH}$ im äußeren Wurzeldentin war erst nach 7 Tagen zu beobachten, die Spitzenwerte wurden erst nach 2-3 Wochen erreicht (apikal 9,0 und koronal 9,3). Dieses Ergebnis zeigt, dass die $\mathrm{OH}^{-}$-lonen schneller im koronalen als im apikalen Bereich diffundieren. Die Diffusion der $\mathrm{Ca}^{2+}-$ Ionen aus der $\mathrm{Ca}(\mathrm{OH})_{2-}$ Paste findet innerhalb der ersten 16 Tage statt (Gomes et al. 1996). Daraus abgeleitet sollte die Liegedauer des $\mathrm{Ca}(\mathrm{OH})_{2}$ bei 2-3 Wochen liegen. Abbott (1990) bestätigt, dass eine Liegedauer von weniger als 2 Wochen nicht empfohlen werden kann, da Entzündungen wenigstens 10-14 Tage zum Abheilen benötigen. Nach Sjögren et al. (1991) ist eine effektive Reduzierung der Bakterien im Wurzelkanal jedoch bereits ab 7 Tagen erreicht. In der Literatur variieren die Angaben zwischen 1-4 Wochen für die optimale Liegedauer des $\mathrm{Ca}(\mathrm{OH})_{2}$. 


\subsubsection{Applikation der Kalziumhydroxideinlage}

Der direkte Kontakt des $\mathrm{Ca}(\mathrm{OH})_{2}$ mit Bakterien führt zu deren Beseitigung, weshalb idealerweise der gesamte Wurzelkanal mit maximaler Dichte und auf die gesamte Arbeitslänge mit $\mathrm{Ca}(\mathrm{OH})_{2}$ gefüllt sein sollte (Sundqvist et al. 1998). Eine Vielzahl an Studien beschäftigt sich daher mit der optimalen Applikation von $\mathrm{Ca}(\mathrm{OH})_{2}$ (Staehle et al. 1997; Deveaux et al. 2000; Estrela et al. 2002; Oztan et al. 2002; Torres et al. 2004; Tan et al. 2013).

Gerade Wurzelkanäle können qualitativ hochwertig mit Hilfe eines Spritzensystems mit einer $\mathrm{Ca}(\mathrm{OH})_{2}$-Suspension gefüllt werden. Verglichen mit dem Lentulo wurden im apikalen Wurzelkanaldrittel weniger Hohlräume festgestellt. Die Applikation mit Lentulo bzw. Spritze erwies sich in Bezug auf den Obturationsgrad und das Auftreten von Hohlräumen als signifikant besser im Vergleich zur Applikation mit einem Reamer (Staehle et al. 1997). Zudem kann der Einsatz von speziell entwickelten Instrumenten, wie z. B. dem PasteinjectInstrument, das Einbringen von $\mathrm{Ca}(\mathrm{OH})_{2}$ in den Wurzelkanal erleichtern (Deveaux et al. 2000; Tan et al. 2013). Dieser schnitt im Vergleich zum GuttaCondensor, dem MecaShaper und einer in ein Ultraschallhandstück befestigten K-Feile signifikant besser ab, kein signifikanter Unterschied wurde zwischen Lentulo und Pasteinject festgestellt (Deveaux et al. 2000). Für gekrümmte Wurzelkanäle dagegen ist die Verwendung des Pasteinjects dem Lentulo überlegen (Oztan et al. 2002).

Zur Überwindung der Wurzelkanalkrümmung benötigt es einer $\mathrm{Ca}(\mathrm{OH})_{2}$ Applikation durch ein flexibles Instrument, weshalb häufig das Einrotieren mit einem Lentulo bevorzugt wird (Torres et al. 2004; Peters et al. 2005). Im Vergleich zur Ultradent-Spitze zeigte der Lentulo bessere Ergebnisse bezüglich der Qualität der $\mathrm{Ca}(\mathrm{OH})_{2}$-Einlage bei $1 \mathrm{~mm}$ und $3 \mathrm{~mm}$ Entfernung zum Apex (Torres et al. 2004). Jedoch besteht in engen und gekrümmten Wurzelkanälen bei der Verwendung des Lentulos das Risiko der Instrumentenfraktur. Dieses Risiko wird durch den Einsatz einer Injektionskanüle verringert. Die risikoarme Anwendung und die guten Füllergebnisse sprechen für die Verwendung von Injektionskanülen (Oztan et al. 2002; Simcock und Hicks 2006).

Trotz unterschiedlicher Applikationsformen wird eine suffiziente medikamentöse $\mathrm{Ca}(\mathrm{OH})_{2}$-Füllung häufig nicht erreicht, vor allem im apikalen Wurzelkanaldrittel 
(Vier-Pelisser et al. 2012). Ein entscheidender Einfluss auf die Applikationsqualität der $\mathrm{Ca}(\mathrm{OH})_{2}$-Einlage kann durch die Wurzelkanalpräparation erfolgen. Peters et al. (2005) stellten fest, dass ein steigender apikaler Wurzelkanaldurchmesser mit einer blasenfreieren und homogeneren $\mathrm{Ca}(\mathrm{OH})_{2}$-Füllung einhergeht. Kanäle mit einer Aufbereitung bis ISO-Größe 40 zeigten die wenigsten Hohlräume innerhalb der $\mathrm{Ca}(\mathrm{OH})_{2}$-Füllung. Dies deckt sich mit dem Ergebnis von Simcock und Hicks (2006). Unabhängig von der verwendeten Fülltechnik zeigten apikal weiter aufbereitete Kanäle (MAF $40=$ master apical file 40) weniger Lufteinschlüsse in der Einlagefüllung (Simcock und Hicks 2006). Ebenfalls Einfluss auf die Qualität der $\mathrm{Ca}(\mathrm{OH})_{2}$-Einlage hat die Konsistenz des $\mathrm{Ca}(\mathrm{OH})_{2}$. Eine Mixtur aus $\mathrm{Ca}(\mathrm{OH})_{2}$ und Glycerin wies bezüglich Länge und Dichte der Einlagefüllung deutlich bessere Ergebnisse auf, als eine Mischung aus $\mathrm{Ca}(\mathrm{OH})_{2}$ und Wasser (Rivera und Williams 1994). Ferner kann eine Kondensation der Einlagefüllung mit Hilfe eines Pluggers (Webber et al. 1981; Estrela et al. 2002), eines Wattepellets oder einer Papierspitze (Estrela et al. 2002) erfolgen.

\subsubsection{Entfernung der Kalziumhydroxideinlage}

Die vollständige Entfernung der $\mathrm{Ca}(\mathrm{OH})_{2}$-Einlage ist für den endodontischen Therapieerfolg essentiell (Ricucci und Langeland 1997). Im Wurzelkanal verbliebenes $\mathrm{Ca}(\mathrm{OH})_{2}$ kann mit eingebrachten Sealern in Wechselwirkung treten (Margelos et al. 1997; Balvedi et al. 2010), beispielsweise reagieren Sealer auf Zinkoxid-Eugenol-Basis mit einer beschleunigten Abbindegeschwindigkeit (Margelos et al. 1997). Treten Sealer bzw. Zemente auf Zinkoxid-Eugenol-Basis in Kontakt mit $\mathrm{Ca}(\mathrm{OH})_{2}$, werden diese brüchig in ihrer Konsistenz und erhalten eine körnige Struktur (Margelos et al. 1997). Zudem steigt laut Kim und Kim (2002) nach einer $\mathrm{Ca}(\mathrm{OH})_{2}$-Einlagefüllung die Anzahl von apikalen Leakages bei der Kombination von Zinkoxid-Eugenol-Sealern mit Guttapercha-Füllungen. Die $\mathrm{Ca}(\mathrm{OH})_{2}$-Proben zeigten außerdem eine ungleiche und dicke Sealerschicht (Kim und Kim 2002). Des Weiteren wurden für Sealer signifikant schlechtere Haftwerte ermittelt, wenn zuvor $\mathrm{Ca}(\mathrm{OH})_{2}$ genutzt wurde. Dies beweist, dass die Adhäsion zwischen Sealer und Wurzelkanalwand durch $\mathrm{Ca}(\mathrm{OH})_{2}$ beeinträchtigt wird (Margelos et al. 1997; Calt und Serper 1999; van der Sluis et al. 2007b; Barbizam et al. 2008). Folglich muss die medikamentöse Einlage vor der endgültigen 
Füllung aus dem Wurzelkanalsystem entfernt werden, um dem Sealer eine Penetration in Kanalunebenheiten und Dentintubuli zu ermöglichen, was im Idealfall einen luftdichten Verschluss ergibt und einem Microleakage langfristig vorbeugt (Lambrianidis et al. 1999; Nandini et al. 2006). Über die Notwendigkeit der $\mathrm{Ca}(\mathrm{OH})_{2}$-Entfernung vor der Obturation des Wurzelkanals besteht Einigkeit, jedoch stellt die vollständige Entfernung bis heute ein Problem dar (Calişkan et al. 1998; Rödig et al. 2010c; Rödig et al. 2011; Sağsen et al. 2012).

Die Möglichkeiten zur Entfernung von $\mathrm{Ca}(\mathrm{OH})_{2}$-Einlagefüllungen sind vielfältig. Sie reichen von der traditionellen Handspülung, der PUI und der schallaktivierten Spülung bis hin zum Einsatz rotierender Instrumente und laserunterstützter Techniken. Eine vollständige Entfernung des in den Wurzelkanal eingebrachten $\mathrm{Ca}(\mathrm{OH})_{2}$ wird jedoch mit keiner der angewandten Techniken zuverlässig erreicht (Margelos et al. 1997; Lambrianidis et al. 1999; Kenee et al. 2006; Lambrianidis et al. 2006; Balvedi et al. 2010; Kuga et al. 2010; Rödig et al. 2011; Wiseman et al. 2011; Khademi et al. 2015).

Die PUl ist in der Entfernung von $\mathrm{Ca}(\mathrm{OH})_{2}$ effektiver als die herkömmliche Handspülung (van der Sluis et al. 2007b; Balvedi et al. 2010; Arslan et al. 2015; Phillips et al. 2015). Die Penetrationstiefe der Spülnadel in den Wurzelkanal stellt einen entscheidenden Faktor bei der Beseitigung von temporären Medikamenten dar (Chou et al. 2014). Neben der PUI scheint ebenfalls die Verwendung der CanalBrush mit 2,5\%igem $\mathrm{NaOCl}$ der Handspülung überlegen zu sein (Taşdemir et al. 2011). Der Einsatz einer passiven ultraschallgestützten Spülung über $3 \times 20$ Sekunden führte zu signifikant weniger Rest-Ca $(\mathrm{OH})_{2}$ im Wurzelkanal als die schallgestützte Spülung (Wiseman et al. 2011). Die PUI erhöht im Vergleich zur manuellen Spülung und schallgestützten Spülung (EndoActivator) den Effekt der $\mathrm{Ca}(\mathrm{OH})_{2}$-Entfernung (Arslan et al. 2015). Die Aktivierung einer Spüllösung (schall- bzw. ultraschallgestützt) verstärkt demnach deren Reinigungswirkung (Ma et al. 2015b; Üstün et al. 2016). Lediglich Ma et al. (2015b) fanden zwischen der schallgestützten Spülung mit dem EndoActivator und der ultraschallgestützten Spülung keinen signifikanten Unterschied.

Im Gegensatz zu herkömmlichen Methoden wie der Handspülung und der PUI erreichen neuartige Methoden wie die GentleWave eine nahezu komplette Entfernung des $\mathrm{Ca}(\mathrm{OH})_{2}$ (Ma et al. 2015a). In kürzlich veröffentlichten Studien 
wurde ebenfalls für die PIPS $®$ (Er:YAG Laser-aktivierte Spülung) eine deutliche Überlegenheit gegenüber der ultraschallgestützten Spülung, der traditionellen Handspülung (Lloyd et al. 2016) und der schallgestützten Spülung (Arslan et al. 2015) festgestellt. Mit einem Medianwert von $0 \%$ bezüglich des Rest- $\mathrm{Ca}(\mathrm{OH})_{2}$ erzielte die PIPS $₫$ signifikant bessere Score-Werte (Lloyd et al. 2016). Außerdem wird der Einsatz von rotierenden Instrumenten als wirksam eingestuft (Kuga et al. 2010; Dadresanfar et al. 2015).

Neben der angewandten Spültechnik hat ebenfalls die Spüllösung Auswirkungen auf die Sauberkeit. In einem Vergleich verschiedener Spüllösungen schnitten $20 \%$ iges EDTA und 10\%ige Zitronensäure besser ab als $1 \%$ iges $\mathrm{NaOCl}$. Eine Kombination verschiedener Spüllösungen resultierte in keiner Verbesserung in der Entfernung des $\mathrm{Ca}(\mathrm{OH})_{2}$ (Rödig et al. 2010c). Calt und Serper (1999) dagegen wiesen nach, dass der Einsatz von EDTA gefolgt von $\mathrm{NaOCl}$ eine vollständige Entfernung des $\mathrm{Ca}(\mathrm{OH})_{2}$ aus dem Wurzelkanal erzielt. EDTA wird ein positiver Effekt auf die Entfernung von $\mathrm{Ca}(\mathrm{OH})_{2}$ bestätigt (Margelos et al. 1997). Dies trifft ebenfalls für 1\%ige Peressigsäure zu (Üstün et al. 2016). Sağsen et al. (2012) bewiesen in einer In-vitro-Studie die Überlegenheit von $1 \%$ iger Peressigsäure gegenüber $\%$ igem $\mathrm{NaOCl}$ und 17\%igem EDTA.

Grundsätzlich bestehen bei der Entfernung von medikamentösen Einlagen aus dem Wurzelkanal Unterschiede, vor allem die Entfernung von $\mathrm{Ca}(\mathrm{OH})_{2}$ wird als schwierig bewertet (Chou et al. 2014). Die Entfernung von Ledermix als medikamentöse Einlagefüllung gelingt im Vergleich zur Entfernung von $\mathrm{Ca}(\mathrm{OH})_{2}$ einfacher (Rödig et al. 2011). Um die Entfernung einer medikamentösen Einlagefüllung zu optimieren, erscheint es sinnvoll, den Wurzelkanal vor der abschließenden Obturation um eine ISO-Größe weiter zu präparieren. Die erneute Instrumentierung der Wurzelkanalwand während der Spülung mit $\mathrm{NaOCI}$ und EDTA ist wichtig (Gorduysus et al. 2012) und verbessert die Entfernung von $\mathrm{Ca}(\mathrm{OH})_{2}$ aus dem Wurzelkanal (Salgado et al. 2009).

Die Tabelle 2-1 fasst die aktuelle Studienlage zur Entfernung von Kalziumhydroxid aus dem Wurzelkanal zusammen. 
Tab. 2-1: Übersichtstabelle Entfernung von $\mathrm{Ca}(\mathrm{OH})_{2}$ - Auszug aktueller Studien

\begin{tabular}{|c|c|c|c|}
\hline Autor & Probenmaterial & Vergleichsgruppen & Ergebnis \\
\hline $\begin{array}{l}\text { Ahmetoğlu et } \\
\text { al. } 2013\end{array}$ & $\begin{array}{l}51 \text { Unterkiefer- } \\
\text { Prämolaren }\end{array}$ & $\begin{array}{l}\text { SAF/ PUI/ } \\
\text { Handspülung }\end{array}$ & $\begin{array}{l}\text { PUI }>\text { SAF }= \\
\text { Handspülung }\end{array}$ \\
\hline $\begin{array}{l}\text { Alturaiki et al. } \\
2015\end{array}$ & $\begin{array}{l}50 \text { einwurzelige } \\
\text { Zähne }\end{array}$ & $\begin{array}{l}\text { MAF/ EndoVac/ } \\
\text { EndoActivator/ } \\
\text { ProUltra/ } \\
\text { Handspülung }\end{array}$ & $\begin{array}{l}\text { EndoActivator > MAF, } \\
\text { EndoVac, ProUltra, } \\
\text { Handspülung }\end{array}$ \\
\hline $\begin{array}{l}\text { Arslan et al. } \\
2015\end{array}$ & $\begin{array}{l}48 \text { einwurzelige } \\
\text { Zähne, } \\
\text { standardisierte } \\
\text { künstliche Gruben }\end{array}$ & $\begin{array}{l}\text { Handspülung/ } \\
\text { PIPS®/ PUI/ } \\
\text { EndoActivator }\end{array}$ & $\begin{array}{l}\text { PIPS } ®>\text { PUI > } \\
\text { EndoActivator, } \\
\text { Handspülung }\end{array}$ \\
\hline $\begin{array}{l}\text { Capar et al. } \\
2014\end{array}$ & $\begin{array}{l}88 \text { einwurzelige } \\
\text { Zähne, } \\
\text { standardisierte } \\
\text { künstliche Gruben }\end{array}$ & $\begin{array}{l}\text { Handspülung/ PUI/ } \\
\text { EndoVac/ SAF } \\
\text { Vergleich bezüglich: } \\
\mathrm{NaOCl} / \mathrm{NaOCl}+ \\
\text { EDTA }\end{array}$ & $\begin{array}{l}\text { NaOCl: PUI > } \\
\text { EndoVac, SAF, } \\
\text { Handspülung } \\
\mathrm{NaOCI}+\text { EDTA: PUI = } \\
\text { SAF > EndoVac = } \\
\text { Handspülung }\end{array}$ \\
\hline $\begin{array}{l}\text { Chou et al. } \\
2014\end{array}$ & $\begin{array}{l}168 \text { einwurzelige } \\
\text { Zähne }\end{array}$ & $\begin{array}{l}\text { Handspülung/ Max-I- } \\
\text { Probe/ } \\
\text { EndoActivator }\end{array}$ & $\begin{array}{l}\text { Handspülung = Max-I- } \\
\text { Probe = } \\
\text { EndoActivator }\end{array}$ \\
\hline $\begin{array}{l}\text { Faria et al. } \\
2014\end{array}$ & 66 Eckzähne & $\begin{array}{l}\text { EndoActivator/ } \\
\text { EndoVac/ PUI/ } \\
\text { Handspülung }\end{array}$ & $\begin{array}{l}\text { EndoActivator = } \\
\text { EndoVac = PUI > } \\
\text { Handspülung }\end{array}$ \\
\hline $\begin{array}{l}\text { Gorduysus et } \\
\text { al. } 2012\end{array}$ & $\begin{array}{l}18 \text { einwurzelige } \\
\text { Zähne }\end{array}$ & $\begin{array}{l}\text { MAF/ MAF + } \\
\text { CanalBrush }\end{array}$ & $\begin{array}{l}\text { apikales Drittel: MAF } \\
>\text { MAF + CanalBrush } \\
\text { koronales \& mittleres } \\
\text { Drittel: MAF = MAF + } \\
\text { CanalBrush }\end{array}$ \\
\hline $\begin{array}{l}\text { Khademi et al. } \\
2015\end{array}$ & 50 Frontzähne & RinsEndo/ PUI & RinsEndo = PUI \\
\hline
\end{tabular}




\begin{tabular}{|c|c|c|c|}
\hline Autor & Probenmaterial & Vergleichsgruppen & Ergebnis \\
\hline $\begin{array}{l}\text { Khaleel et al. } \\
2013\end{array}$ & $\begin{array}{l}15 \text { einwurzelige } \\
\text { Zähne } \\
\text { (wiederverwendet) }\end{array}$ & $\begin{array}{l}\text { Handspülung/ } \\
\text { ProTaper/ } \\
\text { EndoActivator/ PUI }\end{array}$ & $\begin{array}{l}\text { EndoActivator = PUI > } \\
\text { ProTaper, } \\
\text { Handspülung }\end{array}$ \\
\hline $\begin{array}{l}\text { Kuga et al. } \\
2010\end{array}$ & $\begin{array}{l}42 \text { Unterkiefer- } \\
\text { Frontzähne }\end{array}$ & $\begin{array}{l}\text { K3 Endo/ ProTaper } \\
\text { Vergleich bezüglich: } \\
2,5 \% \mathrm{NaOCl} / \\
17 \% \text { EDTA }\end{array}$ & $\begin{array}{l}\text { ProTaper > K3 Endo } \\
\text { kein Unterschied } \\
\text { bezüglich der } \\
\text { Spüllösung }\end{array}$ \\
\hline $\begin{array}{l}\text { Lloyd et al. } \\
2016\end{array}$ & $\begin{array}{l}30 \text { Unterkiefer- } \\
\text { Molaren }\end{array}$ & $\begin{array}{l}\text { PIPS®/ PUI/ } \\
\text { Handspülung }\end{array}$ & $\begin{array}{l}\text { apikales Drittel: } \\
\text { PIPS } ®> \\
\text { Handspülung > PUI } \\
\text { koronales \& mittleres } \\
\text { Drittel: PIPS } ®=\text { PUI = } \\
\text { Handspülung }\end{array}$ \\
\hline Ma et al. 2015 & $\begin{array}{l}30 \text { Unterkiefer- } \\
\text { Molaren }\end{array}$ & $\begin{array}{l}\text { Handspülung/ PUI/ } \\
\text { GentleWave }\end{array}$ & $\begin{array}{l}\text { GentleWave > PUI > } \\
\text { Handspülung }\end{array}$ \\
\hline Ma et al. 2015 & $\begin{array}{l}30 \text { Unterkiefer- } \\
\text { Molaren }\end{array}$ & $\begin{array}{l}\text { EndoActivator/ PUI/ } \\
\text { Handspülung }\end{array}$ & $\begin{array}{l}\text { PUI = EndoActivator > } \\
\text { Handspülung }\end{array}$ \\
\hline $\begin{array}{l}\text { Phillips et al. } \\
2015\end{array}$ & 86 Eckzähne & $\begin{array}{l}\text { Handspülung/ } \\
\text { Handspülung + } \\
\text { apikale Feile/ } \\
\text { Handspülung + PUI/ } \\
\text { Handspülung + } \\
\text { apikale Feile + PUI }\end{array}$ & $\begin{array}{l}\text { Handspülung + } \\
\text { apikale Feile + PUI > } \\
\text { Handspülung + PUI > } \\
\text { Handspülung + } \\
\text { apikale Feile > } \\
\text { Handspülung }\end{array}$ \\
\hline $\begin{array}{l}\text { Rödig et al. } \\
2010\end{array}$ & $\begin{array}{l}100 \text { Oberkiefer- } \\
\text { Frontzähne, } \\
\text { standardisierte } \\
\text { künstliche Gruben }\end{array}$ & $\begin{array}{l}20 \% \text { EDTA/ } \\
10 \% \text { Zitronensäure/ } \\
1 \% \mathrm{NaOCl} / \\
1 \% \mathrm{NaOCl}+10 \% \\
\text { Zitronensäure/ } \\
1 \% \mathrm{NaOCl}+20 \% \\
\text { EDTA }\end{array}$ & $\begin{array}{l}\text { Zitronensäure, } \\
\text { EDTA > NaOCl } \\
\text { eine Kombination von } \\
\text { Spüllösungen hat } \\
\text { keinen signifikanten } \\
\text { Effekt }\end{array}$ \\
\hline
\end{tabular}




\begin{tabular}{|c|c|c|c|}
\hline Autor & Probenmaterial & Vergleichsgruppen & Ergebnis \\
\hline $\begin{array}{l}\text { Rödig et al. } \\
2011\end{array}$ & $\begin{array}{l}60 \text { einwurzelige } \\
\text { Zähne, } \\
\text { standardisierte } \\
\text { künstliche Gruben }\end{array}$ & PUI/ RinsEndo & PUI = RinsEndo \\
\hline $\begin{array}{l}\text { Sağsen et al. } \\
2012\end{array}$ & $\begin{array}{l}58 \text { Oberkiefer- } \\
\text { Frontzähne }\end{array}$ & $\begin{array}{l}17 \% \text { EDTA/ } \\
2,5 \% \mathrm{NaOCI}+2,5 \% \\
\text { EDTA/ } \\
1 \% \text { Peressigsäure/ } \\
0,5 \% \text { Peressigsäure }\end{array}$ & $\begin{array}{l}\text { apikales Drittel: } \\
\text { 1\% Peressigsäure > } \\
17 \% \text { EDTA = 2,5\% } \\
\mathrm{NaOCl}+2,5 \% \text { EDTA } \\
=0,5 \% \text { Peressigsäure } \\
\text { mittleres Drittel: } \\
17 \% \text { EDTA = 2,5\% } \\
\text { NaOCl + 2,5\% EDTA } \\
=1 \% \text { Peressigsäure }= \\
0,5 \% \text { Peressigsäure } \\
\text { koronales Drittel: } \\
\text { 1\% Peressigsäure > } \\
\text { 17\% EDTA, 2,5\% } \\
\text { NaOCl + 2,5\% EDTA, } \\
0,5 \% \text { Peressigsäure }\end{array}$ \\
\hline $\begin{array}{l}\text { Taşdemir et al. } \\
2011\end{array}$ & $\begin{array}{l}24 \text { Unterkiefer- } \\
\text { Prämolaren }\end{array}$ & $\begin{array}{l}\text { Handspülung/ PUI/ } \\
\text { CanalBrush }\end{array}$ & $\begin{array}{l}\text { PUI, CanalBrush > } \\
\text { Handspülung }\end{array}$ \\
\hline $\begin{array}{l}\text { van der Sluis et } \\
\text { al. } 2007\end{array}$ & $\begin{array}{l}16 \text { Unterkiefer- } \\
\text { Prämolaren } \\
\text { (wiederverwendet), } \\
\text { standardisierte } \\
\text { künstliche Gruben }\end{array}$ & $\begin{array}{l}\text { PUI/ Handspülung } \\
\text { Vergleich bezüglich } \\
\text { Spüllösung: } \\
\text { NaOCl/ Wasser }\end{array}$ & $\begin{array}{l}\mathrm{PUI}+\mathrm{NaOCl}> \\
\mathrm{PUI}+\text { Wasser = } \\
\text { Handspülung + } \\
\mathrm{NaOCl}\end{array}$ \\
\hline $\begin{array}{l}\text { Wiseman et al. } \\
2011\end{array}$ & $\begin{array}{l}46 \text { Unterkiefer- } \\
\text { Molaren }\end{array}$ & PUI/ EndoActivator & PUI > EndoActivator \\
\hline $\begin{array}{l}\text { Zorzin et al. } \\
2016\end{array}$ & $\begin{array}{l}130 \text { einwurzelige } \\
\text { Zähne }\end{array}$ & $\begin{array}{l}\text { FlexMaster 45/.04/ } \\
\text { CanalBrush/ PUI }\end{array}$ & $\begin{array}{l}\text { PUI > CanalBrush > } \\
\text { FlexMaster }\end{array}$ \\
\hline
\end{tabular}




\section{Ziele der Studie}

Das Ziel der Studie ist der Vergleich zwischen traditionellen und neuartigen Spültechniken zur Entfernung von Kalziumhydroxid aus dem Wurzelkanal. Dabei werden die verschiedenen Spültechniken untereinander verglichen und zugleich auf Unterschiede in der Wirksamkeit der Spültechnik zwischen apikalem und koronalem Wurzelkanaldrittel eingegangen.

Untersucht wurden die folgenden Techniken:

- die schallgestützte Spülung mit einem vibrierenden Polymerstab (EndoActivator)

- die passive Ultraschallspülung

- die schallgestützte Spülung mit einem vibrierenden Polymerstab (EDDY)

- die traditionelle manuelle Spülung mit einer konventionellen Spritze (Handspülung)

- $\quad$ als Kontrollgruppe diente eine Gruppe ohne Spülung.

Die in der Literatur beschriebenen Daten werden mit den Resultaten der Studie verglichen und diskutiert. 


\section{Material und Methoden}

Vier verschiedene Spültechniken wurden im Hinblick auf ihre Wirksamkeit bei der Entfernung von Kalziumhydroxid aus dem Wurzelkanal beurteilt. Zu diesen Techniken gehören der EndoActivator, die passive Ultraschallspülung, der EDDY und die Handspülung. Der für diese Studie gewählte Versuchsaufbau lehnt sich an das von Lee et al. (2004) beschriebene Studiendesign an. Dieses Modell wurde in vielen Studien übernommen (van der Sluis et al. 2005a; van der Sluis et al. 2005b; Jiang et al. 2010a; Rödig et al. 2010b; Srirekha et al. 2013), gilt daher als zuverlässig, anerkannt und erlaubt einen Vergleich der Resultate verschiedener Studien.

Das Studienprotokoll wurde am 24.03.2016 mit der Nummer DOK_29_2016 von der Ethik-Kommission der UMG genehmigt.

\subsection{Auswahl der Zahnproben}

Für die Versuche wurden 80 humane extrahierte Zähne verwendet. Dabei erfolgte die Extraktion aus zahnmedizinischen Gründen und stand in keinerlei Zusammenhang mit der Studie. Für alle Zähne, die in dieser Untersuchung verwendet wurden, lag eine schriftliche Einwilligung des Patienten zur Verwendung des extrahierten Zahnes für wissenschaftliche Zwecke vor.

Für die Auswahl der Zähne galten folgende Kriterien:

- mittlere und seitliche Oberkiefer-Inzisivi, Eckzähne oder einwurzelige Prämolaren

- Mindestlänge der Zähne $19 \mathrm{~mm}$

- runder Wurzelquerschnitt und gerade Wurzel

- Wurzelwachstum abgeschlossen

- $\quad$ unbeschädigter Apex

- $\quad$ keine Wurzelkaries und keine Zahnfrakturen

- keine bisherigen endodontischen Maßnahmen 
- die Querschnittsgröße des apikalen Wurzelkanalanteils sollte vor Beginn der Instrumentierung nicht größer als ein Handinstrument der ISO-Größe 35 , d. h. $0,35 \mathrm{~mm}$ betragen.

\subsection{Herstellung standardisierter Zahnproben}

\subsubsection{Präparation des Wurzelkanals}

Die Lagerung der Zähne nach der Extraktion erfolgte in aqua dest. (B. Braun, Melsungen, Deutschland). Um den Zahn zu säubern, wurde mit einem Scaler (HLW, Wernberg-Köblitz, Deutschland) das verbleibende Weich- und Hartgewebe von der Wurzeloberfläche gelöst. Nach Präparation der koronalen Zugangskavität wurde die Kronenpulpa entfernt und der Wurzelkanaleingang dargestellt. Mit einem Reamer (VDW, München, Deutschland) der ISO-Größe 10 wurde die Gängigkeit des Wurzelkanals überprüft, wobei der Reamer minimal über das Foramen apicale hinausgeschoben wurde, um ein freies Foramen apicale zu gewährleisten. Im nachfolgenden Schritt wurde der Wurzelkanaldurchmesser mit Hilfe von Reamern bestimmt. Lag die Querschnittsgröße im apikalen Wurzelkanalanteil vor Beginn der Instrumentierung bereits über der ISO-Größe 35, wurde der Zahn aus der Versuchsreihe ausgeschlossen und durch einen neuen Zahn ersetzt. Alle Zähne wurden unter Wasserkühlung von koronal mit Diamantschleifern (Komet, Lemgo, Deutschland) auf eine Einheitslänge von $19 \mathrm{~mm}$ gekürzt.

Die Präparation des Wurzelkanals erfolgte mit maschinell betriebenen NiTiInstrumenten, dem Mtwo®-System (VDW, München, Deutschland). Präpariert wurde im Crown-Down-Verfahren bis zur Größe 40/.04 bei einer standardisierten Arbeitslänge von $18 \mathrm{~mm}$. Die Reihenfolge der Nickel-Titan-Feilen erfolgte nach den Richtlinien des Herstellers. Entsprechend den Herstellerangaben wurde jede Feile nach achtmaligem Gebrauch entsorgt.

Nach jeder Instrumentengröße wurde mit je $2 \mathrm{ml} 3 \%$ iger NaOCl-Lösung (Hedinger, Stuttgart, Deutschland) mit Hilfe einer 5-ml-Spritze (Becton, Dickinson and Company, Franklin Lakes, USA) und einer 30-gauge-NaviTip-Kanüle (Endoneedle, Vedefar N.V., Dilbeek, Belgien) gespült, wie bei Taşdemir et al. (2011) beschrieben. Die Abschlussspülung erfolgte mit $5 \mathrm{ml}$ EDTA (Lege artis Pharma, Dettenhausen, Deutschland) und $5 \mathrm{ml} 3 \%$ iger NaOCl-Lösung. 
Abschließend wurde der Wurzelkanal mit einer Papierspitze der ISO-Größe 40 (Orbis Dental, Münster, Deutschland) getrocknet.

\subsubsection{Herstellung der Wurzelhälften}

Um eine exakte Repositionierung der beiden Zahnhälften zueinander zu gewährleisten, mussten individuelle Förmchen hergestellt werden. Dabei wurde der noch nicht getrennte Zahn in ein verformbares Abformmaterial auf Silikonbasis (Silaplast Futur, Detax, Ettlingen, Deutschland) gedrückt. Die Silikonmasse wiederum wurde in ein Röhrchen aus Acrylglas (Röhm, Brüttisellen, Schweiz) eingebettet. Die Höhe der Röhrchen lag bei ca. $17 \mathrm{~mm}$, wie bei McGill et al. (2008) beschrieben (siehe Abbildung 4-1).

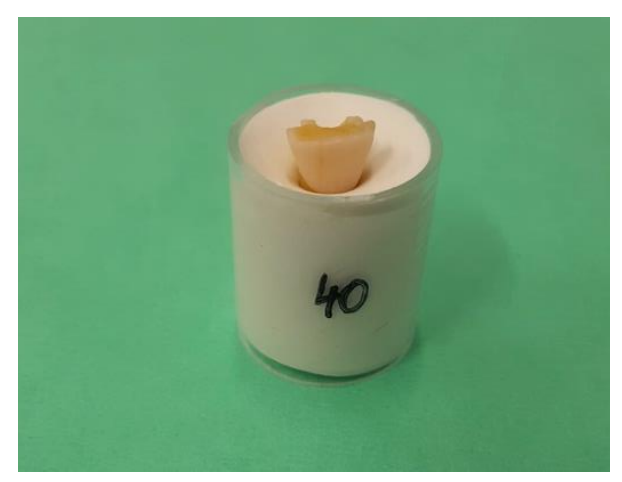

Abb. 4-1: Zahn im Acrylröhrchen mit Silikonmasse

Anschließend wurde ein Guttaperchastift (VDW, München, Deutschland) der ISO-Größe 40 in den Wurzelkanal eingebracht. Mit einer diamantierten Trennscheibe (Horico, Berlin, Deutschland) wurden zwei vertikale Rillen in mesial-distaler Ausrichtung in den Zahn gefräst und darauf geachtet, das Kanallumen nicht zu eröffnen (siehe Abbildung 4-2). Die Spaltung der Zähne entlang der Längsrillen in zwei Hälften erfolgte mit einem Wachsmesser (Henry Schein Dental, Langen, Deutschland). Unter dem Dental-Mikroskop (OPMI pico, Carl Zeiss, Jena, Deutschland) wurden die beiden Zahnhälften spaltfrei zusammengesetzt und überprüft, ob die Wurzelkanalwand während des Spaltprozesses keinen Schaden erlitten hatte. Zähne, die nicht wieder spaltfrei zusammengesetzt werden konnten, wurden aus der Studie ausgeschlossen. 


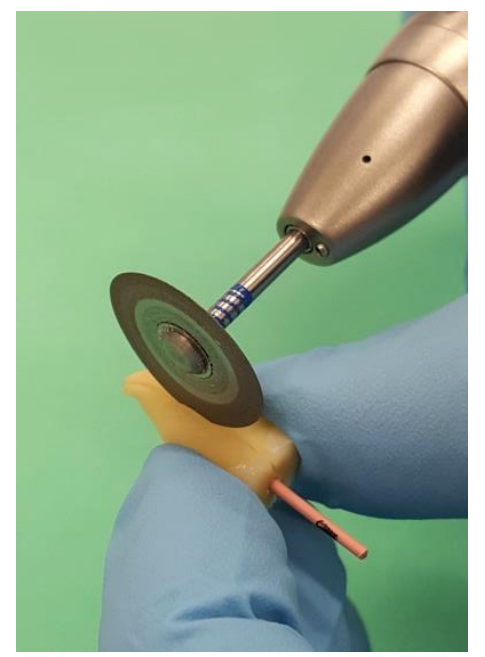

Abb. 4-2: Zahn beim Fräsen der vertikalen Rille mit einer diamantierten Trennscheibe

\subsubsection{Präparation der apikalen und koronalen Gruben}

Für die Präparation der Gruben wurden eigens Instrumente modifiziert. Zunächst mussten der Handgriff eines Fingerspreaders (VDW, München, Deutschland) der ISO-Größe 35 entfernt sowie die Instrumentenspitze mit Hilfe einer diamantierten Trennscheibe „V"-förmig zugeschliffen werden. Die Breite der Spitze sollte dabei $0,2 \mathrm{~mm}$ betragen. Für die Präparation der Gruben wurde das Instrument in den Nadelhalter des Ultraschallgeräts (VDW.Ultra®, VDW, München, Deutschland) eingegliedert.

Die Abbildung 4-3 zeigt schematisch die Lage und Ausdehnung der Kavität. In einer Wurzelhälfte wurde im apikalen Wurzeldrittel im Abstand von 2-6 mm zum Apex die apikale Grube, in der dazugehörigen gegenüberliegenden Wurzelhälfte im koronalen Wurzeldrittel im Abstand von 10-14 mm zum Apex die koronale Grube präpariert. Die Dimensionen der Kavität sollten $4 \mathrm{~mm}$ in der Länge, $0,2 \mathrm{~mm}$ in der Breite und 0,5 mm in der Tiefe betragen, wie von Lee et al. (2004) beschrieben.

Die künstlich geschaffenen Kavitäten in der Wurzelkanalwand sollen nicht durch Instrumente zu erreichende Wurzelkanalbereiche imitieren. Dazu können beispielsweise Unebenheiten in der Kanalwand gehören, die durch eine maschinelle Präparation nicht erreicht werden, oder auch Engstellen von ovalen Wurzelquerschnitten, in deren Areale die Spüllösung nicht ausreichend eindringt. 


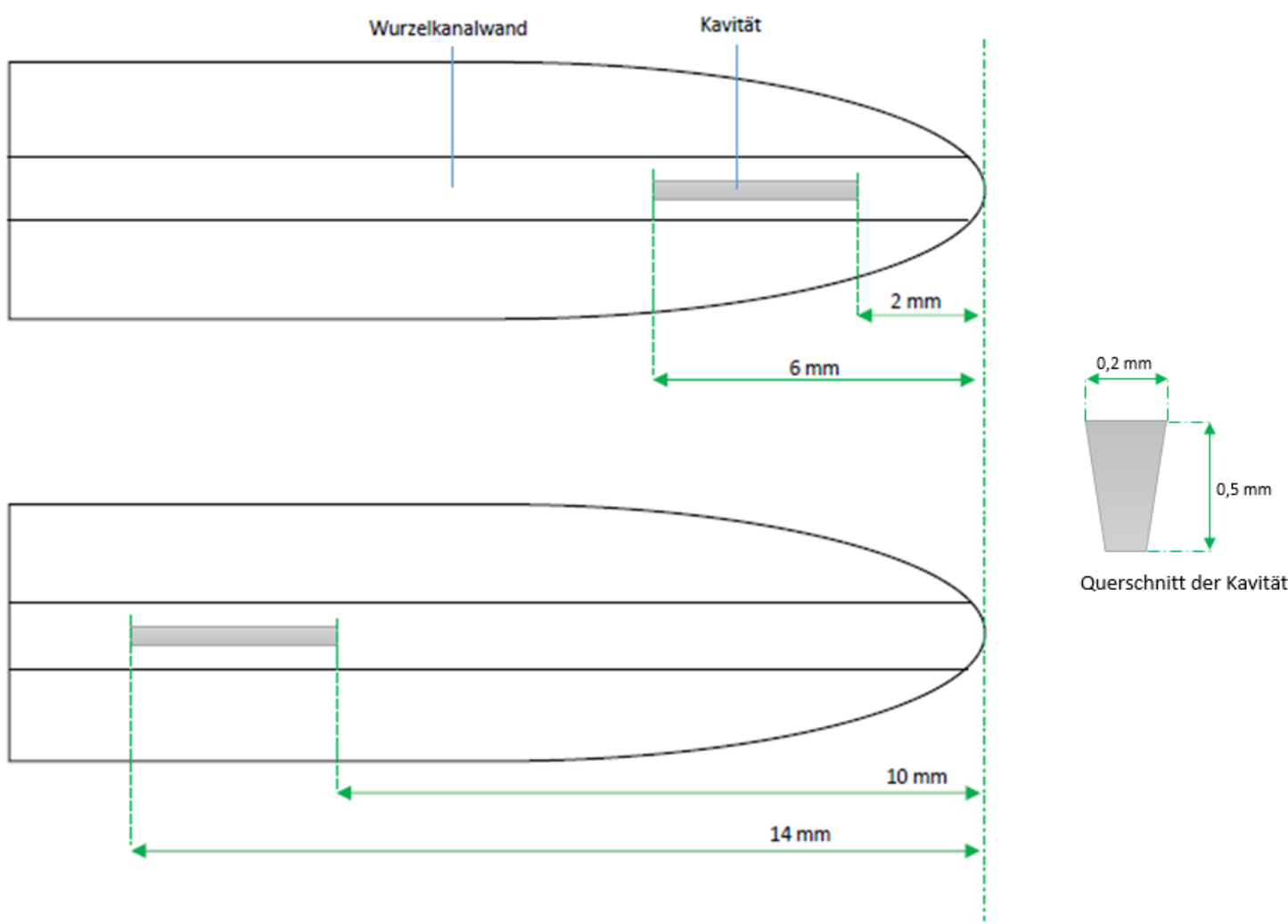

Abb. 4-3: Schematische Darstellung der Kavität nach Lage und Ausdehnung in den verschiedenen Wurzelhälften im vertikalen und horizontalen Schnitt, nach Lee et al. (2004).

\subsubsection{Bilderfassung}

Für die Auswertung wurden digitale Bilder angefertigt. Die Bilderfassung erfolgte unter einem Stereomikroskop (Stemi SV 11, Carl Zeiss, Jena, Deutschland) mit einer Kamera (Leica Camera AG, Wetzlar, Deutschland). Dabei wurde mit einer 12-32fachen Mikroskopvergrößerung gearbeitet. Die Kamera verfügt über eine Bildauflösung von 5 Megapixeln. Die Mikroskopeinstellungen blieben während des gesamten Versuchszeitraums unverändert. Individuell angefertigte Silikonschlüssel (Silaplast Futur) sicherten gleichbleibende Bilderfassungsbedingungen und Lichtverhältnisse. Das Silaplast wurde nach Herstellerangaben angemischt und während der elastischen Phase für jede Zahnhälfte ein Schlüssel angefertigt. Dabei wurde die Zahnhälfte nach optimalen Lichtverhältnissen ausgerichtet, um Schattenprojektionen oder Überbelichtungen zu vermeiden.

Noch vor Befüllen der Kavitäten in den Wurzelhälften wurden je Zahnhälfte zwei Aufnahmen angefertigt: Zunächst eine Übersichtsaufnahme bei 12facher Vergrößerung (siehe Abbildung 4-4 und 4-6) und eine Detailaufnahme der jeweiligen Kavität bei 32facher Vergrößerung (siehe Abbildung 4-5 und 4-7). Im 
weiteren Verlauf wurde je Zahnhälfte ein weiteres Foto der gefüllten Kavität mit Kalziumhydroxid und eines mit der gespülten Kavität angefertigt.

Mit Hilfe der digitalen Bilder ließ sich nach Beendigung des Spülvorgangs eine Bewertung des Rückstandes an Kalziumhydroxid in den Gruben des Wurzelkanals vornehmen.

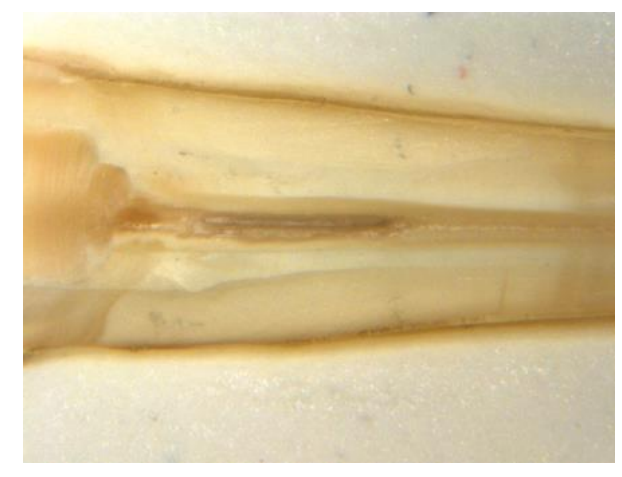

Abb. 4-4: Übersicht koronale Kavität

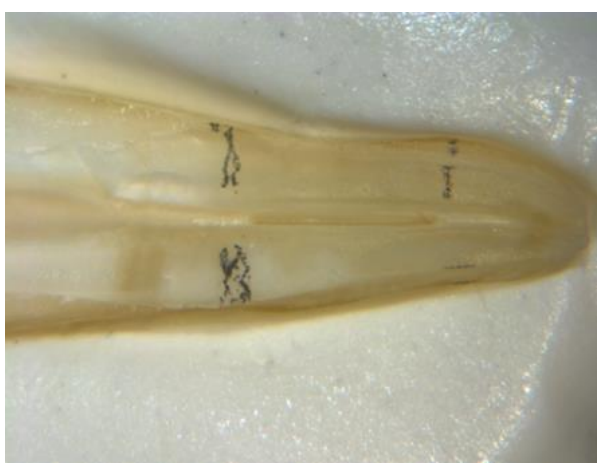

Abb. 4-6: Übersicht apikale Kavität

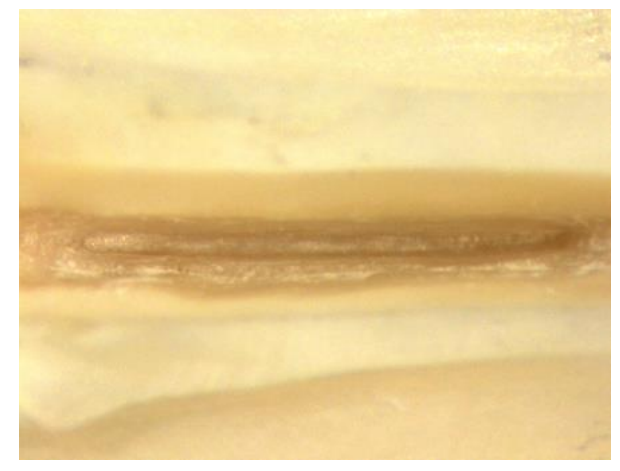

Abb. 4-5: Vergrößerung koronale Kavität

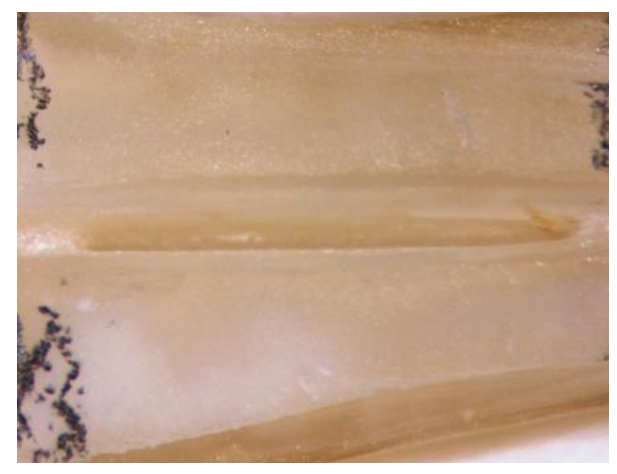

Abb. 4-7: Vergrößerung apikale Kavität

\subsubsection{Befüllen mit Kalziumhydroxid}

Unter dem Stereomikroskop wurde die jeweilige Grube mit dem Kalziumhydroxidpräparat UltraCal®XS (Ultradent Products Inc., South Jordan, Utah, USA) gefüllt. Dabei wurde das UltraCal囚XS mit einer NaviTip-Applikationskanüle (Ultradent Products Inc., South Jordan, Utah, USA) unter leichtem Druck eingeführt. Mit diesem Vorgehen wurde sichergestellt, dass die gesamte Kavität mit UltraCal®XS gefüllt ist. Überschüssiges UltraCal®XS wurde mit einer Papierspitze oder einem Fingerspreader vorsichtig entlang der Kanalwand entfernt. Anschließend wurde eine Detailaufnahme der gefüllten Kavität angefertigt (siehe Abbildung 4-8). 


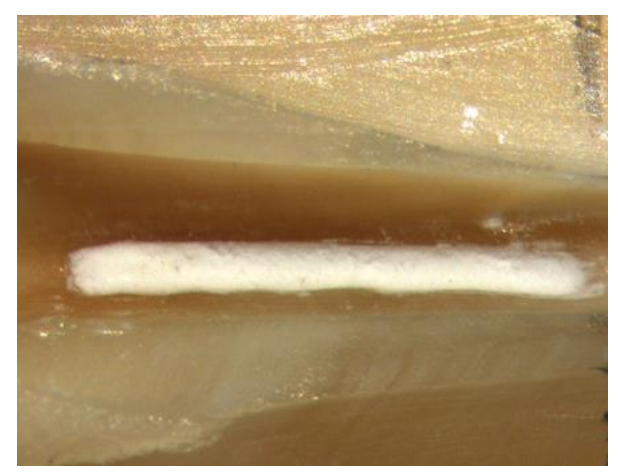

Abb. 4-8: Gefüllte Kavität

Unter mikroskopischer Kontrolle wurden die beiden Zahnhälften spaltfrei zusammengesetzt und die Längsrillen mit Cervikalwachs (Geo Cervikalwachs, Renfert, Hilzingen, Deutschland) verschlossen (siehe Abbildung 4-9). Eine apikale Versiegelung mit Hilfe von Klebewachs (Geo Klebewachs, Renfert, Hilzingen, Deutschland) sollte das Entweichen von Spülflüssigkeit durch das Foramen apicale verhindern und diente der Simulation einer In-vivo-Situation (Schoeffel 2007). Bei diesem Schritt wurde präzise darauf geachtet, dass das Klebewachs ausschließlich von außen aufliegt und nicht in den Wurzelkanal eindringt. Zur Hilfestellung diente ein Guttaperchastift der ISO-Größe 40, der bis auf Arbeitslänge in den Wurzelkanal eingebracht wurde (Paragliola et al. 2010).

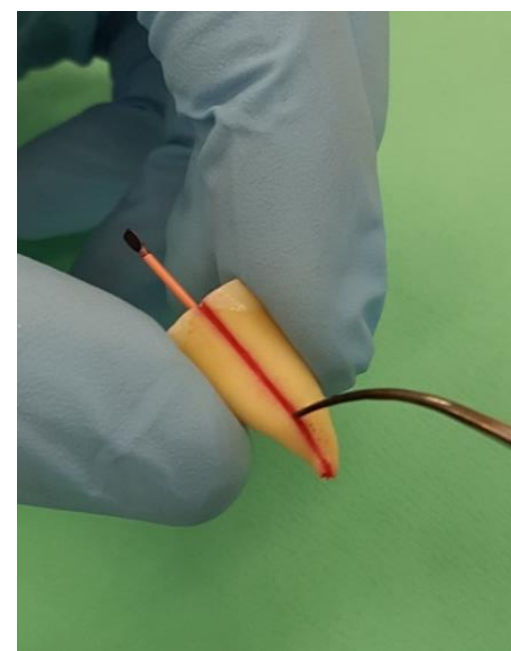

Abb. 4-9: Zusammengesetzter Zahn beim Verschluss mit Cervikalwachs

Anschließend wurde der Zahn in die zuvor angefertigten individuellen Silaplastschlüssel im Acrylglas-Röhrchen eingefügt. Diese garantierten einen spaltfreien Verschluss der beiden Zahnhälften zueinander. Der koronale Zahnanteil wurde zirkulär mit Klebewachs an das Silaplast gebunden. Mit einer NaviTip-Applikationskanüle wurde das UltraCal®XS in den gesamten 
Wurzelkanal eingebracht. Dies erfolgte mit einer fließenden Bewegung in apikalkoronaler Richtung. Wie von Braun und Nolden (1999) empfohlen, wurde durch ein kleines Wattekügelchen (Pluradent, Offenbach, Deutschland), welches am Wurzelkanaleingang appliziert wurde, das UltraCal®XS im Wurzelkanal kompaktiert. Um einen dichten Verschluss des Wurzelkanals zu erzielen, wurde dieser koronal mit Cavit ${ }^{\mathrm{TM} W}$ (3M ESPE, Neuss, Deutschland) in $2 \mathrm{~mm}$ Stärke verschlossen.

Zusätzlich wurde von allen Zähnen mit Hilfe eines Dentalröntgengeräts (Heliodent DS D3302, Sirona Dental, Bensheim, Deutschland) bei einer Belichtungszeit von 0,08 Sekunden, $7 \mathrm{~mA}$ und $60 \mathrm{kvDc}$ eine Einzelzahnaufnahme (siehe Abbildung 4-10) des Zahnes im Acryl-Röhrchen erstellt. Anhand dieses Bildes konnte überprüft werden, ob der gesamte Wurzelkanal mit Kalziumhydroxid gefüllt ist. Unzureichend gefüllte Wurzelkanäle wurden gereinigt, wieder mit UltraCal®XS gefüllt und einer erneuten Röntgenkontrolle unterzogen.

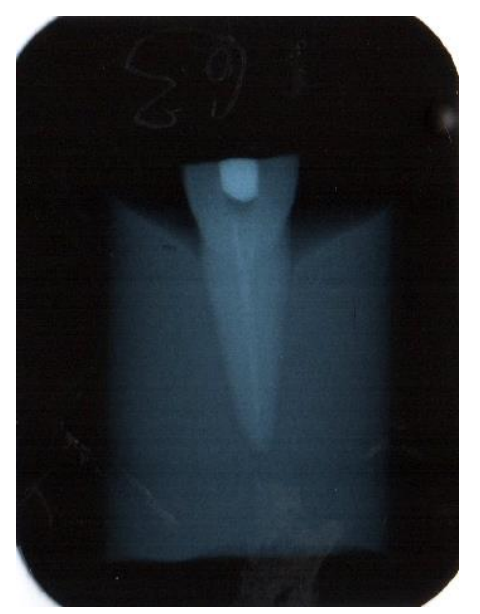

Abb. 4-10: Einzelzahnaufnahme zur Kontrolle einer homogenen Füllung des Wurzelkanals mit Kalziumhydroxid.

Abschließend wurden die Zähne für 7 Tage im Inkubator (Climacell 111, MMM Medcenter, München, Deutschland) bei $37{ }^{\circ} \mathrm{C}$ und $100 \%$ iger Luftfeuchtigkeit aufbewahrt. Die Proben wurden in einem wiederverschließbaren Kunststoffbehälter (Inkcompany, Jena, Deutschland) gelagert, welcher mit aqua dest. befüllt war. 


\subsection{Voruntersuchungen}

Die Voruntersuchung wurde an zehn Zähnen durchgeführt, je Spültechnik zwei Zähne. Nach Beendigung der Versuchsreihe wurden die Durchführung und dabei aufgetretene Fragen und Probleme kritisch begutachtet und diskutiert.

Die Kriterien für die Auswahl der Zähne waren identisch mit denen der endgültigen Versuchsreihe. Ebenso erfolgten die Separation der Wurzelhälften und die Präparation der Gruben nach den zuvor aufgeführten Prinzipien.

Ausschließlich bei der Verwendung eines geeigneten Kalziumhydroxidpräparates ergab sich Diskussionsbedarf. Es wurde ein Vergleich zwischen UltraCal $₫ X S$ (Ultradent Products Inc., South Jordan, Utah, USA) und Hypocal ${ }^{8}$ (Merz Dental, Lütjenburg, Deutschland) vorgenommen. Die Wirkstoffe beider Kalziumhydroxidpräparate sind identisch, es besteht allerdings ein Unterschied in der Zusammensetzung, welcher sich unter anderem in der Viskosität und unterschiedlichen Verarbeitung äußert. UltraCal ${ }^{\circledR} X S$ besitzt einen $35 \%$ igen Anteil an Kalziumhydroxid und zeigt eine geringe Viskosität. Hypocal囚 dagegen besteht zu 45\% aus Kalziumhydroxid, damit steigt gleichzeitig auch die Viskosität. Die vom Hersteller mitgelieferten Injektionskanülen weisen unterschiedliche Größen auf. UltraCal囚XS wird mit einer Kanüle der Größe 30 (Außendurchmesser 0,3 mm) und Hypocal ${ }^{\circledR}$ mit einer Kanüle der Größe 90 (Außendurchmesser 0,9 mm) geliefert. Die Breite der künstlich geschaffenen Gruben sollte bei 0,2 mm liegen. Die Applikation des Kalziumhydroxids mit einer Kanüle der Größe 30 gestaltete sich präziser als mit einer größeren Kanüle. Die Wahl für das in dieser Studie verwendete Kalziumhydroxid fiel deshalb auf UltraCal®XS.

Das zuvor vorläufige Spülprotokoll wurde beibehalten und entspricht dem später (siehe 4.5.1) aufgelisteten.

Außerdem dienten die Voruntersuchungen der Überprüfung aller Herstellerangaben zu den Materialien und der Beseitigung möglicher Fehlerquellen. Für die Versuchsreihen wurden einheitliche Vorgehensweisen definiert, um ein standardisiertes Experiment zu garantieren. 


\subsection{Verwendete Aktivierungsgeräte}

\subsubsection{EndoActivator}

Mit dem EndoActivator erfolgt eine hydrodynamische Aktivierung der Spülflüssigkeit. Auf das Handstück (DENTSPLY Maillefer, Santa Barbara, USA) wurde ein ActivatorTip (DENTSPLY Maillefer, Santa Barbara, USA) in der Größe medium (25/.04) gesteckt. Gemäß der Herstellerangabe wurden die Ansätze nach einmaligem Gebrauch verworfen. Die Aufsätze sind flexibel, nicht schneidend und besitzen Tiefenmarkierungen bei 18, 19 und $20 \mathrm{~mm}$ (siehe Abbildung 4-11). Um die maximale Eindringtiefe von $16 \mathrm{~mm}$ einzuhalten wurde eine zusätzliche Farbmarkierung bei $16 \mathrm{~mm}$ angebracht.

Während der Spülung wurde der EndoActivator auf eine Frequenz von $10.000 \mathrm{cpm}$ eingestellt. Die Spülung erfolgte in drei Zyklen à 20 Sekunden. Während der 20 Sekunden wurden mit Hilfe der manuellen Spülung je $2 \mathrm{ml}$ aqua dest. zugeführt. Außerdem wurden je Spülzyklus 10 vertikale Hubbewegungen von 2-3 mm durchgeführt. Das gesamte Spülvolumen (mit Eingangs- und Abschlussspülung) betrug $9 \mathrm{ml}$.

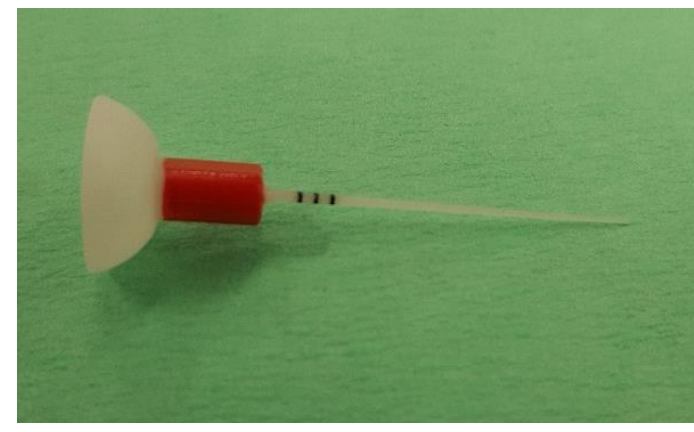

Abb. 4-11: Spülspitze ActivatorTip Größe medium

\subsubsection{Passive Ultraschallspülung}

Für die passive Ultraschallspülung wurde auf den Ultraschallgenerator VDW.Ultra® (VDW, München, Deutschland) zurückgegriffen. Das Gerät kann je nach Indikation auf verschiedene Intensitätsstufen (Frequenzbereiche) eingestellt werden. Für die Aktivierung von Spülflüssigkeiten sollten maximal $30 \%$ eingestellt werden. Im Falle einer Revision wird empfohlen, zwischen $30-$ $50 \%$ der Maximalfrequenz zu arbeiten. Die Präparation von Zugangskavitäten sollte mit $40-60 \%$ erfolgen. Die Nutzung der Maximalintensität kann bei der Entfernung von Metallstiften notwendig sein. Demzufolge wurde das Gerät für die 
Versuchsdurchführung auf $30 \%$ eingestellt. Für die passive ultraschallgestützte Spülung wurde die IRRI S 21/25 (VDW, München, Deutschland) als Spülspitze ausgewählt (siehe Abbildung 4-12).

Die Spülung erfolgte in drei Zyklen à 20 Sekunden. Da das Gerät ohne Flüssigkeitszufuhr arbeitet, wurden mit einer 5-ml-Spritze und 30-gauge-NaviTipKanüle auf je 20 Sekunden $2 \mathrm{ml}$ aqua dest. zugeführt. Das gesamte Spülvolumen betrug $9 \mathrm{ml}$. Die maximale Eindringtiefe lag bei $16 \mathrm{~mm}$.

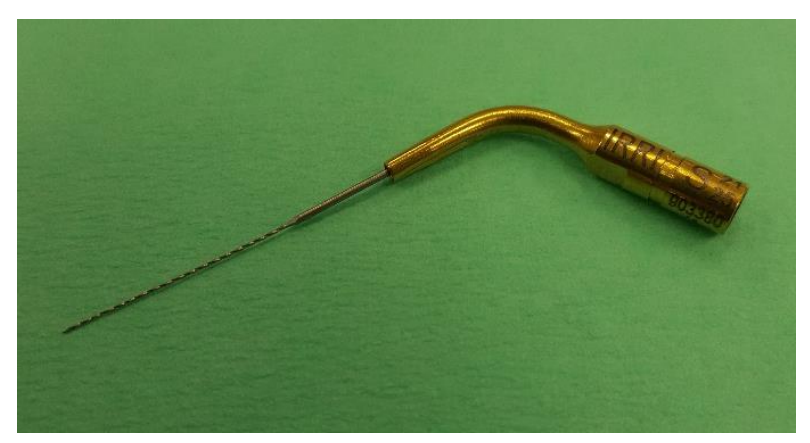

Abb. 4-12: Spülspitze IRRI S 21/25

\subsubsection{EDDY}

Mit der Spülspitze EDDY (VDW, München, Deutschland) ist eine schallbasierte Aktivierung von Spülflüssigkeiten möglich. Die Spülspitze ist flexibel, steril und für den Einmalgebrauch vorgesehen. Die Spitze hat eine aktive Länge von $28 \mathrm{~mm}$ mit zahlreichen Tiefenmarkierungen (siehe Abbildung 4-13). Um die maximale Eindringtiefe von $16 \mathrm{~mm}$ einzuhalten, wurde eine zusätzliche Farbmarkierung angebracht. Die Spülspitze muss in ein EDDY-kompatibles Handstück, z. B. Airscaler Proxeo (W\&H Dentalwerk, Bürmoos, Österreich), eingeschraubt werden. Der Frequenzbereich liegt bei 5000 bis $6000 \mathrm{~Hz}$.

Die Aktivierung des EDDY erfolgte in drei Zyklen à 20 Sekunden nach Einbringen von je $2 \mathrm{ml}$ aqua dest. Pro Spülzyklus wurden dabei 10 vertikale Auf- und Abbewegungen von 2-3 mm durchgeführt. Das gesamte Spülvolumen betrug $9 \mathrm{ml}$. 


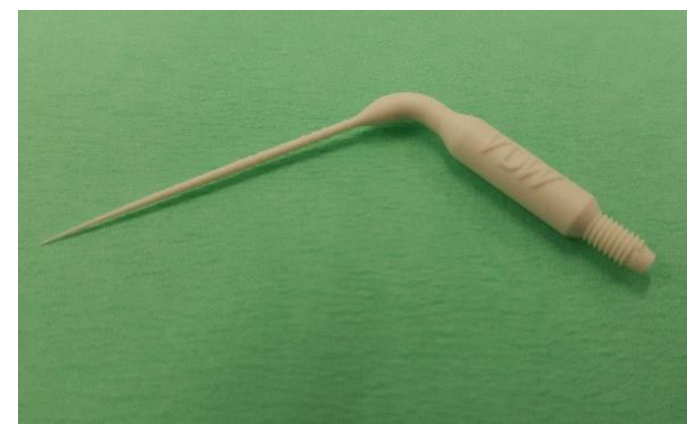

Abb. 4-13: Spülspitze EDDY

\subsubsection{Manuelle Spülung}

Für die Handspülung wurde eine 5-ml-Spritze (Becton, Dickinson and Company, Franklin Lakes, USA) mit einer 30-gauge-NaviTip-Kanüle (Endoneedle, Vedefar N.V., Dilbeek, Belgien) verwendet. Als Spüllösung kam aqua dest. zum Einsatz. Mit Hilfe eines Gummistoppers an der Spülkanüle wurde die maximale Eindringtiefe von $16 \mathrm{~mm}$ markiert. Die manuelle Spülung erfolgte in drei Zyklen, wobei je Spülzyklus mit $2 \mathrm{ml}$ aqua dest. für je 20 Sekunden gespült wurde. Innerhalb eines Spülzyklus erfolgten 10 vertikale Hubbewegungen von 2-3 mm. Das gesamte Spülvolumen (mit Eingangs- und Abschlussspülung) je Kanal betrug $9 \mathrm{ml}$.

\subsection{Versuchsaufbau}

In dieser Studie wurden 60 extrahierte Zähne randomisiert in vier Gruppen eingeteilt, je 15 Zähne wurden dem EndoActivator, der passiven Ultraschallspülung, dem EDDY und der Handspülung zugeordnet. Die Kontrollgruppe bestand aus 10 Zähnen und 10 Zähne wurden für die Voruntersuchungen benötigt.

Nach 7 Tagen kam es zur Entnahme der Proben aus dem Inkubator. Zunächst wurden das Cavit ${ }^{\mathrm{TM}} \mathrm{W}$ und das Wattekügelchen entfernt. Abschließend erfolgte die Entfernung des Kalziumhydroxids mit Hilfe der verschiedenen zuvor aufgeführten Spültechniken. Grundlage war folgendes Spülprotokoll (siehe 4.5.1.1-4.5.1.5). 


\subsubsection{Versuchsgruppen}

\subsubsection{Gruppe 1: EndoActivator}

15 Zähne

Spülprotokoll:

- Spülung mit $1 \mathrm{ml}$ aqua dest. in 30 Sekunden mit 5-ml-Spritze und 30-gaugeNaviTip-Kanüle

- Penetration des Wurzelkanals mit Reamer ISO 10 auf Arbeitslänge

- Aktivierung des EndoActivators mit $10.000 \mathrm{cpm}$ für 3x20 Sekunden mit der Spitze medium (25/.04), je Zyklus wurden $2 \mathrm{ml}$ aqua dest. zugeführt

- während eines Spülzyklus 10 vertikal pumpende Bewegungen von 2-3 mm im Wurzelkanal

- Eindringtiefe des EndoActivators: $2 \mathrm{~mm}$ kürzer als Arbeitslänge, also maximal $16 \mathrm{~mm}$

- Abschlussspülung mit $2 \mathrm{ml}$ aqua dest.

\subsubsection{Gruppe 2: Passive Ultraschallspülung}

15 Zähne

Spülprotokoll:

- $\quad$ Spülung mit $1 \mathrm{ml}$ aqua dest. in 30 Sekunden mit 5-ml-Spritze und 30-gaugeNaviTip-Kanüle

- Penetration des Wurzelkanals mit Reamer ISO 10 auf Arbeitslänge

- 3 Zyklen: 3x20 Sekunden bei passiver Aktivierung des VDW.Ultra®-Dental ultrasonic generators mit einer Irrisafe-Feile (IRRI S 21/25), dabei wurden je Zyklus $2 \mathrm{ml}$ aqua dest. zugeführt

- Eindringtiefe der Ultraschallspitze: $2 \mathrm{~mm}$ kürzer als Arbeitslänge, also maximal $16 \mathrm{~mm}$

- Abschlussspülung mit $2 \mathrm{ml}$ aqua dest.

\subsubsection{Gruppe 3: EDDY}

15 Zähne

Spülprotokoll: 
- Spülung mit $1 \mathrm{ml}$ aqua dest. in 30 Sekunden mit 5-ml-Spritze und 30-gaugeNaviTip-Kanüle

- Penetration des Wurzelkanals mit Reamer ISO 10 auf Arbeitslänge

- Aktivierung des EDDY (EDDY ${ }^{\mathrm{TM}}$-kompatibler Airscaler Proxeo ZA-55LM) mit $5.000 \mathrm{~Hz}$ bei 3,0 bar für $3 \times 20$ Sekunden nach Einbringen von je $2 \mathrm{ml}$ aqua dest. mit der Spitze medium

- während eines Spülzyklus 10 vertikal pumpende Bewegungen von 2-3 mm im Wurzelkanal

- Eindringtiefe des EDDY: 2 mm kürzer als Arbeitslänge, also maximal $16 \mathrm{~mm}$

- Abschlussspülung mit $2 \mathrm{ml}$ aqua dest.

\subsubsection{Gruppe 4: Manuelle Spülung}

15 Zähne

\section{Spülprotokoll:}

- Spülung mit $1 \mathrm{ml}$ aqua dest. in 30 Sekunden mit 5-ml-Spritze und 30-gaugeNaviTip-Kanüle

- Penetration des Wurzelkanals mit Reamer ISO 10 auf Arbeitslänge

- 3 Zyklen: Spülung mit je $2 \mathrm{ml}$ aqua dest. in je 20 Sekunden mit 5-ml-Spritze und 30-gauge-NaviTip-Kanüle

- während eines Spülzyklus 10 vertikal pumpende Bewegungen von 2-3 mm im Wurzelkanal

- Eindringtiefe der NaviTip-Spülkanülenspitze: $2 \mathrm{~mm}$ kürzer als Arbeitslänge, also maximal $16 \mathrm{~mm}$

- Abschlussspülung mit $2 \mathrm{ml}$ aqua dest.

\subsubsection{Gruppe 5: Kontrollgruppe}

10 Zähne

Die Proben wurden nach 7 Tagen im Inkubator ohne Spülung unter dem Mikroskop untersucht und abschließend bewertet. 


\subsection{Auswertung}

\subsubsection{Score-System}

Der Wurzelkanal wurde mit Papierspitzen der ISO-Größen 25 bis 40 getrocknet, im Anschluss der Zahn aus dem Acryl-Röhrchen entnommen und die beiden Zahnhälften vorsichtig voneinander getrennt. Für die folgende Auswertung wurde je Zahnhälfte ein digitales Bild unter dem Stereomikroskop erstellt. Dieses Bild zeigt die gespülte Kavität in 32facher Vergrößerung und bei einer Bildauflösung von 5 Megapixeln. Für die Erstellung der Bilder dienten die zuvor eingefrorene Einstellung des Mikroskops sowie der individuell hergestellte Silaplastschlüssel. Durch dieses Vorgehen wurde sichergestellt, dass die Bilder der gefüllten und gespülten Kavität in gleicher Projektion und unter gleichen Lichtbedingungen aufgenommen wurden.

Die Bewertung der Kalziumhydroxidrückstände in den jeweiligen Gruben und im Wurzelkanallumen wurde von zwei zuvor kalibrierten Untersuchern vorgenommen. Die Bewertung fand an einem farbkalibrierten Bildschirm unter gleichen Lichtbedingungen in einem abgedunkelten Raum statt. Die zuvor angefertigten Bilder der gefüllten Kavität konnten als Hilfestellung hinzugezogen werden.

Die Auswertung erfolgte in Anlehnung an das von Lee et al. (2004) beschriebene Score-System:

- Score 0: $\leq 25 \%$ der Kavität sind gefüllt mit Kalziumhydroxid (siehe Abbildung 4-14)

- Score 1: $\leq 50 \%$ der Kavität sind gefüllt mit Kalziumhydroxid (siehe Abbildung 4-15)

- Score 2: $\leq 75 \%$ der Kavität sind gefüllt mit Kalziumhydroxid (siehe Abbildung 4-16)

- Score 3: > 75\% der Kavität sind gefüllt mit Kalziumhydroxid (siehe Abbildung 4-17) 


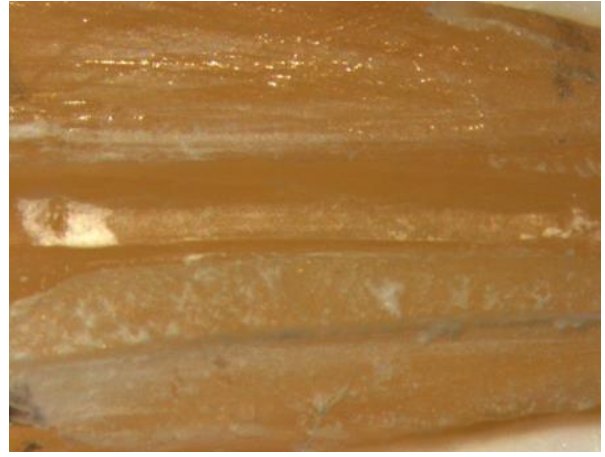

Abb. 4-14: Kavität mit Score 0

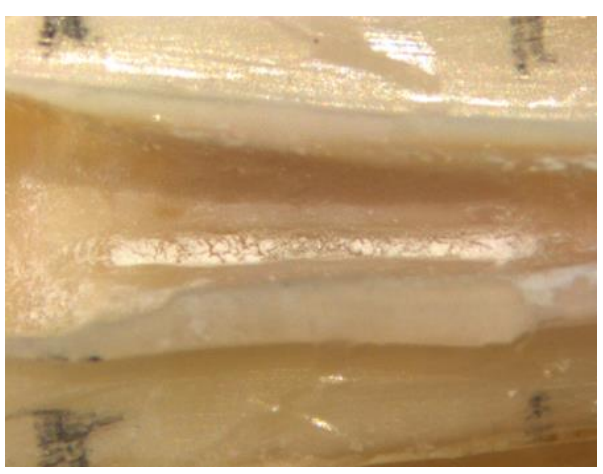

Abb. 4-16: Kavität mit Score 2

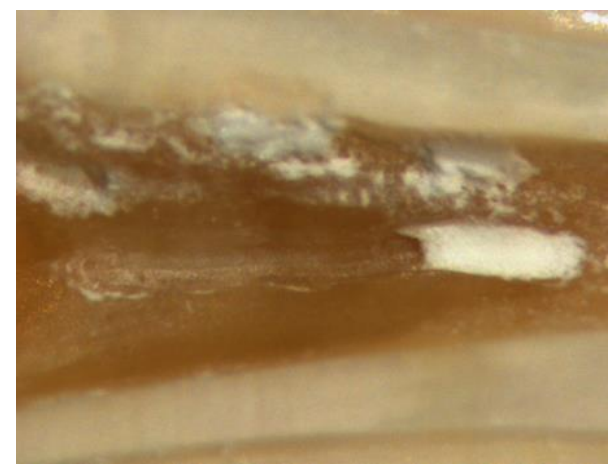

Abb. 4-15: Kavität mit Score 1

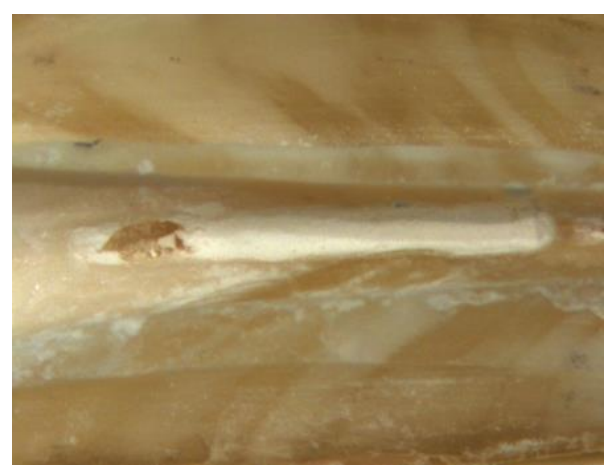

Abb. 4-17: Kavität mit Score 3

Dieselben Scores wurden auch für die Bewertung der Kalziumhydroxidrückstände an den Wänden des Wurzelkanallumens verwendet. Die Proben wurden vor der Auswertung von einer unabhängigen Person verschlüsselt und anschließend in einer zufälligen Reihenfolge ausgewertet, sodass eine Identifikation des verwendeten Spülsystems durch die Auswerter nicht möglich war.

\subsubsection{Kalibrierung}

Vor Beginn der Auswertung wurden die beiden Auswerter kalibriert. Jeder Untersucher bewertete alleine 40 zufällig aus der Versuchsreihe ausgewählte digitale Fotografien. Diese Bilder deckten den gesamten Score-Bereich ab. Anschließend wurden beide Auswertungen miteinander verglichen und über abweichende Bewertungen diskutiert. In einer zweiten Bewertung derselben Bilder wurde das Prozedere wiederholt. Zwischen der ersten und zweiten Auswertung lagen 7 Tage. Beide Auswertungen fanden an einem farbkalibrierten Bildschirm unter gleichen Lichtbedingungen in einem abgedunkelten Raum statt. 
Der Bildschirm für die Kalibrierung war identisch mit dem der endgültigen Auswertung, welche weitere 7 Tage später folgte.

Für die Kalibrierung wurden die intra- und interindividuelle Reliabilität ermittelt (siehe 5.1).

\subsubsection{Statistische Auswertung}

Um die Reproduzierbarkeit der Ergebnisse zu überprüfen, wurden die intra- und interindividuelle Reliabilität bewertet. Dazu erfolgte die Berechnung der CohensKappa-Werte.

Für die statistische Auswertung wurde ein nichtparametrisches Analyseverfahren angewendet (Brunner et al. 2002). Für den Paarvergleich in Abhängigkeit von der Lage der Kavität wurde ein Post-Hoc-Vergleich mit Hilfe des Mann-Whitney-UTests durchgeführt. Die Korrektur der $p$-Werte für das globale Signifikanzniveau wurde nach Bonferroni-Holm vorgenommen. Das Signifikanzniveau wurde auf $\alpha \leq 0,05$ festgelegt.

Die statistische Auswertung erfolgte mit Statistika 12.0. Tabellen und Diagramme wurden mit Statistika 12.0 und Excel Microsoft Office 365 erstellt. 


\section{$5 \quad$ Ergebnisse}

\subsection{Reproduzierbarkeit der Ergebnisse}

Um neben einem standardisierten Versuchsaufbau eine standardisierte Bewertung der Proben zu garantieren, wurden im Vorfeld der Auswertung beide Untersucher kalibriert. Im Anschluss wurden die intraindividuelle und interindividuelle Reliabilität bestimmt, um Rückschlüsse auf die Reproduzierbarkeit zu ermöglichen.

\subsubsection{Intraindividuelle Reliabilität}

Die intraindividuelle Reliabilität beschreibt die Reproduzierbarkeit von Ergebnissen bei wiederholter Auswertung durch einen Bewerter. Dies kann mit dem Cohens-Kappa-Koeffizienten beurteilt werden. Ein Cohens-Kappa-Wert von $\geq 0,8$ steht für eine gute Reproduzierbarkeit.

Die intraindividuelle Reproduzierbarkeit bei der Vergabe der Score-Werte ist für beide Auswerter als sehr gut zu bezeichnen. Für den Untersucher A wurde ein Wert von 0,8986 und für den Untersucher B ein Wert von 0,8925 ermittelt (siehe Tabelle 5-1).

Tab. 5-1: Kappa-Koeffizienten für die intraindividuelle Reproduzierbarkeit beider Untersucher

\begin{tabular}{|l|c|c|}
\hline Einfacher Kappa-Koeffizient & Untersucher A & Untersucher B \\
\hline Kappa & 0,8986 & 0,8925 \\
\hline 95\% untere Konfigurationsgrenze & 0,8062 & 0,7937 \\
\hline 95\% obere Konfigurationsgrenze & 0,9910 & 0,9912 \\
\hline
\end{tabular}

\subsubsection{Interindividuelle Reliabilität}

Die interindividuelle Reliabilität spiegelt die Übereinstimmung zweier Bewerter wider. Dazu wurde ebenfalls der Cohens-Kappa-Wert bestimmt (siehe Tabelle 5-2). Der Interreader-Vergleich fällt mit 0,8156 größer als 0,8 aus. Während der Kalibrierung und Bewertung des Endversuchs unterschieden sich die Ergebnisse 
der beiden Untersucher maximal um einen Score-Wert. Die Übereinstimmung zwischen beiden Bewertern ist daher ebenfalls als sehr gut zu bezeichnen.

Tab. 5-2: Kappa-Koeffizient für die interindividuelle Übereinstimmung beider Untersucher

\begin{tabular}{|l|l|}
\hline Einfacher Kappa-Koeffizient & \multicolumn{2}{|l|}{} \\
\hline Kappa & 0,8156 \\
\hline $95 \%$ untere Konfigurationsgrenze & 0,7397 \\
\hline $95 \%$ obere Konfigurationsgrenze & 0,8915 \\
\hline
\end{tabular}

\subsection{Ergebnisse des Hauptversuchs}

Die Bewertung erfolgte mit Hilfe eines Score-Systems, weshalb eine Normalverteilung der Daten nicht automatisch vorliegt, daher wurde ein nichtparametrisches Verfahren angewandt. Das Signifikanzniveau wurde auf $\alpha \leq 0,05$ festlegt.

In Bezug auf die Lage der Kavitäten (apikal, koronal) wurde mit Hilfe des MannWhitney-U-Tests kein signifikanter Unterschied $(p=0,19)$ festgestellt. Für die einzelnen Spültechniken wurde mit dem Kruskal-Wallis-Test ein signifikanter Unterschied ermittelt. Für das Wurzelkanallumen ergab sich $p=0,00$, für die apikale Zahnhälfte $p=0,0001$ und für die koronale Zahnhälfte $p=0,00$.

Da eine Interaktion der Spültechnik mit der Lage der Kavität nicht ausgeschlossen werden konnte, fand die Auswertung getrennt für das Wurzelkanallumen, die apikale und die koronale Kavität statt.

\subsubsection{Ergebnisse für das Wurzelkanallumen}

Die Tabelle 5-3 zeigt die ermittelten p-Werte für die Paarvergleiche zwischen den Spültechniken. Die p-Werte wurden mit dem Mann-Whitney-U-Test und der Bonferroni-Holm-Korrektur bestimmt. Das Signifikanzniveau wurde auf $\alpha \leq 0,05$ festgelegt. Signifikante $\mathrm{p}-$ Werte sind rot markiert.

Die Reinigung der Kavität mit dem EDDY oder der passiven Ultraschallspülung zeigt sich der Handspülung und dem EndoActivator signifikant überlegen. Zwischen dem EDDY und der passiven Ultraschallspülung besteht kein signifikanter Unterschied $(p=0,46)$.

Der EndoActivator schnitt signifikant schlechter ab als die passive Ultraschallspülung und der EDDY. Der Unterschied zwischen EndoActivator und 
Handspülung ist nicht signifikant $(p=0,19)$. Beide Verfahren können als gleichwertig angesehen werden.

Tab. 5-3: Spültechniken im Paarvergleich für das Wurzelkanallumen. Die rote Markierung zeigt eine Signifikanz an. Signifikanzniveau $\alpha \leq 0,05$.

\begin{tabular}{|c|c|c|c|c|}
\hline \multicolumn{2}{|c|}{ Spültechnik } & Handspülung & $\begin{array}{c}\text { Ultraschall- } \\
\text { spülung }\end{array}$ & \multicolumn{2}{c|}{$\begin{array}{c}\text { Endo- } \\
\text { Activator }\end{array}$} & EDDY \\
\hline Kontrollgruppe & 0,64 & 0,00 & 0,17 & 0,00 \\
\hline Handspülung & & 0,00 & 0,19 & 0,00 \\
\hline Ultraschallspülung & & & 0,01 & 0,46 \\
\hline EndoActivator & & & & 0,01 \\
\hline
\end{tabular}

Tabelle 5-4 zeigt die Verteilung der absoluten Score-Werte für das Wurzelkanallumen. Die relative Häufigkeit der Score-Werte ist in Abbildung 5-1 in Form eines Säulendiagramms festgehalten.

Tab. 5-4: Absolute Häufigkeit der Score-Werte für das Wurzelkanallumen

\begin{tabular}{|c|c|c|c|c|c||c|} 
& $\begin{array}{c}\text { Kontroll- } \\
\text { gruppe }\end{array}$ & $\begin{array}{c}\text { Hand- } \\
\text { spülung }\end{array}$ & $\begin{array}{c}\text { Ultraschall- } \\
\text { spülung }\end{array}$ & \multicolumn{2}{|c||}{$\begin{array}{c}\text { Endo- } \\
\text { Activator }\end{array}$} & EDDY \\
\hline Score 0 & 0 & 0 & 17 & 7 & 26 & $\mathbf{5 0}$ \\
\hline Score 1 & 0 & 3 & 14 & 3 & 10 & $\mathbf{3 0}$ \\
\hline Score 2 & 0 & 2 & 9 & 7 & 4 & $\mathbf{2 2}$ \\
\hline Score 3 & 40 & 55 & 20 & 43 & 20 & $\mathbf{1 7 8}$ \\
\hline \hline Summe & $\mathbf{4 0}$ & $\mathbf{6 0}$ & $\mathbf{6 0}$ & $\mathbf{6 0}$ & $\mathbf{6 0}$ & $\mathbf{2 8}$ \\
\hline
\end{tabular}




\section{Relative Häufigkeit Wurzelkanallumen}

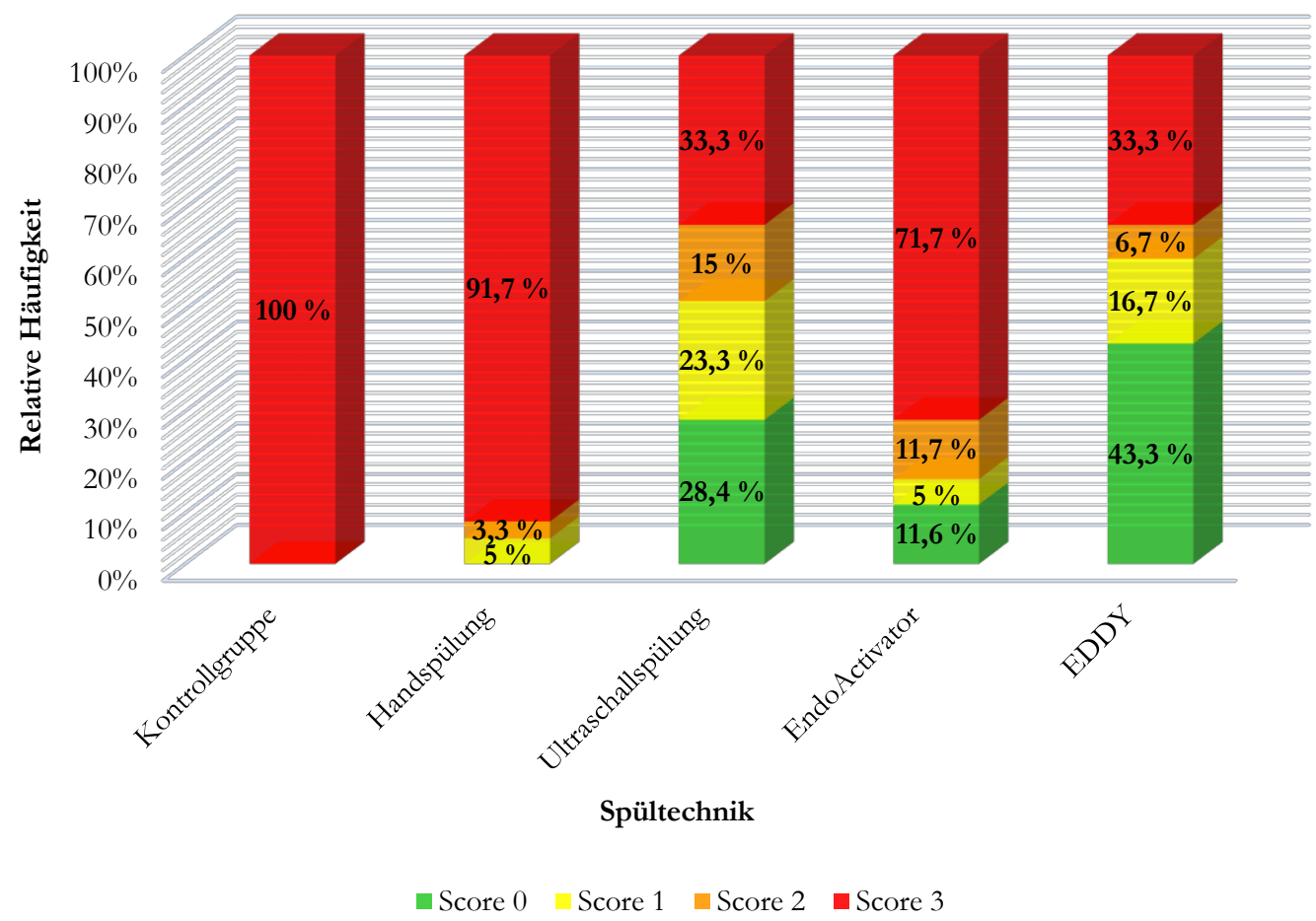

Abb. 5-1: Relative Häufigkeit der Score-Werte für das Wurzelkanallumen

Die manuelle Spülung erreichte die schlechteste Reinigungswirkung. Zu 91,7\% wurde der Score 3 und nur zu 3,3\% der Score 2 bzw. zu 5\% der Score 1 vergeben. Der Score 0, d. h. $\leq 25 \%$ der Kanalwand sind mit Kalziumhydroxid gefüllt, wurde nie vergeben. Der EndoActivator weist immerhin in $11,6 \%$ der Fälle einen Score 0 auf. Score 1 wurde mit 5\% und Score 2 mit 11,7\% bewertet. Die Spülwirkung wurde zu $71,7 \%$ mit Score 3 beurteilt. Damit erreichte der EndoActivator keine zufriedenstellende Entfernung von Kalziumhydroxid aus dem Kanallumen.

Eine deutlich bessere Reinigungswirkung lässt sich bei der passiven Ultraschallspülung erkennen. Diese zeigt im Vergleich eine Zunahme der niedrigeren Score-Werte (Score $0=28,4 \%$, Score $1=23,3 \%$ ). 15\% der Proben wurden mit Score 2 bewertet und jeder 3. Zahn mit Score 3.

Der EDDY weist mit 43,3\% den deutlich höchsten Wert für Score 0 und damit die beste Reinigungswirkung auf. Score 1 wurde in $16,7 \%$ und Score 2 in $6,7 \%$ der Proben vergeben. Wie bei der passiven Ultraschallspülung weist jeder 3. Zahn bei dem EDDY einen Score 3 auf. 


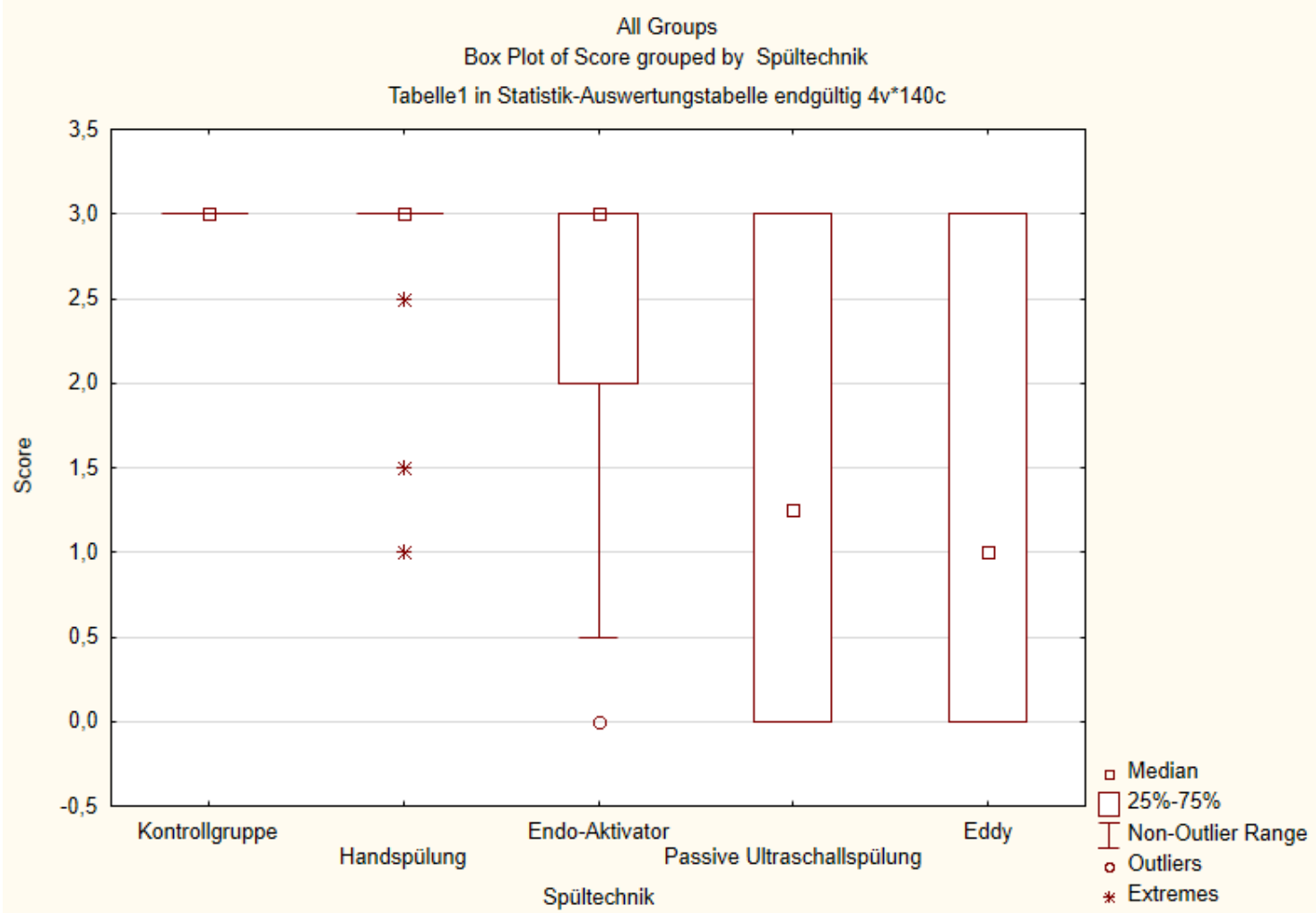

Abb. 5-2: Boxplot der verschiedenen Spültechniken für das Wurzelkanallumen

Grafisch veranschaulicht werden die Ergebnisse in einem Boxplot (siehe Abbildung 5-2). Die Kontrollgruppe weist im Median den Wert 3 auf, es wurden keine anderen Score-Werte verteilt. Die Handspülung zeigt ebenfalls einen Median bei 3, allerdings finden sich vereinzelte Extremwerte. Ein Medianwert von 3 lässt sich ebenso bei dem EndoActivator ablesen. Die Mehrheit der Werte liegt aber im Bereich der Scores 3 und 2, außerdem wurden Ausreißer von Score 0 vergeben. Für die passive Ultraschallspülung und den EDDY wurden alle ScoreWerte vergeben. Die passive Ultraschallspülung zeigt einen Median von 1,25, der EDDY einen Median von 1.

\subsubsection{Ergebnisse für die Reinigung der koronalen Kavität}

Die Paarvergleiche zwischen den einzelnen Spültechniken für die Kavität im koronalen Drittel wurden ebenfalls mit dem Mann-Whitney-U-Test durchgeführt. Die resultierenden $p$-Werte sind in Tabelle 5-5 zusammengefasst.

Die passive Ultraschallspülung zeigt, ebenso wie der EDDY, signifikante Unterschiede zur Handspülung und zum EndoActivator. Beide Spültechniken unterscheiden sich nicht signifikant $(p=1,93)$ und können als gleichwertig 
angesehen werden. Zwischen der Handspülung und dem EndoActivator besteht kein signifikanter Unterschied $(p=1,0)$.

Tab. 5-5: Spültechniken im Paarvergleich für die koronale Kavität. Die rote Markierung zeigt eine Signifikanz an. Signifikanzniveau $\alpha \leq 0,05$.

\begin{tabular}{|c|c|c|c|c|}
\hline \multicolumn{2}{|c|}{ Spültechnik } & Handspülung & $\begin{array}{c}\text { Ultraschall- } \\
\text { spülung }\end{array}$ & $\begin{array}{c}\text { Endo- } \\
\text { Activator }\end{array}$ \\
\hline Kontrollgruppe & 1,35 & 0,08 & 1,80 & 0,17 \\
\hline Handspülung & & 0,01 & 1,00 & 0,03 \\
\hline Ultraschallspülung & & & 0,01 & 1,93 \\
\hline EndoActivator & & & & 0,03 \\
\hline
\end{tabular}

Die absolute Verteilung der Score-Werte für die Kavität im koronalen Wurzelkanaldrittel wurde in Tabelle 5-6 zusammengefasst. Die Abbildung 5-3 veranschaulicht die relative Verteilung der Score-Werte in Form eines Säulendiagramms.

Tab. 5-6: Absolute Häufigkeit der Score-Werte für die koronale Kavität

\begin{tabular}{|c|c|c|c|c|c||c|} 
& $\begin{array}{c}\text { Kontroll- } \\
\text { gruppe }\end{array}$ & $\begin{array}{c}\text { Hand- } \\
\text { spülung }\end{array}$ & $\begin{array}{c}\text { Ultraschall- } \\
\text { spülung }\end{array}$ & \multicolumn{2}{c||}{$\begin{array}{c}\text { Endo- } \\
\text { Activator }\end{array}$} & EDDY \\
\hline Score 0 & 0 & 0 & 8 & 0 & 10 & 18 \\
\hline Score 1 & 0 & 1 & 5 & 0 & 6 & 12 \\
\hline Score 2 & 0 & 2 & 7 & 3 & 2 & 14 \\
\hline Score 3 & 20 & 27 & 10 & 27 & 12 & 96 \\
\hline \hline Summe & 20 & 30 & 30 & 30 & 30 & 140 \\
\hline
\end{tabular}




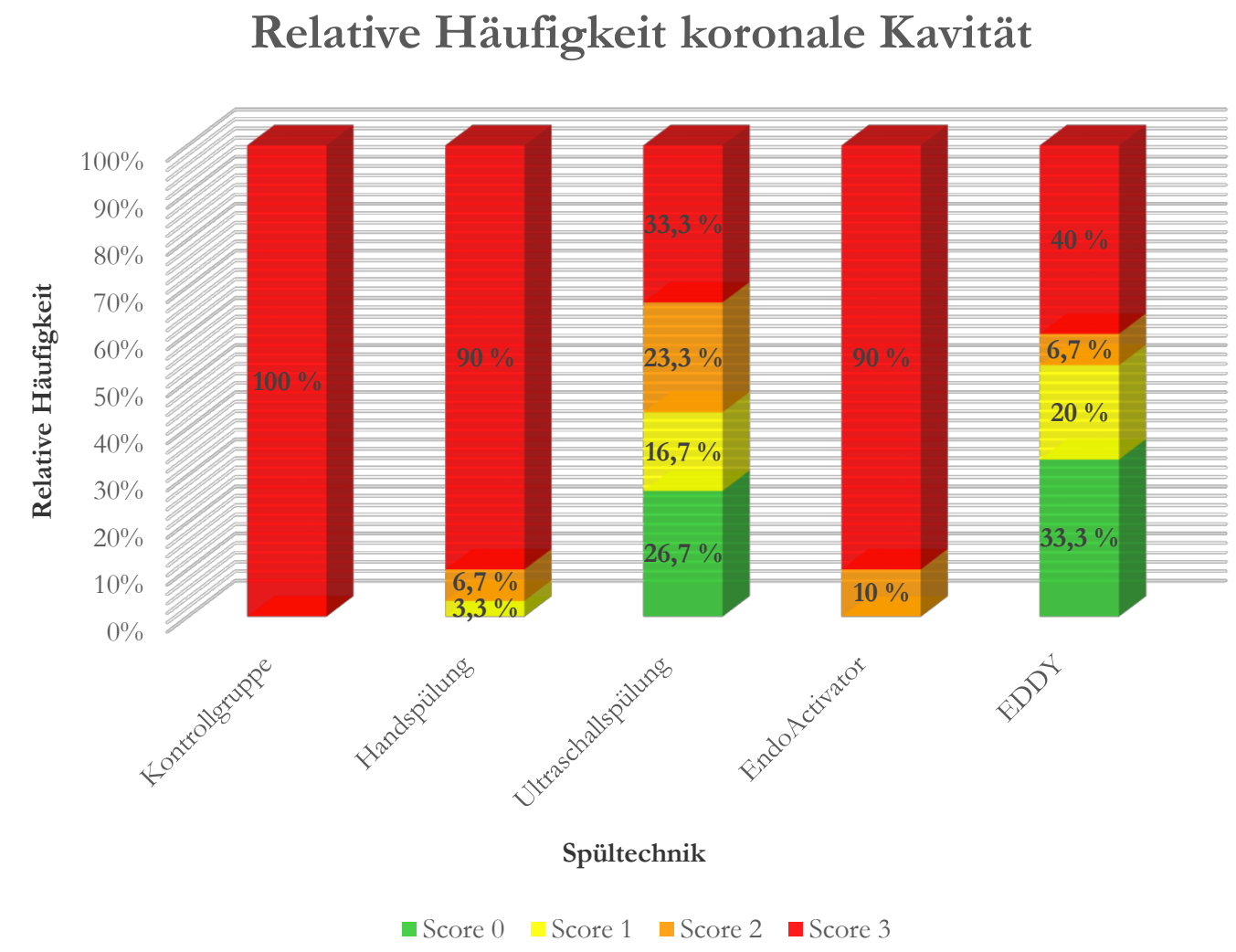

Abb. 5-3: Relative Häufigkeit der Score-Werte für die koronale Kavität

Der Score 0 wird nur bei zwei Spültechniken erreicht: der passiven Ultraschallspülung $(26,7 \%)$ und dem EDDY (33,3\%). Mit der Handspülung wurde Score 1 in nur 3,3\%, mit der passiven Ultraschallspülung in 16,7\% und dem EDDY in 20\% der Fälle erreicht. Der Score 2 wurde für die passive Ultraschallspülung in 23,3\% und für den EndoActivator in 10\% der Fälle, bei der Handspülung ebenso oft wie bei dem EDDY (6,7\%) vergeben. Kalziumhydroxidrückstände von $>75 \%$ wurden zu $90 \%$ bei der Handspülung und dem EndoActivator, zu 40\% beim EDDY und zu 33,3\% bei der passiven Ultraschallspülung in der koronalen Kavität gefunden. Im Vergleich mit der Abbildung 5-1 zeigt sich in Abbildung 5-3 ein deutlicher Unterschied in der Verteilung der Score-Werte für den EndoActivator. Für die koronale Kavität wurden die Score-Werte 0 und 1 beim EndoActivator nie erreicht, wohingegen sie für das Wurzelkanallumen in $11,6 \%$ und $5 \%$ der Fälle vergeben wurden. Demzufolge steigt auch der Score 3 von $71,7 \%$ auf $90 \%$ an. Dies wird in der Boxplot-Darstellung wiederholt sichtbar (siehe Abbildung 5-4). 
Apikal/Koronal=Koronal

Box Plot of Score grouped by Spültechnik

Tabelle1 in Statistik-Auswertungstabelle endgültig $4 v^{*} 140 \mathrm{c}$

Exclude condition: NOT( UCASE("Apikal/Koronal") = "KORONAL"\$)

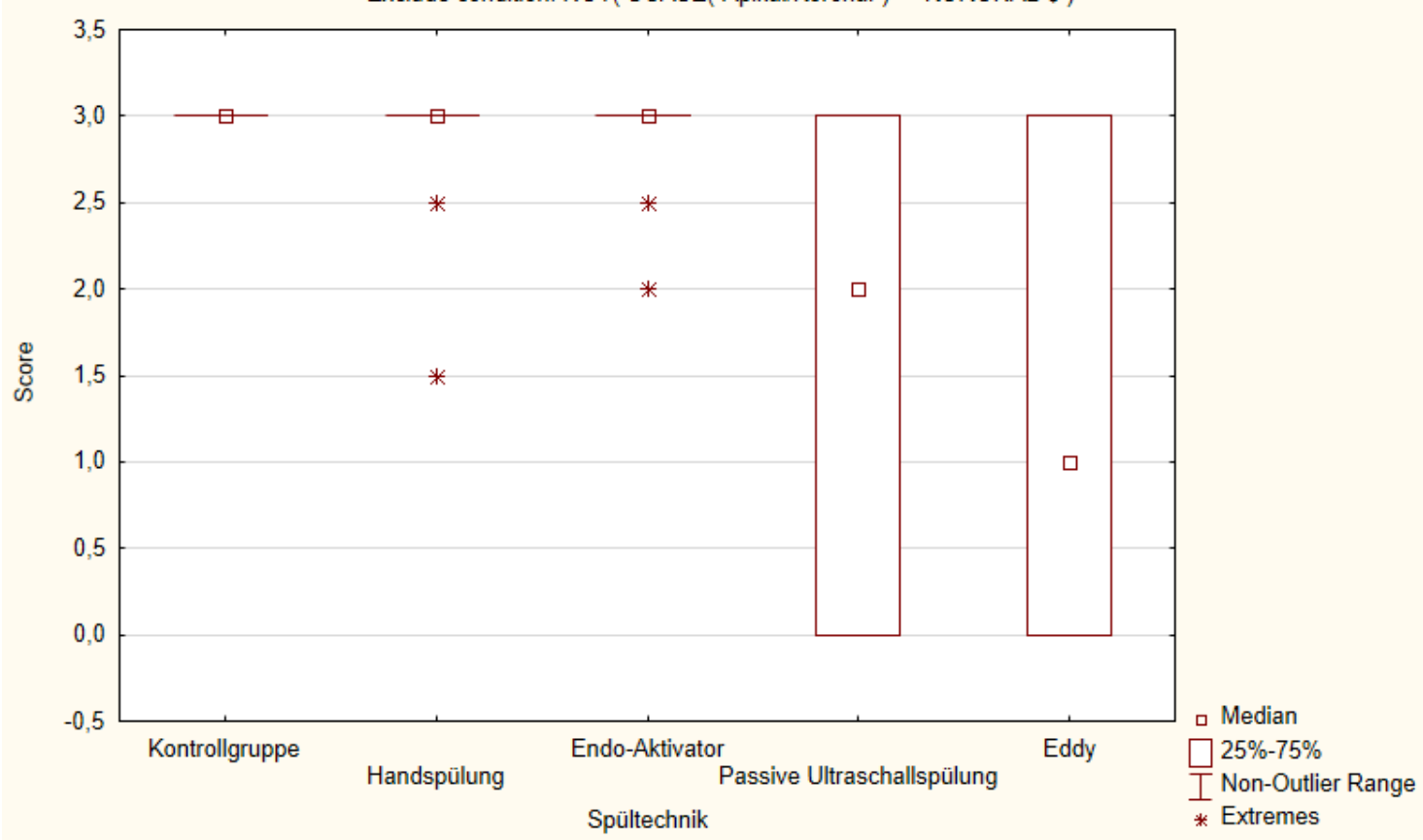

Abb. 5-4: Boxplot der verschiedenen Spültechniken für die koronale Kavität

\subsubsection{Ergebnisse für die Reinigung der apikalen Kavität}

In Tabelle 5-7 sind die p-Werte der Paarvergleiche zwischen den Spültechniken für die apikale Kavität aufgeführt. Die p-Werte wurden wie zuvor mit dem MannWhitney-U-Test und der Korrektur nach Bonferroni-Holm bestimmt.

Aus der Tabelle lässt sich ablesen, dass die Reinigungswirkung der Spültechniken für die apikale Kavität nur für jeweils zwei Spültechniken signifikante Unterschiede aufweist. Diese sind die Handspülung mit der passiven Ultraschallspülung $(p=0,01)$ bzw. dem EDDY $(p=0,00)$. Anders als bei der koronalen Kavität zeigt sich bei der apikalen Kavität keine deutliche Überlegenheit des EDDY bzw. der passiven Ultraschallspülung gegenüber dem EndoActivator. 
Tab. 5-7: Spültechniken im Paarvergleich für die apikale Kavität. Die rote Markierung zeigt eine Signifikanz an. Signifikanzniveau $\alpha \leq 0,05$.

\begin{tabular}{|c|c|c|c|c|}
\hline \multicolumn{1}{|c|}{ Spültechnik } & Handspülung & $\begin{array}{c}\text { Ultraschall- } \\
\text { spülung }\end{array}$ & $\begin{array}{c}\text { Endo- } \\
\text { Activator }\end{array}$ & EDDY \\
\hline Kontrollgruppe & 0,64 & 0,13 & 0,32 & 0,08 \\
\hline Handspülung & & 0,01 & 0,11 & 0,00 \\
\hline Ultraschallspülung & & 0,91 & 0,65 \\
\hline EndoActivator & & & & 0,35 \\
\hline
\end{tabular}

Die absolute Verteilung der Score-Werte ist in Tabelle 5-8 aufgelistet. In Abbildung 5-5 ist die relative Häufigkeit der Score-Werte dargestellt.

Tab. 5-8: Absolute Häufigkeit der Score-Werte für die apikale Kavität

\begin{tabular}{|c|c|c|c|c|c|c|}
\hline & $\begin{array}{c}\text { Kontroll- } \\
\text { gruppe }\end{array}$ & $\begin{array}{l}\text { Hand- } \\
\text { spülung }\end{array}$ & $\begin{array}{l}\text { Ultraschall- } \\
\text { spülung }\end{array}$ & $\begin{array}{l}\text { Endo- } \\
\text { Activator }\end{array}$ & EDDY & Summe \\
\hline Score 0 & 0 & 0 & 9 & 7 & 16 & 32 \\
\hline Score 1 & 0 & 2 & 9 & 3 & 4 & 18 \\
\hline Score 2 & 0 & 0 & 2 & 4 & 2 & 8 \\
\hline Score 3 & 20 & 28 & 10 & 16 & 8 & 82 \\
\hline Summe & 20 & 30 & 30 & 30 & 30 & 140 \\
\hline
\end{tabular}




\section{Relative Häufigkeit apikale Kavität}

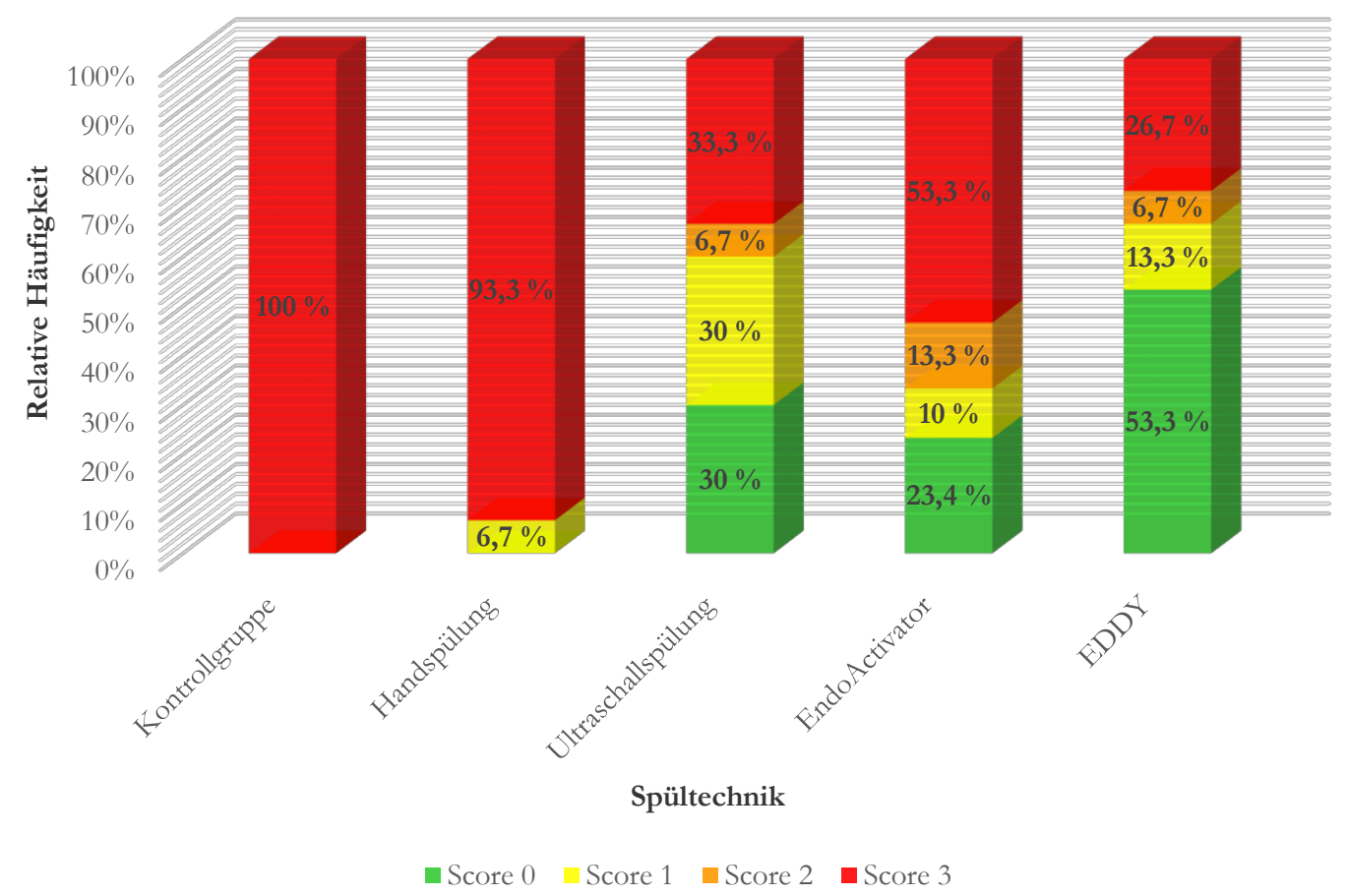

Abb. 5-5: Relative Häufigkeit der Score-Werte für die apikale Kavität

Im Vergleich mit der Tabelle 5-5 und der Abbildung 5-3, welche die Ergebnisse für die koronale Kavität zeigen, wird sichtbar, dass die apikale Kavität insgesamt besser zu reinigen war. Der Score $0, \leq 25 \%$ der Kavität sind mit Kalziumhydroxid gefüllt, wurde in $23,4 \%$ beim EndoActivator, in $30 \%$ bei der passiven Ultraschallspülung und in 53,3\% der Fälle beim EDDY erzielt. Damit wurde der Score 0 bei der apikalen Kavität fast doppelt so oft vergeben wie bei der koronalen Kavität. Im Vergleich zur koronalen Kavität erreichten erstmals alle vier Spültechniken den Score 1. Der Anteil der Handspülung ist mit $6,7 \%$ am geringsten, steigt über den EndoActivator (10\%) und den EDDY (13,3\%) auf bis zu 30\% für die passive Ultraschallspülung an. Der Score 2 ist mit jeweils 6,7\% bei dem EDDY und der passiven Ultraschallspülung und mit 13,3\% beim EndoActivator vertreten. Der Anteil der Kavitäten, die nach der Reinigung über $75 \%$ an Kalziumhydroxidrückständen aufweisen, sinkt um knapp 30\%. Die Handspülung zeigt für den Score 3 zwischen der koronalen (90\%) und apikalen $(93,3 \%)$ Kavität ein nahezu identisches Bild. Identisch ist der Wert für die passive Ultraschallspülung mit $33,3 \%$. Für den EDDY sinkt der Anteil von $40 \%$ in der 
koronalen Kavität auf $26,7 \%$ in der apikalen Kavität. Diese Tendenz ist für den EndoActivator noch eindeutiger (apikale Kavität 53,5\%, koronale Kavität 90\%).

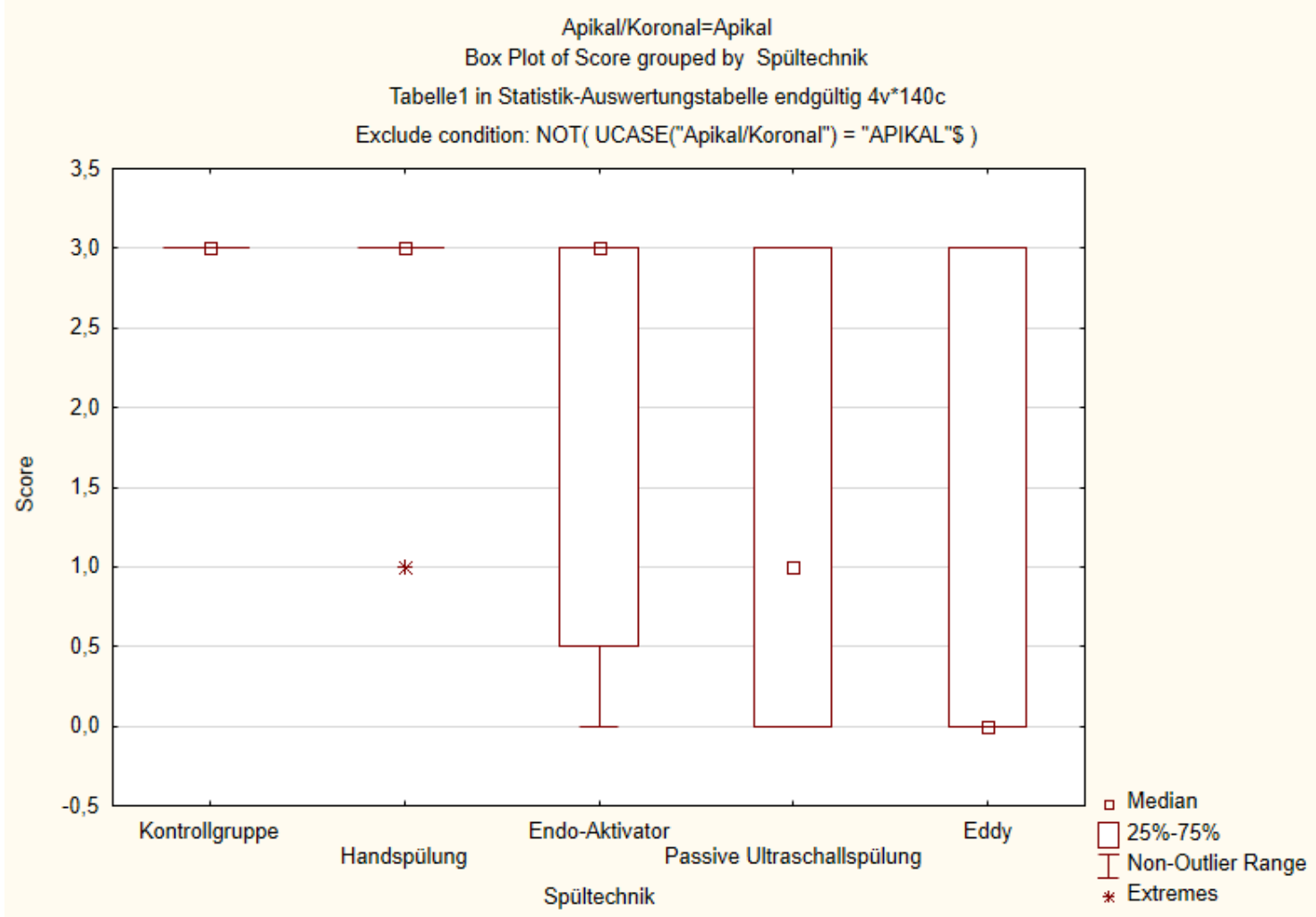

Abb. 5-6: Boxplot der verschiedenen Spültechniken für die apikale Kavität

Die Abbildung 5-6 zeigt, dass der EDDY mit einem Median von 0 die beste Reinigungswirkung für die apikale Kavität erzielt. Für die passive Ultraschallspülung wurde ein Median von 2 bestimmt. In beiden Fällen verbessert sich der Medianwert im Vergleich zur koronalen Kavität jeweils um einen Score-Wert. Für beide Spültechniken wurden alle Score-Werte vergeben. Für die Handspülung und den EndoActivator stimmen die Mediane mit denen für die koronale Kavität überein. Hatte der EndoActivator zuvor nur Extreme bei 2,5 und 2, so werden in der Mehrheit nun Werte zwischen 3 bis 0,5 erreicht. Dies verdeutlicht nochmals, dass die apikale Grube insgesamt besser von Kalziumhydroxid gereinigt wurde als die koronale Kavität. 


\section{Diskussion}

Eine erfolgreiche endodontische Behandlung beruht auf der Reduktion der Menge an Bakterien und deren Stoffwechselprodukten im Wurzelkanal auf ein Minimum. $\mathrm{Ca}(\mathrm{OH})_{2}$ ist aufgrund seiner antibakteriellen Wirkung gegen eine Vielzahl von Bakterienspezies das am häufigsten verwendete temporäre Medikament in der Endodontie (Bystrom et al. 1985; Kawashima et al. 2009). Trotzdem sollte $\mathrm{Ca}(\mathrm{OH})_{2}$ vor der endgültigen Obturation des Wurzelkanals vollständig entfernt werden. Ein Verbleib des $\mathrm{Ca}(\mathrm{OH})_{2}$ reduziert die Haftwerte des Sealers, hat negative Auswirkungen auf die Sealerpenetration (Calt und Serper 1999), führt zu einer beschleunigten Abbindegeschwindigkeit des Sealers (Margelos et al. 1997) und begünstigt die Entstehung von Microleakages (Kim und Kim 2002). Dennoch stellt die vollständige Entfernung des $\mathrm{Ca}(\mathrm{OH})_{2}$ mit den üblichen Techniken eine Herausforderung dar und wird nicht immer erreicht (Calişkan et al. 1998; Lambrianidis et al. 1999; Rödig et al. 2011; Wiseman et al. 2011; Sağsen et al. 2012; Silva et al. 2015; Topçuoğlu et al. 2015). Dieser Umstand führt zur stetigen Entwicklung neuer Methoden, Techniken und Geräte. In der vorliegenden Studie wurden die traditionelle Handspülung, die passive Ultraschallspülung, der EndoActivator und der neu entwickelte EDDY in der Entfernung von $\mathrm{Ca}(\mathrm{OH})_{2}$ aus künstlich geschaffenen Kavitäten innerhalb des Wurzelkanals bewertet und verglichen.

\subsection{Diskussion der Methode}

Um die Menge von verbliebenen Restmaterial im Wurzelkanal bzw. an der Wurzelkanalwand zu ermitteln und zu bewerten, wurden in den bisherigen Studien verschiedene Methoden genutzt, z. B. Mikro-CTs (Wiseman et al. 2011; Ma et al. 2015b; Silva et al. 2015), Rasterelektronenmikroskope (Rödig et al. 2010b; Ahmetoğlu et al. 2013), Stereomikroskope (Capar et al. 2014; Topçuoğlu et al. 2015) oder digitale Fotografien (Lee et al. 2004; Taşdemir et al. 2011). In der vorliegenden Studie wurde die Menge des zurückgebliebenen $\mathrm{Ca}(\mathrm{OH})_{2}$ mit Hilfe von digitalen Bildern und eines Score-Systems bestimmt. Diese Methodik 
stützt sich auf das von Lee et al. 2004 beschriebene und seitdem in zahlreichen Studien (van der Sluis et al. 2005a; van der Sluis et al. 2005b; van der Sluis et al. 2007b; Jiang et al. 2010a; Srirekha et al. 2013; Arslan et al. 2014b; Arslan et al. 2015) verwendete Studiendesign. Ein Nachteil dieses Verfahrens ist, dass durch die digitalen Bilder ausschließlich eine Bewertung der bedeckten Oberfläche vorgenommen und nicht das Volumen des verbliebenen $\mathrm{Ca}(\mathrm{OH})_{2}$ berechnet wird. Eine exakte Volumenbestimmung erfolgt beim Einsatz des MikroCTs. Diese Methode ist jedoch kostenintensiver.

Die Bewertung der Kavitäten und des Wurzelkanallumens erfolgte durch zwei kalibrierte Untersucher. Zwischen Untersuchern können Unterschiede in der Bewertung auftreten, z. B. aufgrund der subjektiven Wahrnehmung oder der Unterschätzung von Restmaterial in Folge der zweidimensionalen Fotografie (Ma et al. 2015b). In der vorliegenden Studie wurden eine intraindividuelle Reliabilität von 0,8925 bzw. 0,8986 und eine interindividuelle Reliabilität von 0,8156 erreicht. Es kann demnach von einer hohen Reproduzierbarkeit ausgegangen werden. Zudem unterschieden sich die Bewertungen beider Untersucher maximal um einen Score-Wert.

Das in dieser Studie angewandte anerkannte Modell der künstlich angelegten Kavitäten von Lee et al. (2004) standardisiert die Ausdehnung und die Lokalisation der Kavität und damit einhergehend die Menge des $\mathrm{Ca}(\mathrm{OH})_{2}$ vor der Spülung (Rödig et al. 2011; Capar et al. 2014). Dadurch erlaubt es einen Vergleich von Ergebnissen bisheriger Studien mit demselben Versuchsaufbau. Zudem sollen die künstlich präparierten Gruben nicht instrumentierte Wurzelkanalbereiche, wie Isthmen, Seitenkanäle oder Kanalunebenheiten, simulieren. Die anatomische Komplexität des Wurzelkanals kann jedoch nicht simuliert werden (Rödig et al. 2010c). Bei der mechanischen Spaltung des Zahnes, welche zur Bewertung des Wurzelkanals nötig ist, kann loses $\mathrm{Ca}(\mathrm{OH})_{2}$ verloren gehen und das Ergebnis beeinflussen (Ma et al. 2015b). Positiv zu bewerten ist, dass in der Beurteilung des Restmaterials nach dem Spülprozess ausschließlich $\mathrm{Ca}(\mathrm{OH})_{2}$ bewertet wird. Des Weiteren kann durch die Separation des Zahnes und die direkte Sicht auf den Wurzelkanal ein direkter Vergleich der Menge des Materials vor und nach der Spülung vorgenommen werden (Lee et al. 2004). In vorherigen Studien erfolgte ausschließlich eine Bewertung nach der Spülung (Wu und Wesselink 1995). 
Die vorliegende Studie wurde an geraden Wurzelkanälen durchgeführt. Es ist bekannt, dass die Reinigung gekrümmter Wurzelkanäle schwieriger ist. Bisher liegen Studien zur Entfernung von $\mathrm{Ca}(\mathrm{OH})_{2}$ aus gekrümmten Wurzelkanälen für die traditionelle Handspülung, die PUI und den EndoActivator vor (Wiseman et al. 2011; Ma et al. 2015b). Die Menge an Rest-Ca(OH)2 war in der Gruppe ohne maschinelle Aktivierung höher, zwischen der PUI und dem EndoActivator wurde kein signifikanter Unterschied festgestellt (Ma et al. 2015b). Nach Wiseman et al. (2011) ist die PUI dem EndoActivator dagegen überlegen. Beide Studien bedienten sich nicht des Modells der künstlich geschaffenen Kavitäten, sondern befüllten und reinigten das gesamte Wurzelkanallumen. Die Auswertung erfolgte mit Hilfe eines Mikro-CTs. Vor allem die apikale Region erwies sich als deutlich schwieriger zu reinigen ( $\mathrm{Ma}$ et al. 2015b). Die Effektivität der Spülsysteme, insbesondere des EDDY, sollte in künftigen Studien an gekrümmten Wurzelkanälen untersucht und mit den gegenwärtig erzielten Resultaten verglichen werden.

Es empfiehlt sich in zukünftigen Studien, die Spültechniken In-vivo zu untersuchen. Es muss überprüft werden, ob die Entfernung von $\mathrm{Ca}(\mathrm{OH})_{2}$ aus künstlichen Kavitäten einfacher gelingt als aus Seitenkanälen, Isthmen oder Ramifikationen, die für die anatomische Komplexität des Wurzelkanals stehen. Ferner begünstigt die Erhaltung der Zahnkrone und somit der Pulpakammer während des Experiments die Spülung in Form eines Spülreservoirs (Silva et al. 2015). In dieser Studie wurden die Zähne von koronal auf eine Einheitslänge von $19 \mathrm{~mm}$ gekürzt. Während der Aktivierung des Spülmediums ist ein Teil der Spüllösung koronal verloren gegangen. Dies lässt vermuten, dass das Volumen der Spülflüssigkeit im Wurzelkanal und der davon ausgehende Druck sanken sowie der hydrodynamische Effekt variierte.

Die Probengröße für die vier Spülgruppen mit $n=15$ und der Kontrollgruppe mit $\mathrm{n}=10$ wurde statistisch als ausreichend bewertet und bereits von anderen Autoren genutzt (van der Sluis et al. 2007b; Ahmetoğlu et al. 2013; Arslan et al. 2015; Topçuoğlu et al. 2015). 


\subsection{Diskussion der Ergebnisse}

Die Reinigungsleistung einer Wurzelkanalspülung ist von verschiedenen Faktoren abhängig, wie beispielsweise der chemischen Aktivität des Spülmediums (Calt und Serper 1999), der maschinellen Aktivierung der Spüllösung, dem Spülvolumen (Lee et al. 2004), der apikalen Aufbereitungsgröße (Falk und Sedgley 2005) und der Eindringtiefe der Spülnadel (Hsieh et al. 2007). Diese Faktoren sollten in der vorliegenden Studie keine Variablen darstellen, um die Leistung der Spültechnik möglichst nicht zu beeinflussen. Aus diesem Grund wurde aqua dest. als Spülmedium verwendet. Destilliertes Wasser besitzt im Gegensatz zu EDTA, Zitronensäure und $\mathrm{NaOCl}$ keinen zusätzlichen Reinigungseffekt, da es unter anderem anorganische Substanzen wie Kalzium nicht auflösen kann. Ein Einsatz der PUI mit 2\%igem NaOCl reduzierte $63,3 \%$ des $\mathrm{Ca}(\mathrm{OH})_{2}$ aus dem Wurzelkanal, wohingegen die PUI mit Wasser nur 6,7\% entfernte. Die Handspülung mit $2 \%$ igem $\mathrm{NaOCl}$ erreichte den gleichen Effekt wie die PUI mit Wasser (van der Sluis et al. 2007b). Eine kombinierte Anwendung von EDTA und $\mathrm{NaOCl}$ führte bei der traditionellen Handspülung zu einer verbesserten Reinigungsleistung (Margelos et al. 1997). Demnach ist die Effektivität einer Spültechnik sowohl von der chemischen Fähigkeit der Spüllösung als auch von deren mechanischer Aktivierung abhängig. Widersprüchliche Ergebnisse zweier Studien können z. B. auf die Verwendung eines anderen Spülmediums zurückzuführen sein.

Ein weiterer Faktor, der bei einem Vergleich verschiedener Studienergebnisse miteinbezogen werden muss, ist das genutzte $\mathrm{Ca}(\mathrm{OH})_{2}$-Präparat. Studien bewiesen, dass die Entfernbarkeit von $\mathrm{Ca}(\mathrm{OH})_{2}$ Unterschiede bezüglich des verwendeten $\mathrm{Ca}(\mathrm{OH})_{2}$-Präparats aufweist (Lambrianidis et al. 2006; Nandini et al. 2006). Auf Öl basierende $\mathrm{Ca}(\mathrm{OH})_{2}$-Präparate wie Metapex sind schwieriger zu entfernen als $\mathrm{Ca}(\mathrm{OH})_{2}$-Puder gemixt mit aqua dest. (Nandini et al. 2006). Das in dieser Studie verwendete UltraCal ${ } X X$ ist eine $35 \%$ ige $\mathrm{Ca}(\mathrm{OH})_{2}$-Paste in wässriger Lösung. Der $\mathrm{Ca}(\mathrm{OH})_{2}$-Gehalt des verwendeten Präparats hat keine Auswirkungen auf die Effizienz der angewandten Methode zur Entfernung des $\mathrm{Ca}(\mathrm{OH})_{2}$ (Lambrianidis et al. 1999). 
Die wesentliche Erkenntnis dieser Studie ist, dass die vollständige Entfernung des $\mathrm{Ca}(\mathrm{OH})_{2}$ trotz neu entwickelter Geräte schwierig bleibt, ultraschall- und schallgestützte Spülsysteme jedoch eine verbesserte Effektivität aufweisen.

Die Handspülung ist aufgrund der einfachen Handhabung und der geringen Kosten die gängigste Spülmethode im Rahmen einer Wurzelkanalbehandlung. Die Spülflüssigkeit wird 1-2 mm über die Spülspitze hinausbefördert. Die Eindringtiefe der Spülspitze wurde für alle Systeme auf $2 \mathrm{~mm}$ koronal der Arbeitslänge festgelegt.

In der Entfernung von $\mathrm{Ca}(\mathrm{OH})_{2}$ aus dem Wurzelkanal erzielte die traditionelle Handspülung die geringste Effizienz. Dieses Ergebnis stimmt mit vorherigen Studien überein (Salgado et al. 2009; Rödig et al. 2010c). In einer kürzlich veröffentlichten Studie ist der Restgehalt an $\mathrm{Ca}(\mathrm{OH})_{2}$ im Wurzelkanal nach der Spülung ohne Aktivierung höher als nach der schall- bzw. ultraschallgestützten Spülung (Ma et al. 2015b). Eine Erklärung für die verminderte Reinigungsleistung der Handspülung stellt der Vapor-Lock-Effekt dar. In 48\% der Fälle liegt während der traditionellen Handspülung ein Vapor-Lock-Effekt vor (Boutsioukis et al. 2014). Gasbläschen werden durch die eingeführte Spülflüssigkeit in den apikalen Wurzelkanalanteil befördert und verhindern in diesem Bereich eine Mikrozirkulation. Der fehlende Austausch des Spülmediums resultiert in einer schwächeren Reinigungsleistung der Handspülung im apikalen Bereich (Tay et al. 2010, Gade et al. 2013). Durch die Verwendung einer open-ended-Nadel und einer apikalen Präparationsgröße von ISO 40 wurde versucht, der Vapor-LockEffekt zu minimieren.

Zudem lassen sich bei der manuellen Spülung behandlerspezifische Abweichungen nicht vermeiden. Boutsioukis et al. (2007) erkannten geschlechtsspezifische Unterschiede. Außerdem ist die Handspülung anfällig für Anwendungsfehler. Eine Lageveränderung der Spülkanüle im Wurzelkanal hat Auswirkungen auf die Effektivität der manuellen Spülung. Ein Abstand mehr als $2 \mathrm{~mm}$ koronal der Arbeitslänge führte zu einer unvollständigen Reinigung des Wurzelkanals (Castelo-Baz et al. 2012).

Eine schallgestützte Aktivierungshilfe ist der EndoActivator. Die hydrodynamische Aktivierung des Spülmediums erfolgt mit einer Frequenz von 2000, 6000 oder $10000 \mathrm{cpm}$. Jiang et al. (2010a) untersuchten in einem In-vitro- 
Experiment den Mechanismus einer schallgestützten Aktivierung. Die Schwingungsamplitude der Schallspitze lag bei 1,2 +/- 0,1 mm, der apikale Wurzelkanaldurchmesser bei $\leq 0,5 \mathrm{~mm}$. Daraus resultiert ein verstärkter Wandkontakt der Activatorspitze mit der Wurzelkanalwand, wodurch ein freies Schwingen der Spülspitze im mit Spüllösung gefüllten Wurzelkanal verhindert wird. Außerdem schien weder eine Kavitation in der Spüllösung, noch an der Schallspitze selbst bzw. an der Wand des Glasmodells stattzufinden. Als Ursache nennen sie die Geschwindigkeit der Schallspitze, welche unter der kavitationsauslösenden Schwelle liegt. Dies könnte eine Erklärung für die nicht zufriedenstellende Reinigungsleistung bieten.

Im koronalen Wurzelkanalbereich erzielte der EndoActivator die gleiche Reinigungsleistung wie die manuelle Spülung. Chou et al. (2014) und Topçuoğlu et al. (2015) bekräftigen dieses Ergebnis. Im apikalen Wurzelkanalbereich zeigte sich dagegen eine Überlegenheit des EndoActivators gegenüber der Handspülung. Arslan et al. (2014b) bestätigen dem EndoActivator einen verbesserten Reinigungseffekt gegenüber der Handspülung bei der Entfernung von antibiotischen Pasten aus künstlich geschaffenen Gruben.

Der EndoActivator zeigte eine deutlich erhöhte Reinigungswirkung in der apikalen Kavität im Vergleich mit der koronalen Kavität. Abgeleitet aus den Erkenntnissen von Jiang et al. (2010a) müsste im apikalen Wurzelkanalbereich ein direkter Kontakt der Schallspitze mit dem $\mathrm{Ca}(\mathrm{OH})_{2}$ bestehen. Die vibrierende Bewegung der Schallspitze könnte dazu führen, dass das $\mathrm{Ca}(\mathrm{OH})_{2}$ in größeren Mengen direkt aus der Kavität gelöst wird. Im koronalen Wurzelkanalbereich wird diese Aufgabe durch die aktivierte Spüllösung übernommen. Die größere Entfernung der Kavität von der Schallquelle könnte zu einem Energieverlust führen.

Für den apikalen Bereich wurde kein signifikanter Unterschied zwischen EndoActivator und PUI festgestellt. Dies stimmt mit den Ergebnissen von Ma et al. (2015b) überein. Allerdings zeigen die Ergebnisse dieser Studie einen signifikanten Unterschied beider Techniken im koronalen Bereich. In diesem Bereich ist die PUI dem EndoActivator deutlich überlegen. Bestätigt wird dieses Resultat wiederum von Wiseman et al. (2011). Eine vollständige Entfernung des $\mathrm{Ca}(\mathrm{OH})_{2}$ wurde wie in vorherigen Studien nicht erreicht (Wiseman et al. 2011; 
Arslan et al. 2015; Ma et al. 2015b; Topçuoğlu et al. 2015). Die reduzierte Reinigungsleistung kann möglicherweise mit der Unfähigkeit erklärt werden, Kavitation auszulösen.

Um eine Vergleichbarkeit mit den anderen Spülspitzen herzustellen, wurde die flexible Polymerspitze in der Größe Medium gewählt. Diese entspricht den Maßen 25/.04. Die Wurzelkanäle wurden bis zur Größe 40/.04 aufbereitet. Inwieweit diese Diskrepanz Auswirkungen auf die Wirksamkeit hat, kann nicht beurteilt werden. Ein Vergleich der Reinigungseffizienz der verschiedenen Activator Tips sollte in zukünftigen Studien erfolgen.

Bei der passiven Ultraschallspülung wird Energie vom Ultraschallgerät über die Spülspitze an das Spülmedium übertragen. Entlang der Spülspitze bilden sich Schwingungsbäuche und -knoten aus (van der Sluis et al. 2007a). Durch die Schwingung wiederum entstehen Kavitationen und acoustic streaming in der Spülflüssigkeit (Ahmad et al. 1987), welche maßgeblich zum Reinigungseffekt beitragen.

Die PUI ist im koronalen und apikalen Wurzelkanaldrittel der manuellen Spülung und dem EndoActivator signifikant überlegen. Dieses Resultat stimmt mit bisherigen Studienergebnissen überein (van der Sluis et al. 2007b; Taşdemir et al. 2011; Ahmetoğlu et al. 2013; Capar et al. 2014; Arslan et al. 2015; Topçuoğlu et al. 2015). Aus mesialen Wurzelkanälen von Unterkiefermolaren konnten Wiseman et al. (2011) $69,5 \% \mathrm{Ca}(\mathrm{OH})_{2}$ mit der PUI und $48,6 \% \mathrm{Ca}(\mathrm{OH})_{2}$ mit dem EndoActivator entfernen. Wie in der vorliegenden Studie lag die Aktivierungszeit bei 3 Zyklen à 20 Sekunden. Ein direkter Vergleich der Resultate ist jedoch nur bedingt möglich, da nicht das Gruben-Modell angewandt, sondern die Entfernung des $\mathrm{Ca}(\mathrm{OH})_{2}$ aus dem gesamten Wurzelkanal bewertet wurde.

Die durch die PUI erzeugten höheren Geschwindigkeiten und das höhere Volumen der Spüllösung (Lee et al. 2004; Jiang et al. 2010b) erklären das Ausspülen von lockerem $\mathrm{Ca}(\mathrm{OH})_{2}$ aus dem Wurzelkanal (van der Sluis et al. 2007b; Wiseman et al. 2011). Jedoch wird trotz der Überlegenheit gegenüber anderen Techniken eine vollständige Entfernung des $\mathrm{Ca}(\mathrm{OH})_{2}$ aus dem Wurzelkanal auch mit der PUI nicht zuverlässig erreicht (Rödig et al. 2011, Ahmetoğlu et al. 2013, Zorzin et al. 2016). Dies deckt sich mit den Ergebnissen dieser Arbeit. Studien bestätigen der PUI ebenfalls eine Überlegenheit 
gegenüber anderen Spülsystemen, wie z.B. dem EndoVac und der SAF (Ahmetoğlu et al. 2013; Capar et al. 2014).

Es wird angenommen, dass eine Aktivierung des Spülmediums den Austausch der Spüllösung fördert, im Wurzelkanal bereits abgestandene Spüllösung wird durch frisch injizierte ersetzt (Ma et al. 2015b). Die in Bewegung versetzte Spüllösung kann loses $\mathrm{Ca}(\mathrm{OH})_{2}$ aufnehmen und aus dem Wurzelkanal schwemmen. Außerdem wird durch die Aktivierung der Flüssigkeit die Penetration der Spüllösung in nicht bearbeitete Wurzelkanalbereiche gefördert (Ma et al. 2015b). Das Spülvolumen stellt eine zusätzliche Einflussgröße auf die Entfernung von $\mathrm{Ca}(\mathrm{OH})_{2}$ dar. Mit steigendem Spülvolumen wurden weniger $\mathrm{Ca}(\mathrm{OH}) 2$-Rückstände hinterlassen (Zorzin et al. 2016). Bei $8 \mathrm{ml}$ Spülvolumen wurde ein $\mathrm{Ca}(\mathrm{OH})_{2}$-Rückstand von $5 \%$ ermittelt (Zorzin et al. 2016). Dieser Wert kann allerdings nicht direkt mit den in dieser Studie ermittelten Werten verglichen werden, da als Spülmedium 3\%iges $\mathrm{NaOCl}$ und 40\%ige Zitronensäure verwendet wurden. In der vorliegenden Studie wurde das Spülvolumen für alle Spülsysteme auf $9 \mathrm{ml}$ aqua dest. standardisiert.

Die in dieser Studie verwendete IRRI S 21/25 wurde gewählt, um eine Vergleichbarkeit mit den anderen Spülspitzen herzustellen. Um die maximale Reinigungswirkung zu erzielen, sollte die Feile frei im Wurzelkanal schwingen (van der Sluis et al. 2007a). Bei einem auf ISO-Größe 40 erweiterten Wurzelkanal konnte eine Dämpfung der Schwingung vermieden werden. Des Weiteren wurde eine periodische Applikation der Spüllösung gewählt. Dies ermöglichte ebenfalls eine bessere Vergleichbarkeit, da die Applikation beim EndoActivator und dem EDDY ebenfalls periodisch erfolgte. Die Insertionstiefe der Spülnadel in den Wurzelkanal konnte durch die Farbmarkierung einfach kontrolliert werden.

Vor kurzem wurde der EDDY auf dem Markt eingeführt. Aktuell liegen nur wenige Studien zum Einsatz mit dem EDDY vor, zur Entfernung von $\mathrm{Ca}(\mathrm{OH})_{2}$ aus dem Wurzelkanal ist gegenwärtig keine Studie veröffentlicht. Sein Frequenzbereich liegt zwischen 5000 bis $6000 \mathrm{~Hz}$. Die Ausbildung von Schallknoten und -bäuchen sorgt für eine Bewegung des Spülmediums um die oszillierende Spülspitze. Zusätzlich erzielt der EDDY wie die PUI die beiden Phänomene Kavitation und acoustic streaming. Das Implodieren der Gasbläschen, die damit verbundene freigesetzte Energie und die durch die hochfrequenten Bewegungen ver- 
ursachten Wirbelströmungen sollen zu einem verbesserten Reinigungseffekt führen. In der vorliegenden Studie erzielte der EDDY die beste Reinigungsleistung. Ein signifikanter Unterschied zwischen den beiden Techniken EDDY und PUI liegt jedoch weder für das koronale noch das apikale Wurzelkanaldrittel vor. Die ähnliche Wirkweise der beiden Spültechniken ließ dieses Ergebnis vermuten.

Urban et al. (2017) bewerteten verschiedene Aktivierungssysteme bezüglich ihrer Reinigungsleistung. Der EDDY, die PUI und der EndoActivator entfernten signifikant mehr Debris als die manuelle Spülung. In der Entfernung des smear layers wurde eine Überlegenheit des EDDY und der PUI gegenüber der Handspülung festgestellt (Urban et al. 2017). Die gegenwärtige Studie bestätigt die Rangliste der einzelnen Spülsysteme untereinander.

Laut Jiang et al. (2011) resultiert eine gesteigerte Reinigungsleistung aus der Zunahme der Ultraschallintensität. Mit steigender Intensität erhöhen sich die Feilenamplitude und die Fließgeschwindigkeit der Spüllösung um die Feile. Die in dieser Studie verwendete minimale Schwingungsfrequenz lag bei $28 \mathrm{kHz}$ für die PUI. Der EDDY arbeitet dagegen in einem Frequenzbereich von 5000 bis $6000 \mathrm{~Hz}$. Eine verbesserte Reinigungsleistung ergibt sich demnach nicht ausschließlich aus einer gesteigerten Frequenzintensität. Diese These sollte in künftigen Studien weiter untersucht werden.

Die Ergebnisse zeigen eine verbesserte Reinigung der apikalen Grube für alle Spültechniken im Vergleich zur koronalen Grube. Dies steht im Widerspruch zu bisherigen Studien, welche erhebliche Mengen an $\mathrm{Ca}(\mathrm{OH})_{2}$ im apikalen Wurzelkanalbereich fanden (Lambrianidis et al. 2006; Nandini et al. 2006; Ma et al. 2015b). Laut Lambrianidis et al. (2006) tendiert $\mathrm{Ca}(\mathrm{OH})_{2} \mathrm{zu}$ einer apikalen Akkumulation während der Säuberung, welche den Spülprozess erschwert. Außerdem kann im koronalen Wurzelkanalbereich durch eine höhere Geschwindigkeit und ein größeres Volumen der Spülflüssigkeit während des Spülvorgangs eine verbesserte Reinigungsleistung erzielt werden (Lee et al. 2004). In vorherigen Studien wird die limitierte Einführung der Spülkanüle und der Ultraschallspitze, Arbeitslänge minus $2 \mathrm{~mm}$, als Ursache für den fehlenden direkten Effekt der Ultraschallaktivität genannt (Nandini et al. 2006; Wiseman et al. 2011). In der vorliegenden Studie wurden die Wurzelkanäle auf eine apikale 
Aufbereitungsgröße von 40/.04 präpariert. Mit einem apikalen Präparationsdurchmesser der ISO-Größe 40 kann eine ausreichende Spülung des Wurzelkanals erfolgen (Ram 1977). Zusätzlich konnte durch die gesteigerte Konizität des Wurzelkanals ein Austausch des neu injizierten Spülmediums mit dem verunreinigten beobachtet werden. Mit Klebewachs wurde ein apikaler Verschluss vorgenommen. Dieser sollte ein Entrinnen der Spüllösung über das Foramen apicale verhindern und die In-vivo-Situation simulieren (Schoeffel 2007). Die Insertionstiefe der Spülnadel mit ausreichend Raum zum Flüssigkeitsaustausch und die apikale Versieglung könnten als Erklärung für die gesteigerte Reinigung der apikalen Grube dienen. Der Strömungsfluss der Spüllösung könnte direkt auf die apikale Grube gerichtet sein. An dieser Stelle muss wiederholt darauf hingewiesen werden, dass die künstlich angelegten Kavitäten nicht die anatomische Komplexität des Wurzelkanalsystems simulieren. Die Studie von Rödig et al. (2010c) bestätigt das vorliegende Ergebnis. Sie untersuchten die Wirksamkeit von $1 \%$ igem $\mathrm{NaOCl}, 10 \%$ iger Zitronensäure und $20 \%$ igem EDTA in der Entfernung von $\mathrm{Ca}(\mathrm{OH})_{2}$ aus künstlich angelegten Gruben im apikalen und koronalen Wurzelkanaldrittel. Für alle Spüllösungen wurde eine verbesserte Reinigungsleistung der apikalen Gruben festgestellt. Das Studiendesign gleicht dem in dieser Studie angewandten. Hinsichtlich des Vergleichs der Entfernbarkeit von $\mathrm{Ca}(\mathrm{OH})_{2}$ aus apikalen und koronalen Kavitäten sollten weitere Studien mit demselben Studiendesign folgen.

Schließlich bleibt die Haupterkenntnis, dass eine vollständige Entfernung des $\mathrm{Ca}(\mathrm{OH})_{2}$ nicht sicher erfolgte. Jedoch wurde unabhängig von der Art der Aktivierung der Spüllösung die Reinigungsleistung bezüglich der Entfernung von $\mathrm{Ca}(\mathrm{OH})_{2}$ aus künstlich angelegten Gruben innerhalb des Wurzelkanals gesteigert. 


\section{Zusammenfassung}

Ziel der Studie: Ein Vergleich zwischen traditionellen (manuelle Spülung, Passive Ultraschallspülung) und neuartigen Spültechniken (EDDY, EndoActivator) zur Entfernung von Kalziumhydroxid aus dem Wurzelkanal. Die unterschiedlichen Spültechniken werden miteinander verglichen und die Wirksamkeit der Spültechnik im koronalen und apikalen Wurzelkanaldrittel untersucht.

Material und Methode: 80 humane extrahierte Oberkiefer-Inzisivi, Eckzähne und einwurzelige Prämolaren mit rundem Wurzelquerschnitt und gerader Wurzel wurden auf eine Einheitslänge von 19 mm gekürzt. Die maschinelle Präparation erfolgte standardisiert mit Nickel-Titan-Instrumenten (Mtwo®-System) im CrownDown-Verfahren bis zur Größe 40/.04 auf eine Arbeitslänge von 18 mm. Die Zähne wurden entlang der mesial-distalen Achse gespalten. Je Wurzelhälfte wurde entweder eine apikale Grube im Abstand von 2-6 mm zum Apex oder eine koronale Grube im Abstand von 10-14 mm zum Apex präpariert. Die Ausdehnung der Kavität betrug $4 \mathrm{~mm}$ in der Länge, 0,2 $\mathrm{mm}$ in der Breite und 0,5 $\mathrm{mm}$ in der Tiefe. Unter einem Stereomikroskop erfolgte das Befüllen der Kavitäten mit UltraCaI®XS. Anschließend wurden die beiden Zahnhälften wieder zusammengesetzt und der gesamte Wurzelkanal mit Kalziumhydroxid gefüllt, die Homogenität der Füllung wurde durch eine Einzelzahnaufnahme röntgenologisch kontrolliert. Der Wurzelkanaleingang wurde mit einem Wattekügelchen und Cavit ${ }^{\mathrm{TM}} \mathrm{W}$ luftdicht verschlossen, das Foramen apicale mit Klebewachs versiegelt, um ein geschlossenes System zu simulieren. Die Lagerung erfolgte für 7 Tage bei $37{ }^{\circ} \mathrm{C}$ und $100 \%$ iger Luftfeuchtigkeit im Inkubator. Die Proben wurden randomisiert in fünf Gruppen, basierend auf dem Spülprotokoll aufgeteilt: EndoActivator $(n=15)$, EDDY $(n=15)$, passive Ultraschallspülung $(n=15)$, Handspülung ( $n=15)$ und Kontrollgruppe $(n=10) .9 \mathrm{ml}$ aqua dest. dienten in allen Gruppen als Spüllösung. Die Zähne wurden nach erfolgter Spülung wieder separiert. Anhand von Fotografien wurde die Auswertung durch zwei kalibrierte Untersucher mit Hilfe eines vierstufigen Score-Systems vorgenommen. Die statistische Auswertung erfolgte mit nichtparametrischen Analyseverfahren, dem 
Post-Hoc-Vergleich durch Mann-Whitney-U-Test und der Korrektur nach Bonferroni-Holm sowie dem Kruskal-Wallis-Test. Das Signifikanzniveau wurde auf $\alpha \leq 0,05$ festgelegt. 10 Zähne wurden für Vorversuche benötigt.

Ergebnis: In der Entfernung von Kalziumhydroxid aus der koronalen Kavität sind die passive Ultraschallspülung und der EDDY der Handspülung und dem EndoActivator signifikant überlegen. Für den apikalen Bereich zeigen die passive Ultraschallspülung und der EDDY eine signifikante Überlegenheit gegenüber der Handspülung. Dennoch erreicht keines der angewendeten Spülsysteme eine vollständige Entfernung des Kalziumhydroxids aus den Kavitäten.

Schlussfolgerung: Eine vollständige Entfernung von Kalziumhydroxid aus dem Wurzelkanal erscheint trotz neu entwickelter Spülsysteme schwierig. Ultraschallund schallgestützte Spülsysteme können die Effektivität verbessern. 


\section{$8 \quad$ Anhang}

Tab. 8-1: Übersicht der Bewertung

\begin{tabular}{|c|c|c|c|c|c|}
\hline \multirow[b]{2}{*}{ Spültechnik } & \multirow[b]{2}{*}{ Probe } & \multicolumn{2}{|c|}{ Bewerter A } & \multicolumn{2}{|c|}{ Bewerter B } \\
\hline & & $\begin{array}{c}\text { apikale } \\
\text { Grube }\end{array}$ & $\begin{array}{c}\text { koronale } \\
\text { Grube }\end{array}$ & $\begin{array}{c}\text { apikale } \\
\text { Grube }\end{array}$ & $\begin{array}{c}\text { koronale } \\
\text { Grube }\end{array}$ \\
\hline \multirow{10}{*}{ Kontrollgruppe } & 1 & 3 & 3 & 3 & 3 \\
\hline & 2 & 3 & 3 & 3 & 3 \\
\hline & 3 & 3 & 3 & 3 & 3 \\
\hline & 4 & 3 & 3 & 3 & 3 \\
\hline & 5 & 3 & 3 & 3 & 3 \\
\hline & 6 & 3 & 3 & 3 & 3 \\
\hline & 7 & 3 & 3 & 3 & 3 \\
\hline & 8 & 3 & 3 & 3 & 3 \\
\hline & 9 & 3 & 3 & 3 & 3 \\
\hline & 10 & 3 & 3 & 3 & 3 \\
\hline \multirow{15}{*}{ Handspülung } & 11 & 3 & 3 & 3 & 3 \\
\hline & 12 & 3 & 3 & 3 & 3 \\
\hline & 13 & 3 & 3 & 3 & 3 \\
\hline & 14 & 3 & 3 & 3 & 3 \\
\hline & 15 & 3 & 3 & 3 & 2 \\
\hline & 16 & 3 & 3 & 3 & 3 \\
\hline & 17 & 3 & 3 & 3 & 3 \\
\hline & 18 & 3 & 3 & 3 & 3 \\
\hline & 19 & 3 & 3 & 3 & 3 \\
\hline & 20 & 3 & 3 & 3 & 3 \\
\hline & 21 & 3 & 3 & 3 & 3 \\
\hline & 22 & 3 & 1 & 3 & 2 \\
\hline & 23 & 1 & 3 & 1 & 3 \\
\hline & 24 & 3 & 3 & 3 & 3 \\
\hline & 25 & 3 & 3 & 3 & 3 \\
\hline
\end{tabular}




\begin{tabular}{|c|c|c|c|c|c|}
\hline \multirow[b]{2}{*}{ Spültechnik } & \multirow[b]{2}{*}{ Probe } & \multicolumn{2}{|c|}{ Bewerter A } & \multicolumn{2}{|c|}{ Bewerter B } \\
\hline & & $\begin{array}{c}\text { apikale } \\
\text { Grube }\end{array}$ & $\begin{array}{l}\text { koronale } \\
\text { Grube }\end{array}$ & $\begin{array}{c}\text { apikale } \\
\text { Grube }\end{array}$ & $\begin{array}{c}\text { koronale } \\
\text { Grube }\end{array}$ \\
\hline \multirow{15}{*}{ EndoActivator } & 26 & 2 & 3 & 2 & 3 \\
\hline & 27 & 2 & 3 & 2 & 3 \\
\hline & 28 & 3 & 3 & 3 & 3 \\
\hline & 29 & 3 & 2 & 3 & 2 \\
\hline & 30 & 3 & 3 & 3 & 3 \\
\hline & 31 & 0 & 3 & 0 & 3 \\
\hline & 32 & 3 & 3 & 3 & 3 \\
\hline & 33 & 3 & 3 & 3 & 3 \\
\hline & 34 & 3 & 3 & 3 & 3 \\
\hline & 35 & 0 & 3 & 0 & 2 \\
\hline & 36 & 1 & 3 & 1 & 3 \\
\hline & 37 & 1 & 3 & 0 & 3 \\
\hline & 38 & 3 & 3 & 3 & 3 \\
\hline & 39 & 3 & 3 & 3 & 3 \\
\hline & 40 & 0 & 3 & 0 & 3 \\
\hline \multirow{15}{*}{$\begin{array}{c}\text { Passive } \\
\text { Ultraschallspülung }\end{array}$} & 41 & 0 & 0 & 0 & 0 \\
\hline & 42 & 0 & 3 & 1 & 2 \\
\hline & 43 & 3 & 1 & 3 & 2 \\
\hline & 44 & 3 & 0 & 3 & 0 \\
\hline & 45 & 1 & 0 & 1 & 0 \\
\hline & 46 & 0 & 2 & 0 & 2 \\
\hline & 47 & 0 & 3 & 0 & 3 \\
\hline & 48 & 1 & 0 & 1 & 0 \\
\hline & 49 & 0 & 1 & 0 & 1 \\
\hline & 50 & 3 & 3 & 3 & 3 \\
\hline & 51 & 3 & 3 & 3 & 3 \\
\hline & 52 & 2 & 1 & 2 & 1 \\
\hline & 53 & 1 & 2 & 1 & 2 \\
\hline & 54 & 1 & 3 & 1 & 2 \\
\hline & 55 & 3 & 3 & 3 & 3 \\
\hline
\end{tabular}




\begin{tabular}{|c|c|c|c|c|c|}
\hline \multirow[b]{2}{*}{ Spültechnik } & \multirow[b]{2}{*}{ Probe } & \multicolumn{2}{|c|}{ Bewerter A } & \multicolumn{2}{|c|}{ Bewerter B } \\
\hline & & $\begin{array}{c}\text { apikale } \\
\text { Grube }\end{array}$ & $\begin{array}{c}\text { koronale } \\
\text { Grube }\end{array}$ & $\begin{array}{c}\text { apikale } \\
\text { Grube }\end{array}$ & $\begin{array}{c}\text { koronale } \\
\text { Grube }\end{array}$ \\
\hline \multirow{15}{*}{ EDDY } & 56 & 3 & 2 & 3 & 2 \\
\hline & 57 & 0 & 1 & 0 & 1 \\
\hline & 58 & 0 & 0 & 0 & 0 \\
\hline & 59 & 0 & 1 & 0 & 1 \\
\hline & 60 & 0 & 3 & 0 & 3 \\
\hline & 61 & 0 & 0 & 0 & 0 \\
\hline & 62 & 0 & 0 & 0 & 0 \\
\hline & 63 & 0 & 0 & 0 & 0 \\
\hline & 64 & 1 & 3 & 1 & 3 \\
\hline & 65 & 0 & 0 & 0 & 0 \\
\hline & 66 & 2 & 3 & 2 & 3 \\
\hline & 67 & 3 & 1 & 3 & 1 \\
\hline & 68 & 1 & 3 & 1 & 3 \\
\hline & 69 & 3 & 3 & 3 & 3 \\
\hline & 70 & 3 & 3 & 3 & 3 \\
\hline
\end{tabular}




\section{$9 \quad$ Materialliste}

Tab. 9-1: Materialliste

\begin{tabular}{|c|c|}
\hline Produkt & Firma \\
\hline $\begin{array}{l}\text { Applikationskanüle Endo-Eze®Tips, } 30 \\
\text { Gauge }\end{array}$ & $\begin{array}{l}\text { Ultradent Products, Inc., South Jordan, } \\
\text { Utah, USA }\end{array}$ \\
\hline Aqua dest. & B. Braun, Melsungen, Deutschland \\
\hline Cavit $^{\mathrm{TM} W}$ & 3M ESPE, Neuss, Deutschland \\
\hline Dental-Mikroskop „OPMI pico“ & Carl Zeiss, Jena, Deutschland \\
\hline Diamantierte Trennscheibe & Horico, Berlin, Deutschland \\
\hline Diamantierter Schallaufsatz & KaVo, Biberach/Riß, Deutschland \\
\hline Diamantschleifkörper & Komet, Lemgo, Deutschland \\
\hline 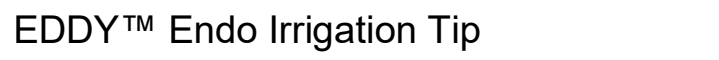 & VDW, München, Deutschland \\
\hline $\begin{array}{l}\text { EDDY }{ }^{\mathrm{TM}} \text {-kompatibler Airscaler Proxeo } \\
\text { ZA-55LM }\end{array}$ & W\&H Dentalwerk, Bürmoos, Österreich \\
\hline EDTA $(17 \%)$ & $\begin{array}{l}\text { Lege artis Pharma, Dettenhausen, } \\
\text { Deutschland }\end{array}$ \\
\hline Endo IT Motor & VDW, München, Deutschland \\
\hline $\begin{array}{l}\text { EndoActivator Activator Tip Medium } \\
(25 / .04)\end{array}$ & $\begin{array}{l}\text { DENTSPLY Maillefer, Santa Barbara, } \\
\text { USA }\end{array}$ \\
\hline EndoActivator Handstück & $\begin{array}{l}\text { DENTSPLY Maillefer, Santa Barbara, } \\
\text { USA }\end{array}$ \\
\hline Fingerspreader ISO-Größe 35 & VDW, München, Deutschland \\
\hline Geo Cervikalwachs & Renfert, Hilzingen, Deutschland \\
\hline Geo Klebewachs & Renfert, Hilzingen, Deutschland \\
\hline Guttapercha-Stifte Größe 40/.02 \& 20/.02 & VDW, München, Deutschland \\
\hline Hypocal@ Economy-Pack & Merz Dental, Lütjenburg, Deutschland \\
\hline Inkubator Climacell 111 & $\begin{array}{l}\text { MMM Medcenter, München, } \\
\text { Deutschland }\end{array}$ \\
\hline Interim-Stand REF 495 & VDW, München, Deutschland \\
\hline Kamera Leica MC 170 HD & Leica Camera AG, Wetzlar, Deutschland \\
\hline
\end{tabular}




\begin{tabular}{|c|c|}
\hline Kunststoffbehälter & Inkcompany, Jena, Deutschland \\
\hline Mtwo®-Feilen bis Größe 40/.04 & VDW, München, Deutschland \\
\hline Mtwo®-SystemBox & VDW, München, Deutschland \\
\hline $\mathrm{NaOCl}(3 \%)$ & Hedinger, Stuttgart, Deutschland \\
\hline Novoflex Macrolight plus & $\begin{array}{l}\text { Novoflex Präzisionstechnik, } \\
\text { Memmingen, Deutschland }\end{array}$ \\
\hline Papierspitzen (color) & ORBIS Dental, Münster, Deutschland \\
\hline Plexiglas XT - Acrylglasrohr & Röhm, Brüttisellen, Schweiz \\
\hline Reamer & VDW, München, Deutschland \\
\hline Röntgengerät Heliodent DS (D3302) & Sirona Dental, Bensheim, Deutschland \\
\hline Scaler & HLW, Wernberg-Köblitz, Deutschland \\
\hline Silaplast Futur & Detax, Ettlingen, Deutschland \\
\hline SONICflex-Handstück 2003L & KaVo, Biberach/Riß, Deutschland \\
\hline Spritze 5 ml „BD Discardit ${ }^{\mathrm{TM}}$ II“ & $\begin{array}{l}\text { Becton, Dickinson and Company, } \\
\text { Franklin Lakes, USA }\end{array}$ \\
\hline Spülnadel „VMK-EndoNeedle“ & Vedefar N.V., Dilbeek, Belgien \\
\hline Stereomikroskop Stemi SV 11 & Carl Zeiss, Jena, Deutschland \\
\hline UltraCalßXS & $\begin{array}{l}\text { Ultradent Products, Inc., South Jordan, } \\
\text { Utah, USA }\end{array}$ \\
\hline $\begin{array}{l}\text { Ultraschallgerät VDW. Ultra® - Dental } \\
\text { ultrasonic generator }\end{array}$ & VDW, München, Deutschland \\
\hline Ultraschallspitze IRRI S 21/25 & VDW, München, Deutschland \\
\hline Wachsmesser & $\begin{array}{l}\text { Henry Schein Dental, Langen, } \\
\text { Deutschland }\end{array}$ \\
\hline Wattekügelchen & Pluradent, Offenbach, Deutschland \\
\hline Winkelstück (rot/grün) & NSK, Tochigi, Japan \\
\hline Zahnbürste meridol & GABA, Hamburg, Deutschland \\
\hline
\end{tabular}




\section{Literaturverzeichnis}

Abbott PV (1990): Medicaments: Aids to success in endodontics. Part 2. Clinical recommendations. Aust Dent J $\underline{35}, 491-496$

Abou-Rass M, Piccinino MV (1982): The effectiveness of four clinical irrigation methods on the removal of root canal debris. Oral Surg Oral Med Oral Pathol $\underline{54}, 323-328$

Agrawal VS, Kapoor S (2012): An in vitro scanning electron microscopic study comparing the efficacy of passive ultrasonic and syringe irrigation methods using sodium hypochlorite in removal of debris from the root canal system. J Ir Dent Assoc $\underline{58}, 156-$ 161

Ahmad M, Pitt Ford TJ, Crum LA (1987): Ultrasonic debridement of root canals: acoustic streaming and its possible role. J Endod $\underline{13}, 490-499$

Ahmad M, Roy RA, Kamarudin AG (1992): Observations of acoustic streaming fields around an oscillating ultrasonic file. Endod Dent Traumatol $\underline{8}, 189-194$

Ahmad M, Pitt Ford TR, Crum LA, Walton AJ (2009): Ultrasonic debridement of root canals: acoustic cavitation and its relevance. 1988. Int Endod J 42, 391-398

Ahmetoğlu F, Şımşek N, Keleş A, Ocak MS, Er K (2013): Efficacy of self-adjusting file and passive ultrasonic irrigation on removing calcium hydroxide from root canals. Dent Mater J $\underline{32}, 1005-1010$

Akcay M, Arslan H, Durmus N, Mese M, Capar ID (2016): Dentinal tubule penetration of AH Plus, iRoot SP, MTA fillapex, and guttaflow bioseal root canal sealers after different final irrigation procedures: A confocal microscopic study. Lasers Surg Med $\underline{48}, 70-76$

Akhlaghi N, Khademi A (2015): Outcomes of vital pulp therapy in permanent teeth with different medicaments based on review of the literature. Dent Res J $\underline{12}, 406-417$

Al-Jadaa A, Paqué F, Attin T, Zehnder M (2009): Necrotic pulp tissue dissolution by passive ultrasonic irrigation in simulated accessory canals: impact of canal location and angulation. Int Endod J 42, 59-65

Alturaiki S, Lamphon H, Edrees H, Ahlquist M (2015): Efficacy of 3 different irrigation systems on removal of calcium hydroxide from the root canal: a scanning electron microscopic study. J Endod $\underline{41}, 97-101$

Andersen M, Lund A, Andreasen JO, Andreasen FM (1992): In vitro solubility of human pulp tissue in calcium hydroxide and sodium hypochlorite. Endod Dent Traumatol $\underline{8}, 104$ 108 
Andrabi SM, Kumar A, Zia A, Iftekhar H, Alam S, Siddiqui S (2014): Effect of passive ultrasonic irrigation and manual dynamic irrigation on smear layer removal from root canals in a closed apex in vitro model. J Investig Clin Dent $\underline{5}, 188-193$

Antunes HS, Rôças IN, Alves FR, Siqueira JF (2015): Total and Specific Bacterial Levels in the Apical Root Canal System of Teeth with Post-treatment Apical Periodontitis. J Endod 41, 1037-1042

Arslan H, Capar ID, Saygili G, Gok T, Akcay M (2014a): Effect of photon-initiated photoacoustic streaming on removal of apically placed dentinal debris. Int Endod J $\underline{47}$, 1072-1077

Arslan H, Akcay M, Capar ID, Ertas H, Ok E, Uysal B (2014b): Efficacy of needle irrigation, EndoActivator, and photon-initiated photoacoustic streaming technique on removal of double and triple antibiotic pastes. J Endod $\underline{40}, 1439-1442$

Arslan H, Akcay M, Capar ID, Saygili G, Gok T, Ertas H (2015): An in vitro comparison of irrigation using photon-initiated photoacoustic streaming, ultrasonic, sonic and needle techniques in removing calcium hydroxide. Int Endod J $\underline{48}, 246-251$

Asnaashari M, Safavi N (2013): Disinfection of Contaminated Canals by Different Laser Wavelengths, while Performing Root Canal Therapy. J Lasers Med Sci 4, 8-16

Athanassiadis B, Abbott PV, Walsh LJ (2007): The use of calcium hydroxide, antibiotics and biocides as antimicrobial medicaments in endodontics. Aust Dent J $\underline{52}, 64-82$

Azim AA, Aksel H, Zhuang T, Mashtare T, Babu JP, Huang GT (2016): Efficacy of 4 Irrigation Protocols in Killing Bacteria Colonized in Dentinal Tubules Examined by a Novel Confocal Laser Scanning Microscope Analysis. J Endod 42, 928-934

Balvedi RP, Versiani MA, Manna FF, Biffi JC (2010): A comparison of two techniques for the removal of calcium hydroxide from root canals. Int Endod J $\underline{43}, 763-768$

Barbizam JV, Trope M, Teixeira EC, Tanomaru-Filho M, Teixeira FB (2008): Effect of calcium hydroxide intracanal dressing on the bond strength of a resin-based endodontic sealer. Braz Dent J 19, 224-227

Basrani B, Tjäderhane L, Santos JM, Pascon E, Grad H, Lawrence HP, Friedman S (2003): Efficacy of chlorhexidine- and calcium hydroxide-containing medicaments against Enterococcus faecalis in vitro. Oral Surg Oral Med Oral Pathol Oral Radiol Endod $\underline{96}, 618-624$

Baumgartner JC (1991): Microbiologic and pathologic aspects of endodontics. Curr Opin Dent $1,737-743$

Baumgartner JC, Cuenin PR (1992): Efficacy of several concentrations of sodium hypochlorite for root canal irrigation. J Endod $\underline{18}, 605-612$

Bhardwaj A, Velmurugan N, Sumitha, Ballal S (2013): Efficacy of passive ultrasonic irrigation with natural irrigants (Morinda citrifolia juice, Aloe Vera and Propolis) in 
comparison with $1 \%$ sodium hypochlorite for removal of $\mathrm{E}$. faecalis biofilm: an in vitro study. Indian J Dent Res 24, 35-41

Blank-Gonçalves LM, Nabeshima CK, Martins GH, Machado ME de L (2011): Qualitative analysis of the removal of the smear layer in the apical third of curved roots: conventional irrigation versus activation systems. J Endod $\underline{37}$, 1268-1271

Blanscet ML, Tordik PA, Goodell GG (2008): An agar diffusion comparison of the antimicrobial effect of calcium hydroxide at five different concentrations with three different vehicles. J Endod 34, 1246-1248

Blome B, Braun A, Sobarzo V, Jepsen S (2008): Molecular identification and quantification of bacteria from endodontic infections using real-time polymerase chain reaction. Oral Microbiol Immunol 23, 384-390

Boutsioukis C, Lambrianidis T, Kastrinakis E, Bekiaroglou P (2007): Measurement of pressure and flow rates during irrigation of a root canal ex vivo with three endodontic needles. Int Endod J 40, 504-513

Boutsioukis C, Lambrianidis T, Kastrinakis E (2009): Irrigant flow within a prepared root canal using various flow rates: a Computational Fluid Dynamics study. Int Endod J $\underline{42}$, 144-155

Boutsioukis C, Verhaagen B, Versluis M, Kastrinakis E, Wesselink PR, van der Sluis LW (2010a): Evaluation of irrigant flow in the root canal using different needle types by an unsteady computational fluid dynamics model. J Endod $\underline{36}, 875-879$

Boutsioukis C, Verhaagen B, Versluis M, Kastrinakis E, van der Sluis LW (2010b): Irrigant flow in the root canal: experimental validation of an unsteady Computational Fluid Dynamics model using high-speed imaging. Int Endod J 43, 393-403

Boutsioukis C, Gogos C, Verhaagen B, Versluis M, Kastrinakis E, van der Sluis LW (2010c): The effect of apical preparation size on irrigant flow in root canals evaluated using an unsteady Computational Fluid Dynamics model. Int Endod J 43, 874-881

Boutsioukis C, Lambrianidis T, Verhaagen B, Versluis M, Kastrinakis E, Wesselink PR, van der Sluis LW (2010d): The effect of needle-insertion depth on the irrigant flow in the root canal: evaluation using an unsteady computational fluid dynamics model. J Endod $\underline{36}, 1664-1668$

Boutsioukis C, Gogos C, Verhaagen B, Versluis M, Kastrinakis E, van der Sluis LW (2010e): The effect of root canal taper on the irrigant flow: evaluation using an unsteady Computational Fluid Dynamics model. Int Endod J 43, 909-916

Boutsioukis C, Verhaagen B, Walmsley AD, Versluis M, van der Sluis LW (2013): Measurement and visualization of file-to-wall contact during ultrasonically activated irrigation in simulated canals. Int Endod J 46, $1046-1055$

Boutsioukis C, Kastrinakis E, Lambrianidis T, Verhaagen B, Versluis M, van der Sluis LW (2014): Formation and removal of apical vapor lock during syringe irrigation: a 
combined experimental and Computational Fluid Dynamics approach. Int Endod J $\underline{47}$, 191-201

Braun A, Nolden R (1999): Applikation eines Kalziumhydroxid-Pastenpräparates in ISOgenormten Kanallumina. Dtsch Zahnärztl Z $\underline{54}$, 258-261

Brännström M, Johnson G (1974): Effects of various conditioners and cleaning agents on prepared dentin surfaces: a scanning electron microscopic investigation. J Prosthet Dent $\underline{31}, 422-430$

Brito PR, Souza LC, Machado de Oliveira JC, Alves FR, De-Deus G, Lopes HP, Siqueira JF Jr. (2009): Comparison of the effectiveness of three irrigation techniques in reducing intracanal Enterococcus faecalis populations: an in vitro study. J Endod 35, 1422-1427

Brunner E, Domhof S, Langer F: Nonparametric Analysis of Longitudinal Data in Factorial Experiments. John Wiley \& Sons, New York 2002

Byström A, Sundqvist G (1981): Bacteriologic evaluation of the efficacy of mechanical root canal instrumentation in endodontic therapy. Scand J Dent Res $\underline{89}, 321-328$

Bystrom A, Claesson R, Sundqvist G (1985): The antibacterial effect of camphorated paramonochlorophenol, camphorated phenol and calcium hydroxide in the treatment of infected root canals. Endod Dent Traumatol 1, 170-175

Cachovan G, Schiffner U, Altenhof S, Guentsch A, Pfister W, Eick S (2013): Comparative antibacterial efficacies of hydrodynamic and ultrasonic irrigation systems in vitro. $\mathrm{J}$ Endod $\underline{39}, 1171-1175$

Calişkan MK, Türkün M, Türkün LS (1998): Effect of calcium hydroxide as an intracanal dressing on apical leakage. Int Endod J $\underline{31}, 173-177$

Calt S, Serper A (1999): Dentinal tubule penetration of root canal sealers after root canal dressing with calcium hydroxide. J Endod $\underline{25}, 431-433$

Capar ID, Aydinbelge HA (2013): Surface change of root canal dentin after the use of irrigation activation protocols: electron microscopy and an energy-dispersive X-ray microanalysis. Microsc Res Tech $\underline{76}$, 893-896

Çapar ID, Aydinbelge HA (2014): Effectiveness of various irrigation activation protocols and the self-adjusting file system on smear layer and debris removal. Scanning $\underline{36}, 640$ 647

Capar ID, Ozcan E, Arslan H, Ertas H, Aydinbelge HA (2014): Effect of different final irrigation methods on the removal of calcium hydroxide from an artificial standardized groove in the apical third of root canals. J Endod $\underline{40}, 451-454$

Caron G, Nham K, Bronnec F, Machtou P (2010): Effectiveness of different final irrigant activation protocols on smear layer removal in curved canals. J Endod $\underline{36}, 1361-1366$

Carver K, Nusstein J, Reader A, Beck M (2007): In vivo antibacterial efficacy of ultrasound after hand and rotary instrumentation in human mandibular molars. J Endod $\underline{33}, 1038-1043$ 
Castelo-Baz P, Martín-Biedma B, Cantatore G, Ruíz-Piñón M, Bahillo J, Rivas-Mundiña $B$, Varela-Patiño $P$ (2012): In vitro comparison of passive and continuous ultrasonic irrigation in simulated lateral canals of extracted teeth. J Endod $\underline{38}, 688-691$

Chai WL, Hamimah H, Cheng SC, Sallam AA, Abdullah M (2007): Susceptibility of Enterococcus faecalis biofilm to antibiotics and calcium hydroxide. J Oral Sci $\underline{49}, 161-$ 166

Chang JW, Cheung AW, Cheung GS (2015): Effect of root canal dimensions, injection rate, and needle design on the apical extrusion of an irrigant: an in vitro study. J Investig Clin Dent $\underline{6}, 221-227$

Chávez de Paz LE, Bergenholtz G, Svensäter G (2010): The effects of antimicrobials on endodontic biofilm bacteria. J Endod $\underline{36}, 70-77$

Chen JE, Nurbakhsh B, Layton G, Bussmann M, Kishen A (2014): Irrigation dynamics associated with positive pressure, apical negative pressure and passive ultrasonic irrigations: a computational fluid dynamics analysis. Aust Endod J $\underline{40}, 54-60$

Cherian B, Gehlot PM, Manjunath MK (2016): Comparison of the Antimicrobial Efficacy of Octenidine Dihydrochloride and Chlorhexidine with and Without Passive Ultrasonic Irrigation - An Invitro Study. J Clin Diagn Res 10, 71-77

Chou K, George R, Walsh LJ (2014): Effectiveness of different intracanal irrigation techniques in removing intracanal paste medicaments. Aust Endod J $\underline{40}, 21-25$

Chow TW (1983): Mechanical effectiveness of root canal irrigation. J Endod $\underline{9}$, 475-479

Dadresanfar B, Abbas FM, Bashbaghi H, Miri SS, Ghorbani F (2015): Intra-canal calcium hydroxide removal by two rotary systems: A comparative study. J Conserv Dent $18,257-$ 260

Dakin HD (1915): On The Use Of Certain Antiseptic Substances In The Treatment Of Infected Wounds. Br Med J 2 , 318-320

Damle SG, Bhattal H, Damle D, Dhindsa A, Loomba A, Singla S (2016): Clinical and radiographic assessment of mineral trioxide aggregate and calcium hydroxide as apexification agents in traumatized young permanent anterior teeth: A comparative study. Dent Res J 13, 284-291

de Almeida AP, Souza MA, Miyagaki DC, Dal Bello Y, Cecchin D, Farina AP (2014): Comparative evaluation of calcium hypochlorite and sodium hypochlorite associated with passive ultrasonic irrigation on antimicrobial activity of a root canal system infected with Enterococcus faecalis: An in vitro study. J Endod 40, 1953-1957

de Gregorio C, Estevez R, Cisneros R, Paranjpe A, Cohenca N (2010): Efficacy of different irrigation and activation systems on the penetration of sodium hypochlorite into simulated lateral canals and up to working length: an in vitro study. J Endod $\underline{36}, 1216$ 1221 
De-Deus G, Reis C, Di Giorgi K, Brandão MC, Audi C, Fidel RA (2011): Interfacial adaptation of the Epiphany self-adhesive sealer to root dentin. Oral Surg Oral Med Oral Pathol Oral Radiol Endod 111, 381-386

Denotti G, Piga R, Montaldo C, Erriu M, Pilia F, Piras A, Luca MD, Orrù G (2009): In Vitro evaluation of Enterococcus faecalis adhesion on various endodontic medicaments. Open Dent J $\underline{3}, 120-124$

Desai P, Himel V (2009): Comparative safety of various intracanal irrigation systems. J Endod $\underline{35}, 545-549$

Deveaux E, Dufour D, Boniface B (2000): Five methods of calcium hydroxide intracanal placement: an in vitro evaluation. Oral Surg Oral Med Oral Pathol Oral Radiol Endod $\underline{89}$, 349-355

Devi AA, Abbott PV (2012): Comparison of the flow characteristics of irrigants with standard and Max-i-Probe needles. Aust Endod J $\underline{38}, 50-54$

DGZMK (2001): Wissenschaftliche Stellungnahme: Zur Prognose von Wurzelkanalbehandlungen. Dtsch Zahnärztl Z $\underline{56}, 206$

Distel JW, Hatton JF, Gillespie MJ (2002): Biofilm formation in medicated root canals. J Endod 28, 689-693

Drake DR, Wiemann AH, Rivera EM, Walton RE (1994): Bacterial retention in canal walls in vitro: effect of smear layer. J Endod $\underline{20}, 78-82$

Drebenstedt S: Desinfektion des Wurzelkanalsystems. In: Rödig T, Hülsmann M, Nordmeyer S, Drebenstedt S (Hrsg.): Grundlagen der modernen Endodontie. Spitta Verlag, Balingen 2009, 175-202

Du R, Zhu YQ (2005): [The influence of smear layer and different sealers on apical microleakage of root canals obturated with Ultrafil-3D system]. Shanghai Kou Qiang Yi Xue $14,648-651$

Estrela C, Sydney GB, Bammann LL, Felippe Júnior O (1995): Mechanism of action of calcium and hydroxyl ions of calcium hydroxide on tissue and bacteria. Braz Dent $\mathrm{J} \underline{6}$, 85-90

Estrela C, Pimenta FC, Ito IY, Bammann LL (1998): In vitro determination of direct antimicrobial effect of calcium hydroxide. J Endod $\underline{24}, 15-17$

Estrela C, Mamede Neto I, Lopes HP, Estrela CR, Pécora JD (2002): Root canal filling with calcium hydroxide using different techniques. Braz Dent $\mathrm{J} \underline{13}, 53-56$

Fabricius L, Dahlén G, Holm SE, Möller AJ (1982): Influence of combinations of oral bacteria on periapical tissues of monkeys. Scand J Dent Res $\underline{90}, 200-206$

Fabricius L, Dahlén G, Sundqvist G, Happonen R-P, Möller AJ (2006): Influence of residual bacteria on periapical tissue healing after chemomechanical treatment and root filling of experimentally infected monkey teeth. Eur J Oral Sci 114, 278-285 
Falk KW, Sedgley CM (2005): The influence of preparation size on the mechanical efficacy of root canal irrigation in vitro. J Endod $\underline{31}, 742-745$

Faria G, Viola KS, Kuga MC, Garcia AJ, Daher VB, De Pasquali Leonardo MF, Tanomaru-Filho M (2014): Effect of rotary instrument associated with different irrigation techniques on removing calcium hydroxide dressing. Microsc Res Tech $\underline{77}$, 642-646

Ferreira FB de A, Torres SA, Rosa OP da S, Ferreira CM, Garcia RB, Marcucci MC, Gomes BP (2007): Antimicrobial effect of propolis and other substances against selected endodontic pathogens. Oral Surg Oral Med Oral Pathol Oral Radiol Endod 104, 709-716

Gade VJ, Sedani SK, Lokade JS, Belsare LD, Gade JR (2013): Comparative evaluation of debris removal from root canal wall by using EndoVac and conventional needle irrigation: An in vitro study. Contemp Clin Dent $\underline{4}, 432-436$

Gencoglu N, Külekçi G (1992): Antibacterial efficacy of root canal medicaments. J Nihon Univ Sch Dent 34, 233-236

Georgopoulou M, Kontakiotis E, Nakou M (1993): In vitro evaluation of the effectiveness of calcium hydroxide and paramonochlorophenol on anaerobic bacteria from the root canal. Endod Dent Traumatol $\underline{9}$, 249-253

Ghinzelli GC, Souza MA, Cecchin D, Farina AP, de Figueiredo JA (2014): Influence of ultrasonic activation on photodynamic therapy over root canal system infected with Enterococcus faecalis--an in vitro study. Photodiagnosis Photodyn Ther 11, 472-478

Gomes BP, Souza SF, Ferraz CC, Teixeira FB, Zaia AA, Valdrighi L, Souza-Filho FJ (2003): Effectiveness of $2 \%$ chlorhexidine gel and calcium hydroxide against Enterococcus faecalis in bovine root dentine in vitro. Int Endod J $\underline{36}, 267-275$

Gomes BP, Vianna ME, Sena NT, Zaia AA, Ferraz CC, Souza Filho FJ (2006): In vitro evaluation of the antimicrobial activity of calcium hydroxide combined with chlorhexidine gel used as intracanal medicament. Oral Surg Oral Med Oral Pathol Oral Radiol Endod $\underline{102}, 544-550$

Gomes BP, Montagner F, Berber VB, Zaia AA, Ferraz CC, de Almeida JF, Souza-Filho FJ (2009): Antimicrobial action of intracanal medicaments on the external root surface. J Dent $\underline{37}, 76-81$

Gomes IC, Chevitarese O, de Almeida NS, Salles MR, Gomes GC (1996): Diffusion of calcium through dentin. J Endod $\underline{22}, 590-595$

Gomma MM, Samy IS, Farag MM, Elinein NA (1992): Vibration pattern of different endosonic instruments. Egypt Dent J $\underline{38}, 131-137$

Gordon W, Atabakhsh VA, Meza F, Doms A, Nissan R, Rizoiu I, Stevens RH (2007): The antimicrobial efficacy of the erbium, chromium:yttrium-scandium-gallium-garnet laser with radial emitting tips on root canal dentin walls infected with Enterococcus faecalis. $\mathrm{J}$ Am Dent Assoc 138, 992-1002 
Gorduysus M, Yilmaz Z, Gorduysus O, Atila B, Karapinar SO (2012): Effectiveness of a new canal brushing technique in removing calcium hydroxide from the root canal system: A scanning electron microscope study. J Conserv Dent $\underline{15}$, 367-371

Grischke J, Müller-Heine A, Hülsmann M (2014): The effect of four different irrigation systems in the removal of a root canal sealer. Clin Oral Investig $\underline{18}, 1845-1851$

Gu L, Kim JR, Ling J, Choi KK, Pashley DH, Tay FR (2009): Review of contemporary irrigant agitation techniques and devices. J Endod $\underline{35}, 791-804$

Guerreiro-Tanomaru JM, Chávez-Andrade GM, de Faria-Júnior NB, Watanabe E, Tanomaru-Filho M (2015): Effect of Passive Ultrasonic Irrigation on Enterococcus faecalis from Root Canals: An Ex Vivo Study. Braz Dent J 26, 342-346

Gulabivala K, Stock CJ: Wurzelkanalaufbereitung. In: Stock CJ, Walker RT, Gulabivala K (Hrsg.): Endodontie. Elsevier Urban \& Fischer, München 2005, 135-172

Guneser MB, Arslan D, Usumez A (2015): Tissue dissolution ability of sodium hypochlorite activated by photon-initiated photoacoustic streaming technique. J Endod $\underline{41}, 729-732$

Gutarts R, Nusstein J, Reader A, Beck M (2005): In vivo debridement efficacy of ultrasonic irrigation following hand-rotary instrumentation in human mandibular molars. J Endod 31, 166-170

Haapasalo M, Shen Y, Qian W, Gao Y (2010): Irrigation in endodontics. Dent Clin North Am $\underline{54}, 291-312$

Haskell EW, Stanley HR, Chellemi J, Stringfellow H (1978): Direct pulp capping treatment: a long-term follow-up. J Am Dent Assoc 97, 607-612

Heithersay GS (1975): Calcium hydroxide in the treatment of pulpless teeth with associated pathology. J Br Endod Soc $\underline{8}, 74-93$

Hsieh YD, Gau CH, Kung Wu SF, Shen EC, Hsu PW, Fu E (2007): Dynamic recording of irrigating fluid distribution in root canals using thermal image analysis. Int Endod $\mathrm{J} \underline{40}$, $11-17$

Huffaker SK, Safavi K, Spangberg LS, Kaufman B (2010): Influence of a passive sonic irrigation system on the elimination of bacteria from root canal systems: a clinical study. J Endod 36, 1315-1318

Jacinto RC, Gomes BP, Desai M, Rajendram D, Shah HN (2007): Bacterial examination of endodontic infections by clonal analysis in concert with denaturing high-performance liquid chromatography. Oral Microbiol Immunol 22, 403-410

Jhamb S, Nikhil V, Singh V (2010): An in vitro study of antibacterial effect of calcium hydroxide and chlorhexidine on Enterococcus faecalis. Indian J Dent Res 21, 512-514 Jiang L-M, Verhaagen B, Versluis M, van der Sluis LW (2010a): Evaluation of a sonic device designed to activate irrigant in the root canal. J Endod $\underline{36}, 143-146$ 
Jiang L-M, Verhaagen B, Versluis M, van der Sluis LW (2010b): Influence of the oscillation direction of an ultrasonic file on the cleaning efficacy of passive ultrasonic irrigation. J Endod $\underline{36}, 1372-1376$

Jiang L-M, Verhaagen B, Versluis M, Langedijk J, Wesselink P, van der Sluis LW (2011): The influence of the ultrasonic intensity on the cleaning efficacy of passive ultrasonic irrigation. J Endod 37, 688-692

Kahn FH, Rosenberg PA, Gliksberg J (1995): An in vitro evaluation of the irrigating characteristics of ultrasonic and subsonic handpieces and irrigating needles and probes. J Endod 21, 277-280

Kawashima N, Wadachi R, Suda H, Yeng T, Parashos P (2009): Root canal medicaments. Int Dent J $\underline{59}, 5-11$

Kenee DM, Allemang JD, Johnson JD, Hellstein J, Nichol BK (2006): A quantitative assessment of efficacy of various calcium hydroxide removal techniques. J Endod $\underline{32}$, 563-565

Khademi AA, Amini K, Ghodsian B, Zahed SM, Teymori F, Shadmehr E (2015): Removal efficiency of calcium hydroxide intracanal medicament with RinsEndo system in comparison with passive ultrasonic irrigation, an in vitro study. Dent Res $\mathrm{J} \underline{12}, 157-160$

Khaleel HY, Al-Ashaw AJ, Yang Y, Pang A, Ma J (2013): Quantitative comparison of calcium hydroxide removal by EndoActivator, ultrasonic and ProTaper file agitation techniques: an in vitro study. J Huazhong Univ Sci Technolog Med Sci $\underline{33}, 142-145$

Kim SK, Kim YO (2002): Influence of calcium hydroxide intracanal medication on apical seal. Int Endod J $\underline{35}$, 623-628

Klyn SL, Kirkpatrick TC, Rutledge RE (2010): In vitro comparisons of debris removal of the EndoActivator system, the $\mathrm{F}$ file, ultrasonic irrigation, and $\mathrm{NaOCl}$ irrigation alone after hand-rotary instrumentation in human mandibular molars. J Endod $\underline{36}, 1367-1371$

Kokkas AB, Boutsioukis AC, Vassiliadis LP, Stavrianos CK (2004): The influence of the smear layer on dentinal tubule penetration depth by three different root canal sealers: an in vitro study. J Endod $\underline{30}, 100-102$

Krause TA, Liewehr FR, Hahn C-L (2007): The antimicrobial effect of MTAD, sodium hypochlorite, doxycycline, and citric acid on Enterococcus faecalis. J Endod $\underline{33}, 28-30$

Kreft B, Marre R, Schramm U, Wirth R (1992): Aggregation substance of Enterococcus faecalis mediates adhesion to cultured renal tubular cells. Infect Immun $\underline{60}, 25-30$

Kuga MC, Tanomaru-Filho M, Faria G, Só MV, Galletti T, Bavello JR (2010): Calcium hydroxide intracanal dressing removal with different rotary instruments and irrigating solutions: a scanning electron microscopy study. Braz Dent J 21, 310-314

Kumar VR, Bahuguna N, Manan R (2015): Comparison of efficacy of various root canal irrigation systems in removal of smear layer generated at apical third: An SEM study. $J$ Conserv Dent $\underline{18}$, 252-256 
KZBV Statistik: Jahrbuch 2016 Statistische Basisdaten zur vertragszahnärztlichen Versorgung. Hrsg. KZBV, Köln 2016

Lambrianidis T, Margelos J, Beltes P (1999): Removal efficiency of calcium hydroxide dressing from the root canal. J Endod $\underline{25}, 85-88$

Lambrianidis T, Kosti E, Boutsioukis C, Mazinis M (2006): Removal efficacy of various calcium hydroxide/chlorhexidine medicaments from the root canal. Int Endod J $\underline{39}, 55$ 61

Lee J-K, Park Y-J, Kum K-Y, Han SH, Chang S-W, Kaufman B, Jiang J, Zhu Q, Safavi $K$, Spångberg $L$ (2013): Antimicrobial efficacy of a human $\beta$-defensin-3 peptide using an Enterococcus faecalis dentine infection model. Int Endod J $\underline{46}, 406-412$

Lee S-J, Wu M-K, Wesselink PR (2004): The effectiveness of syringe irrigation and ultrasonics to remove debris from simulated irregularities within prepared root canal walls. Int Endod J $\underline{37}, 672-678$

Leonardo MR, da Silva LA, Tanomaru Filho M, Bonifácio KC, Ito IY (2000): In vitro evaluation of antimicrobial activity of sealers and pastes used in endodontics. J Endod $\underline{26}, 391-394$

Likhitkar MS, Kulkarni SV, Burande A, Solanke V, Kumar CS, Kamble B (2016): To evaluate the influence of smear layer with different instruments and obturation methods on microleakage of root canal filled teeth: In vitro study. J Int Soc Prev Community Dent 6, 240-244

Lin J-C, Lu J-X, Zeng Q, Zhao W, Li W-Q, Ling J-Q (2016): Comparison of mineral trioxide aggregate and calcium hydroxide for apexification of immature permanent teeth: A systematic review and meta-analysis. J Formos Med Assoc 115, 523-530

Lin LM, Skribner JE, Gaengler P (1992): Factors associated with endodontic treatment failures. J Endod 18, 625-627

Lloyd A, Navarrete G, Marchesan MA, Clement D (2016): Removal of calcium hydroxide from Weine Type II systems using photon-induced photoacoustic streaming, passive ultrasonic, and needle irrigation: a microcomputed tomography study. J Appl Oral Sci $\underline{24}$, 543-548

Lumley PJ, Walmsley AD (1992): Effect of precurving on the performance of endosonic $\mathrm{K}$ files. J Endod 18, 232-236

Ma J, Shen Y, Yang Y, Gao Y, Wan P, Gan Y, Patel P, Curtis A, Khakpour M, Haapasalo M (2015a): In vitro study of calcium hydroxide removal from mandibular molar root canals. J Endod 41, 553-558

Ma JZ, Shen Y, Al-Ashaw AJ, Khaleel HY, Yang Y, Wang ZJ, Peng B, Haapasalo M (2015b): Micro-computed tomography evaluation of the removal of calcium hydroxide medicament from $\mathrm{C}$-shaped root canals of mandibular second molars. Int Endod J $\underline{48}$, 333-341 
Mader CL, Baumgartner JC, Peters DD (1984): Scanning electron microscopic investigation of the smeared layer on root canal walls. J Endod $\underline{10}, 477-483$

Mancini M, Cerroni L, Iorio L, Armellin E, Conte G, Cianconi L (2013): Smear layer removal and canal cleanliness using different irrigation systems (EndoActivator, EndoVac, and passive ultrasonic irrigation): field emission scanning electron microscopic evaluation in an in vitro study. J Endod $\underline{39}, 1456-1460$

Manogue M, Patel S, Walker RT: The Principles of Endodontics. Oxford University Press, New York 2005

Margelos J, Eliades G, Verdelis C, Palaghias G (1997): Interaction of calcium hydroxide with zinc oxide-eugenol type sealers: a potential clinical problem. J Endod $\underline{23}, 43-48$

Mattigatti S, Ratnakar P, Moturi S, Varma S, Rairam S (2012): Antimicrobial effect of conventional root canal medicaments vs propolis against Enterococcus faecalis, Staphylococcus aureus and Candida albicans. J Contemp Dent Pract $\underline{13}$, 305-309

McComb D, Smith DC (1975): A preliminary scanning electron microscopic study of root canals after endodontic procedures. J Endod 1, 238-242

McGill S, Gulabivala K, Mordan N, Ng Y-L (2008): The efficacy of dynamic irrigation using a commercially available system (RinsEndo) determined by removal of a collagen „biomolecular film" from an ex vivo model. Int Endod J $\underline{41}, 602-608$

Mohammadi Z (2008): Sodium hypochlorite in endodontics: an update review. Int Dent J $\underline{58}, 329-341$

Mohammadi Z (2015): Effects Of Root Canal Irrigants On The Planktonic Form Of Enterococcus Faecalis: A Review. Niger J Med 24, 261-267

Mohammadi Z, Shalavi S (2014): Antifungal effects of root canal irrigants and medicaments. An update review. N Y State Dent J $\underline{80}, 58-63$

Mohammadi Z, Soltani MK, Shalavi S (2014): An update on the management of endodontic biofilms using root canal irrigants and medicaments. Iran Endod J $\underline{9}, 89-97$

Mohammadi Z, Giardino L, Palazzi F, Asgary S (2015): Agonistic and Antagonistic Interactions between Chlorhexidine and Other Endodontic Agents: A Critical Review. Iran Endod J $\underline{10}, 1-5$

Mohmmed SA, Vianna ME, Penny MR, Hilton ST, Mordan N, Knowles JC (2016): A novel experimental approach to investigate the effect of different agitation methods using sodium hypochlorite as an irrigant on the rate of bacterial biofilm removal from the wall of a simulated root canal model. Dent Mater $\underline{32}, 1289-1300$

Mokhtari H, Shahi S, Janani M, Reyhani MF, Mokhtari Zonouzi HR, Rahimi S, Sadr Kheradmand HR (2015): Evaluation of Apical Leakage in Root Canals Obturated with Three Different Sealers in Presence or Absence of Smear Layer. Iran Endod J 10, $131-$ 134 
Möller ÅJ, Fabricius L, Dahlén G, Sundqvist G, Happonen R-P (2004): Apical periodontitis development and bacterial response to endodontic treatment. Experimental root canal infections in monkeys with selected bacterial strains. Eur J Oral Sci 112, 207215

Moser JB, Heuer MA (1982): Forces and efficacy in endodontic irrigation systems. Oral Surg Oral Med Oral Pathol $\underline{53}, 425-428$

Muhammad OH, Chevalier M, Rocca J-P, Brulat-Bouchard N, Medioni E (2014): Photodynamic therapy versus ultrasonic irrigation: interaction with endodontic microbial biofilm, an ex vivo study. Photodiagnosis Photodyn Ther 11, 171-181

Munley PJ, Goodell GG (2007): Comparison of passive ultrasonic debridement between fluted and nonfluted instruments in root canals. J Endod $\underline{33}, 578-580$

Munoz HR, Camacho-Cuadra K (2012): In vivo efficacy of three different endodontic irrigation systems for irrigant delivery to working length of mesial canals of mandibular molars. J Endod $\underline{38}$, 445-448

Naenni N, Thoma K, Zehnder M (2004): Soft tissue dissolution capacity of currently used and potential endodontic irrigants. J Endod $\underline{30}, 785-787$

Nandini S, Velmurugan N, Kandaswamy D (2006): Removal efficiency of calcium hydroxide intracanal medicament with two calcium chelators: volumetric analysis using spiral CT, an in vitro study. J Endod $\underline{32}, 1097-1101$

Nerwich A, Figdor D, Messer HH (1993): pH changes in root dentin over a 4-week period following root canal dressing with calcium hydroxide. J Endod 19, 302-306

Neuhaus KW, Liebi M, Stauffacher S, Eick S, Lussi A (2016): Antibacterial Efficacy of a New Sonic Irrigation Device for Root Canal Disinfection. J Endod 42, 1799-1803

Orstavik D, Haapasalo M (1990): Disinfection by endodontic irrigants and dressings of experimentally infected dentinal tubules. Endod Dent Traumatol $\underline{6}, 142-149$

Oztan MD, Akman A, Dalat D (2002): Intracanal placement of calcium hydroxide: a comparison of two different mixtures and carriers. Oral Surg Oral Med Oral Pathol Oral Radiol Endod 94, 93-97

Paragliola R, Franco V, Fabiani C, Mazzoni A, Nato F, Tay FR, Breschi L, Grandini S (2010): Final rinse optimization: influence of different agitation protocols. J Endod $\underline{36}$, 282-285

Park DS, Torabinejad M, Shabahang S (2004): The effect of MTAD on the coronal leakage of obturated root canals. J Endod $\underline{30}, 890-892$

Pasqualini D, Cuffini AM, Scotti N, Mandras N, Scalas D, Pera F, Berutti E (2010): Comparative evaluation of the antimicrobial efficacy of a $5 \%$ sodium hypochlorite subsonic-activated solution. J Endod $\underline{36}, 1358-1360$ 
Pavelić B, Anić I, Najzar-Fleger D, Stilinović B, Temmer K (1991): [The antimicrobial efficiency of aqueous solutions of calcium hydroxide on Streptococcus mutans, Streptococcus faecalis and Candida albicans, in vitro]. Acta Stomatol Croat $\underline{25}, 207-212$

Peters Cl, Koka RS, Highsmith S, Peters OA (2005): Calcium hydroxide dressings using different preparation and application modes: density and dissolution by simulated tissue pressure. Int Endod J 38, 889-895

Peters OA, Laib A, Göhring TN, Barbakow F (2001): Changes in root canal geometry after preparation assessed by high-resolution computed tomography. J Endod 27, 1-6

Phillips M, McClanahan S, Bowles W (2015): A titration model for evaluating calcium hydroxide removal techniques. J Appl Oral Sci $\underline{23}, 94-100$

Portenier I, Haapasalo H, Ørstavik D, Yamauchi M, Haapasalo M (2002): Inactivation of the Antibacterial Activity of lodine Potassium lodide and Chlorhexidine Digluconate Against Enterococcus faecalis by Dentin, Dentin Matrix, Type-I Collagen, and Heat-Killed Microbial Whole Cells. J Endod 28, 634-637

Portenier I, Waltimo T, Ørstavik D, Haapasalo M (2005): The susceptibility of starved, stationary phase, and growing cells of Enterococcus faecalis to endodontic medicaments. J Endod 31, 380-386

Prabhakar AR, Hadakar SG, Raju OS (2012): Comparative evaluation of $\mathrm{pH}$ and antibacterial effect of various calcium hydroxide combinations on $\mathrm{E}$. faecalis and its effect on root strength: An in vitro study. Contemp Clin Dent $\underline{3}, 42-47$

Rahimi S, Janani M, Lotfi M, Shahi S, Aghbali A, Vahid Pakdel M, Salem Milani A, Ghasemi N (2014): A Review of Antibacterial Agents in Endodontic Treatment. Iran Endod J $\underline{9}, 161-168$

Ram Z (1977): Effectiveness of root canal irrigation. Oral Surg Oral Med Oral Pathol 44 , 306-312

Ramamoorthi S, Nivedhitha MS, Divyanand MJ (2015): Comparative evaluation of postoperative pain after using endodontic needle and EndoActivator during root canal irrigation: A randomised controlled trial. Aust Endod J 41, 78-87

Rico-Romano C, Zubizarreta-Macho Á, Baquero-Artigao M-R, Mena-Álvarez J (2016): An analysis in vivo of intracanal bacterial load before and after chemo-mechanical preparation: A comparative analysis of two irrigants and two activation techniques. J Clin Exp Dent $\underline{8}$, e9-e13

Ricucci D, Langeland K (1997): Incomplete calcium hydroxide removal from the root canal: a case report. Int Endod J $\underline{30}, 418-421$

Rivera EM, Williams K (1994): Placement of calcium hydroxide in simulated canals: comparison of glycerin versus water. J Endod 20, 445-448 
Rödig T, Bozkurt M, Konietschke F, Hülsmann M (2010a): Comparison of the Vibringe system with syringe and passive ultrasonic irrigation in removing debris from simulated root canal irregularities. J Endod $\underline{36}, 1410-1413$

Rödig T, Döllmann S, Konietschke F, Drebenstedt S, Hülsmann M (2010b): Effectiveness of different irrigant agitation techniques on debris and smear layer removal in curved root canals: a scanning electron microscopy study. J Endod 36, 1983-1987

Rödig T, Vogel S, Zapf A, Hülsmann M (2010c): Efficacy of different irrigants in the removal of calcium hydroxide from root canals. Int Endod J $\underline{43}, 519-527$

Rödig T, Sedghi M, Konietschke F, Lange K, Ziebolz D, Hülsmann M (2010d): Efficacy of syringe irrigation, RinsEndo and passive ultrasonic irrigation in removing debris from irregularities in root canals with different apical sizes. Int Endod J $\underline{43}, 581-589$

Rödig T, Hirschleb M, Zapf A, Hülsmann M (2011): Comparison of ultrasonic irrigation and RinsEndo for the removal of calcium hydroxide and Ledermix paste from root canals. Int Endod J 44 , 1155-1161

Rodríguez-Figueroa C, McClanahan SB, Bowles WR (2014): Spectrophotometric determination of irrigant extrusion using passive ultrasonic irrigation, EndoActivator, or syringe irrigation. J Endod 40, 1622-1626

Saatchi M, Shokraneh A, Navaei H, Maracy MR, Shojaei H (2014): Antibacterial effect of calcium hydroxide combined with chlorhexidine on Enterococcus faecalis: a systematic review and meta-analysis. J Appl Oral Sci 22, 356-365

Sağsen B, Ustün Y, Aslan T, Canakçi BC (2012): The effect of peracetic acid on removing calcium hydroxide from the root canals. J Endod $\underline{38}, 1197-1201$

Sakamoto M, Rôças IN, Siqueira JF, Benno Y (2006): Molecular analysis of bacteria in asymptomatic and symptomatic endodontic infections. Oral Microbiol Immunol $\underline{21}, 112$ 122

Sakamoto M, Siqueira JF, Rôças IN, Benno Y (2007): Bacterial reduction and persistence after endodontic treatment procedures. Oral Microbiol Immunol 22, 19-23

Salgado RJ, Moura-Netto C, Yamazaki AK, Cardoso LN, de Moura AA, Prokopowitsch I (2009): Comparison of different irrigants on calcium hydroxide medication removal: microscopic cleanliness evaluation. Oral Surg Oral Med Oral Pathol Oral Radiol Endod $107,580-584$

Sawicki L, Pameijer CH, Emerich K, Adamowicz-Klepalska B (2008): Histological evaluation of mineral trioxide aggregate and calcium hydroxide in direct pulp capping of human immature permanent teeth. Am J Dent 21, 262-266

Schoeffel GJ (2007): The EndoVac method of endodontic irrigation: safety first. Dent Today $\underline{26}, 92,94,96$ passim

Sen BH, Wesselink PR, Türkün M (1995): The smear layer: a phenomenon in root canal therapy. Int Endod J 28, 141-148 
Shen Y, Stojicic S, Qian W, Olsen I, Haapasalo M (2010): The synergistic antimicrobial effect by mechanical agitation and two chlorhexidine preparations on biofilm bacteria. $\mathrm{J}$ Endod $\underline{36}, 100-104$

Silva LJ, Pessoa OF, Teixeira MB, Gouveia CH, Braga RR (2015): Micro-CT evaluation of calcium hydroxide removal through passive ultrasonic irrigation associated with or without an additional instrument. Int Endod J 48, 768-773

Simcock RM, Hicks ML (2006): Delivery of calcium hydroxide: comparison of four filling techniques. J Endod 32, 680-682

Siqueira JF, Lopes HP (1999): Mechanisms of antimicrobial activity of calcium hydroxide: a critical review. Int Endod J 32, 361-369

Siqueira JF, Sen BH (2004): Fungi in endodontic infections. Oral Surg Oral Med Oral Pathol Oral Radiol Endod 97, 632-641

Siqueira JF, Rôças IN (2008): Clinical implications and microbiology of bacterial persistence after treatment procedures. J Endod 34, 1291-1301

Siqueira JF, Rôças IN (2009): Diversity of endodontic microbiota revisited. J Dent Res $\underline{88}, 969-981$

Sjögren U, Figdor D, Spångberg L, Sundqvist G (1991): The antimicrobial effect of calcium hydroxide as a short-term intracanal dressing. Int Endod J $\underline{24}$, 119-125

Srirekha A, Rashmi K, Hegde J, Lekha S, Rupali K, Reshmi G (2013): An in vitro evaluation of passive ultrasonic agitation of different irrigants on smear layer removal after post space preparation: a scanning electron microscopic study. J Indian Prosthodont Soc $\underline{13}, 240-246$

Staehle HJ, Thomä C, Müller HP (1997): Comparative in vitro investigation of different methods for temporary root canal filling with aqueous suspensions of calcium hydroxide. Endod Dent Traumatol $\underline{13}, 106-112$

Stock CJ (1991): Current status of the use of ultrasound in endodontics. Int Dent J $\underline{41}$, 175-182

Stuart CH, Schwartz SA, Beeson TJ, Owatz CB (2006): Enterococcus faecalis: its role in root canal treatment failure and current concepts in retreatment. J Endod $\underline{32}, 93-98$

Su Y, Wang C, Ye L (2011): Healing rate and post-obturation pain of single- versus multiple-visit endodontic treatment for infected root canals: a systematic review. J Endod $\underline{37}, 125-132$

Sundqvist G, Figdor D, Persson S, Sjögren U (1998): Microbiologic analysis of teeth with failed endodontic treatment and the outcome of conservative re-treatment. Oral Surg Oral Med Oral Pathol Oral Radiol Endod $\underline{85}$, 86-93

Tan JM, Parolia A, Pau AK (2013): Intracanal placement of calcium hydroxide: a comparison of specially designed paste carrier technique with other techniques. BMC Oral Health $\underline{13}, 52$ 
Tanomaru JM, Pappen FG, Tanomaru Filho M, Spolidorio DM, Ito IY (2007): In vitro antimicrobial activity of different gutta-percha points and calcium hydroxide pastes. Braz Oral Res $\underline{21}, 35-39$

Taşdemir T, Celik D, Er K, Yildirim T, Ceyhanli KT, Yeşilyurt C (2011): Efficacy of several techniques for the removal of calcium hydroxide medicament from root canals. Int Endod J $44,505-509$

Tay FR, Gu L-S, Schoeffel GJ, Wimmer C, Susin L, Zhang K, Arun SN, Kim J, Looney SW, Pashley DH (2010): Effect of vapor lock on root canal debridement by using a sidevented needle for positive-pressure irrigant delivery. J Endod $\underline{36}, 745-750$

Topçuoglu HS, Akti A, Düzgün S, Ceyhanli KT, Topçuoglu G (2015): Effectiveness of different irrigation procedures for removal of dentin debris from a simulated internal resorption cavity. Int J Artif Organs $\underline{38}, 165-169$

Topçuoğlu HS, Düzgün S, Ceyhanlı KT, Aktı A, Pala K, Kesim B (2015): Efficacy of different irrigation techniques in the removal of calcium hydroxide from a simulated internal root resorption cavity. Int Endod J $\underline{48}, 309-316$

Torres CP, Apicella MJ, Yancich PP, Parker MH (2004): Intracanal placement of calcium hydroxide: a comparison of techniques, revisited. J Endod 30, 225-227

Türkün M, Sevgican F, Aran B (2005): Effect of endodontic irrigants on microleakage of coronal restorations. Am J Dent 18, 353-358

Urban K, Donnermeyer D, Schäfer E, Bürklein S (2017): Canal cleanliness using different irrigation activation systems: a SEM evaluation. Clin Oral Investig 21, 2681-2687

Uroz-Torres D, González-Rodríguez MP, Ferrer-Luque CM (2010): Effectiveness of the EndoActivator System in removing the smear layer after root canal instrumentation. $J$ Endod $\underline{36}, 308-311$

Üstün Y, Aslan T, Sagsen B, Dincer AN (2016): The effects of different irrigation protocols on removing calcium hydroxide from the root canals. Niger J Clin Pract $\underline{19}, 465-470$

Valera MC, Silva KC da, Maekawa LE, Carvalho CA, Koga-Ito CY, Camargo CH, Lima RS (2009): Antimicrobial activity of sodium hypochlorite associated with intracanal medication for Candida albicans and Enterococcus faecalis inoculated in root canals. $\mathrm{J}$ Appl Oral Sci 17, 555-559

van der Sluis LW, Wu MK, Wesselink PR (2005a): A comparison between a smooth wire and a K-file in removing artificially placed dentine debris from root canals in resin blocks during ultrasonic irrigation. Int Endod J $\underline{38}, 593-596$

van der Sluis LW, Wu MK, Wesselink PR (2005b): The efficacy of ultrasonic irrigation to remove artificially placed dentine debris from human root canals prepared using instruments of varying taper. Int Endod J $\underline{38}, 764-768$ 
van der Sluis LW, Gambarini G, Wu MK, Wesselink PR (2006): The influence of volume, type of irrigant and flushing method on removing artificially placed dentine debris from the apical root canal during passive ultrasonic irrigation. Int Endod J $\underline{39}, 472-476$

van der Sluis LW, Versluis M, Wu MK, Wesselink PR (2007a): Passive ultrasonic irrigation of the root canal: a review of the literature. Int Endod J $\underline{40}, 415-426$

van der Sluis LW, Wu MK, Wesselink PR (2007b): The evaluation of removal of calcium hydroxide paste from an artificial standardized groove in the apical root canal using different irrigation methodologies. Int Endod J $\underline{40}, 52-57$

Vier-Pelisser FV, Meng A, Benedete Netto LC, Só MV (2012): Influence of the instrumentation technique and apical preparation diameter on calcium hydroxide filling in simulated curved canals. Indian J Dent Res $\underline{23}$, 784-788

Waltimo TM, Orstavik D, Sirén EK, Haapasalo MP (1999): In vitro susceptibility of Candida albicans to four disinfectants and their combinations. Int Endod J $\underline{32}, 421-429$

Waltimo TM, Sen BH, Meurman JH, Ørstavik D, Haapasalo MP (2003): Yeasts in apical periodontitis. Crit Rev Oral Biol Med 14, 128-137

Walton RE (1984): Intracanal medicaments. Dent Clin North Am 28, 783-796

Webber RT, Schwiebert KA, Cathey GM (1981): A technique for placement of calcium hydroxide in the root canal system. J Am Dent Assoc 103, 417-421

Weller RN, Brady JM, Bernier WE (1980): Efficacy of ultrasonic cleaning. J Endod $\underline{6}$, 740-743

White RR, Goldman M, Lin PS (1984): The influence of the smeared layer upon dentinal tubule penetration by plastic filling materials. J Endod $\underline{10}, 558-562$

Wiseman A, Cox TC, Paranjpe A, Flake NM, Cohenca N, Johnson JD (2011): Efficacy of sonic and ultrasonic activation for removal of calcium hydroxide from mesial canals of mandibular molars: a microtomographic study. J Endod 37, 235-238

Wu MK, Wesselink PR (1995): Efficacy of three techniques in cleaning the apical portion of curved root canals. Oral Surg Oral Med Oral Pathol Oral Radiol Endod $\underline{79}$, 492-496

Xu Q, Fan M, Fan B, Cheung GS, Hu H (2005): A new quantitative method using glucose for analysis of endodontic leakage. Oral Surg Oral Med Oral Pathol Oral Radiol Endod $\underline{99}, 107-111$

Yeung W, Raldi DP, Cunha RS, Mello I (2014): Assessment of smear layer removal protocols in curved root canals. Aust Endod J $\underline{40}, 66-71$

Yost RA, Bergeron BE, Kirkpatrick TC, Roberts MD, Roberts HW, Himel VT, Sabey KA (2015): Evaluation of 4 Different Irrigating Systems for Apical Extrusion of Sodium Hypochlorite. J Endod 41, 1530-1534

Zehnder M (2006): Root canal irrigants. J Endod 32, 389-398 
Zehnder M, Lehnert B, Schönenberger K, Waltimo T (2003): [Irrigants and intracanal medicaments in endodontics]. Schweiz Monatsschr Zahnmed 113, 756-763

Zorzin J, Wießner J, Wießner T, Lohbauer U, Petschelt A, Ebert J (2016): Removal of Radioactively Marked Calcium Hydroxide from the Root Canal: Influence of Volume of Irrigation and Activation. J Endod 42, 637-640 


\section{Danksagung}

Mein größter Dank gilt Herrn Prof. Dr. med. dent. Michael Hülsmann für die Vergabe des Dissertationsthemas, seine zeitnahen Korrekturen und Denkanstöße. Die geduldige, zuverlässige und angenehme Betreuung hat maßgeblich zu der Fertigstellung dieser Arbeit beigetragen. Seine Art der Betreuung ist für mich nie selbstverständlich gewesen.

Außerdem möchte ich Frau Carola Hartje für die Besorgung der Materialien und die aufbauenden, ehrlichen und herzlichen Worte danken.

Ein weiterer Dank geht an Christoph Beckmann, der während der unzähligen Stunden im Labor tapfer an meiner Seite gearbeitet hat und für Probleme immer eine Lösung parat hatte. 